San Jose State University

SJSU ScholarWorks

Master's Theses

Master's Theses and Graduate Research

Fall 2010

\title{
Shock Layer Radiation Measurements for Mars and Venus Entry Conditions in an Electric Arc Shock Tube
}

Ramon Martinez

San Jose State University

Follow this and additional works at: https://scholarworks.sjsu.edu/etd_theses

\section{Recommended Citation}

Martinez, Ramon, "Shock Layer Radiation Measurements for Mars and Venus Entry Conditions in an Electric Arc Shock Tube" (2010). Master's Theses. 3875.

DOI: https://doi.org/10.31979/etd.7tet-gmke

https://scholarworks.sjsu.edu/etd_theses/3875

This Thesis is brought to you for free and open access by the Master's Theses and Graduate Research at SJSU ScholarWorks. It has been accepted for inclusion in Master's Theses by an authorized administrator of SJSU ScholarWorks. For more information, please contact scholarworks@sjsu.edu. 


\title{
SHOCK LAYER RADIATION MEASUREMENTS FOR MARS AND VENUS ENTRY CONDITIONS IN AN ELECTRIC ARC SHOCK TUBE
}

\author{
A Thesis \\ Presented to \\ The Faculty of the Department of Mechanical and Aerospace Engineering \\ San José State University \\ In Partial Fulfillment \\ of the Requirements for the Degree \\ Master of Science
}

by

Ramon Martinez

December 2010 
(C) 2010

Ramon Martinez

ALL RIGHTS RESERVED 
The Designated Thesis Committee Approves the Thesis Titled

SHOCK LAYER RADIATION MEASUREMENTS FOR MARS AND VENUS ENTRY CONDITIONS IN AN ELECTRIC ARC SHOCK TUBE

by

Ramon Martinez

APPROVED FOR THE DEPARTMENT OF MECHANICAL AND AEROSPACE

ENGINEERING

SAN JOSÉ STATE UNIVERSITY

DECEMBER 2010

Dr. Periklis Papadopoulos, Department of Mechanical and Aerospace Engineering Dr. Nikos Mourtos, Department of Mechanical and Aerospace Engineering Dr. Brett Cruden, $\quad$ Engineering Research and Consulting (ERC), Inc. 


\begin{abstract}
SHOCK LAYER RADIATION MEASUREMENTS FOR MARS AND VENUS ENTRY CONDITIONS IN AN ELECTRIC ARC SHOCK TUBE
\end{abstract}

by

\title{
Ramon Martinez
}

This work reports on upgrades in the Electric Arc Shock Tube (EAST) Facility and shockwave characterization experiments performed at National Aeronautics and Space Administration (NASA) Ames Research Center (ARC). The importance of testing in the EAST Facility is shown, detailing research work that has occurred in the facility. A facility description follows, in order to explain how the facility is structured and how it conducts operations. The EAST Facility upgrade project is summarized to present current advancements in the facility. Calibration techniques are explained, and experimental data is presented. This data is obtained with the use of highly specialized spectroscopic, vacuum, and optical equipment that is unique to this facility and was upgraded as part of the upgrade project. Experimental data is shown for Mars and Venus tests, spanning the Vacuum Ultra Violet (VUV) to Infrared (IR) portions of the spectrum. Shock layer temperature analysis is performed for various data points in both Mars and Venus tests. 


\section{ACKNOWLEDGEMENTS}

I would like to thank Dr. Periklis Papadopoulos and Dr. Nikos Mourtos for their support throughout this work. I would also like to thank Dr. Brett Cruden and Dr. Christopher Dateo for giving me the opportunity to become a member of the EAST radiation testing team. Also, I would like to thank Mark S. McGlaughlin and James Joyce for maintaining and operating the EAST Facility and for mentoring me on countless facility related activities. To my fellow classmates Nicholas Pham and Hai Le, it was fun working with both of you. 


\section{TABLE OF CONTENTS}

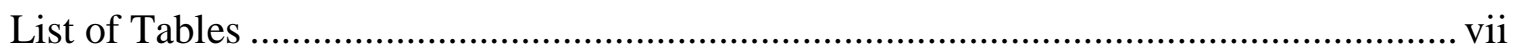

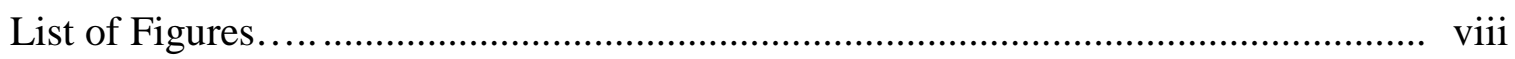

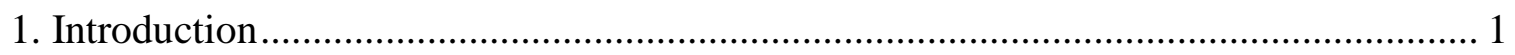

2. Experimental Facility Description …………………........................................ 4

3. The EAST Facility Upgrade Project .................................................................. 7

3.1 Facility and Instrumentation Upgrades ....................................................... 7

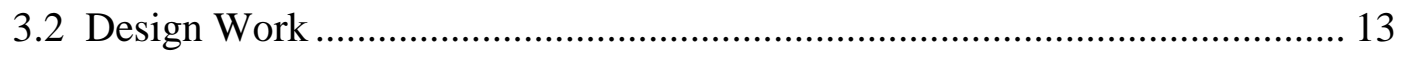

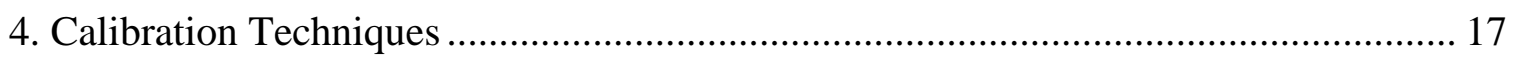

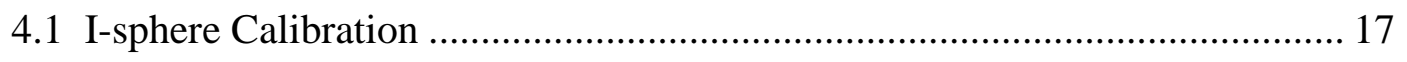

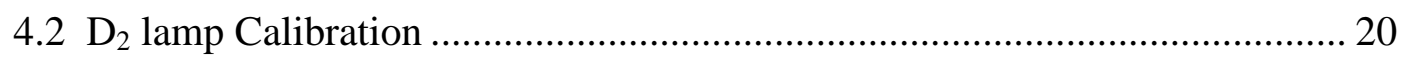

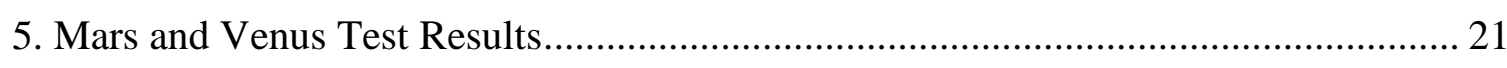

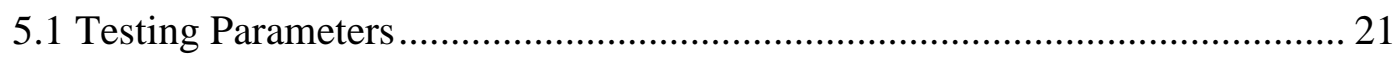

5.2 Test Condition: 0.25 Torr, 8 km/s (Nominal) …………………………..... 23

5.3 Composite Spectrum for Various Test Conditions in Mars and Venus............ 37

6. Mars and Venus Temperature Analysis .................................................................. 38

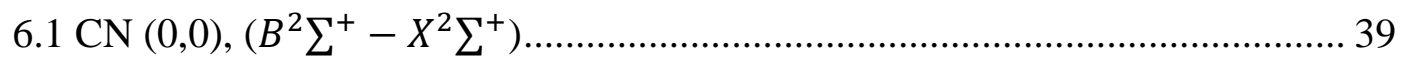



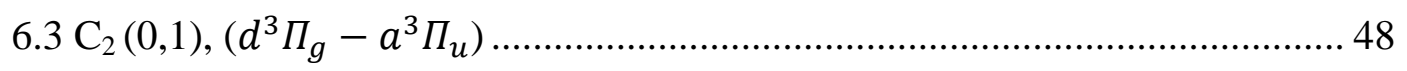

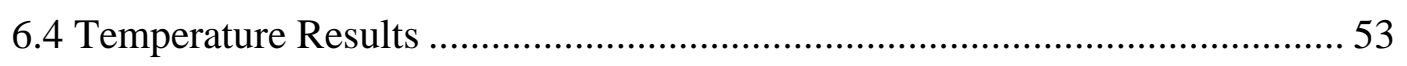

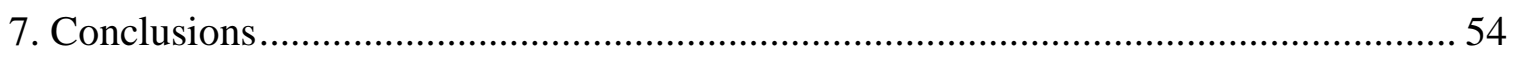



Appendix

Fabrication Drawings …………………………………...................................... 57 


\section{LIST OF TABLES}

Table 3.1: Imaging spectrograph specifications after EAST upgrade. ........................... 10

Table 5.1: EAST Facility pressure readings for Shot 39 .......................................... 23

Table 5.2: TOA locations and shock arrival times based on Shot 39 data . .................... 26

Table 5.3: Spectrometer and camera set points for Shot 39........................................ 29

Table 5.4: Spectrometer and camera set points for Shot 44.. …................................ 32

Table 6.1: Rotational and Vibrational temperature fits for various $\mathrm{CN}(0,0)$ systems ... 41

Table 6.2: Rotational temperature fits for various $\mathrm{C}_{2}(0,0)$ systems ............................ 47

Table 6.3: Rotational and Vibrational temperature fits for various $C_{2}(0,1)$ systems...... 49 


\section{LIST OF FIGURES}

Figure 2.1: The EAST Facility at NASA Ames Research Center ..................................... 5

Figure 2.2: The 6-tier capacitor capacitance bank ....................................................... 6

Figure 3.1: CAD of EAST Facility modifications and upgrades ..................................... 8

Figure 3.2: Solid model of the vacuum box with imaging system integrated . .................. 9

Figure 3.3: The oxygen plasma cleaning source installed in the shock tube ................... 11

Figure 3.4: The new EAST Facility test section with PCBs and PMTs installed ............ 12

Figure 3.5: CAD model for the Arc Driver Liner........................................................... 14

Figure 3.6: $\mathrm{CAD}$ model for the $\mathrm{D}_{2}$ Lamp Calibration Mounting Assembly .................... 15

Figure 3.7: CAD model for the I-sphere Calibration Mounting Assembly. ..................... 16

Figure 4.1: I-sphere calibration taken at the center location ........................................... 18

Figure 4.2: I-sphere calibration taken at the upstream location ...................................... 18

Figure 4.3: I-sphere calibration taken at the downstream location ................................. 19

Figure 4.4: Flatfield for the center, upstream, and downstream calibrations .................. 19

Figure 4.5: $\mathrm{D}_{2}$ lamp calibration for the VUV system at a single position. ....................... 20

Figure 5.1: PMT M trace for Shot 39 .................................................................. 25

Figure 5.2: Time of shock arrival for PCB O, Shot 39 ………..................................... 26

Figure 5.3: TOA vs. distance data with a second order polynomial fit for Shot 39 ......... 27

Figure 5.4: VUV calibrated shot data for Shot 39 .................................................... 30

Figure 5.5: Blue calibrated shot data for Shot 39 ..................................................... 30

Figure 5.6: Red calibrated shot data for Shot 39.......................................................... 31

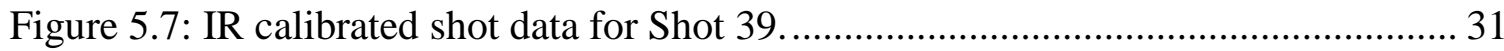

Figure 5.8: VUV calibrated shot data for Shot 44 .................................................. 33

Figure 5.9: Blue calibrated shot data for Shot 44 .................................................... 33

Figure 5.10: IR calibrated shot data for Shot 44..................................................... 34

Figure 5.11: IR calibrated shot data for Shot 45..................................................... 34

Figure 5.12: IR calibrated shot data for Shot 42..................................................... 35

Figure 5.13: Mars composite spectrum at 0.25 Torr, $8 \mathrm{~km} / \mathrm{s}$ nominal shock velocity...... 36

Figure 5.14: Mars and Venus combined composite spectrum. ................................... 37

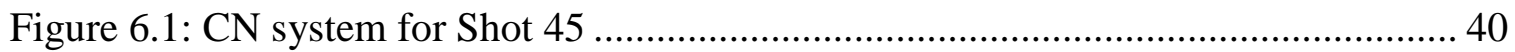

Figure 6.2: Shot 45 temperature fit for a $\mathrm{CN}(0,0)$ system............................................ 40 


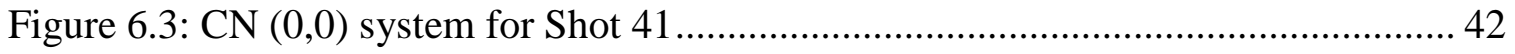

Figure 6.4: Temperature fit for Shot 41 at a position of $3.42 \mathrm{~cm}$............................... 43

Figure 6.5: Vibrational and Rotational temperature as function of shock position.......... 44



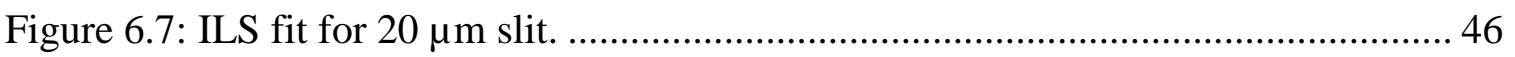

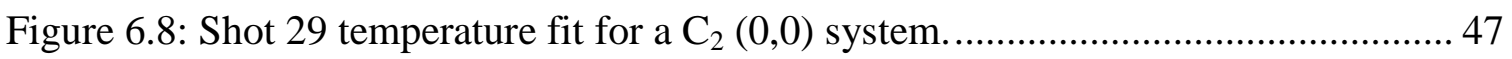

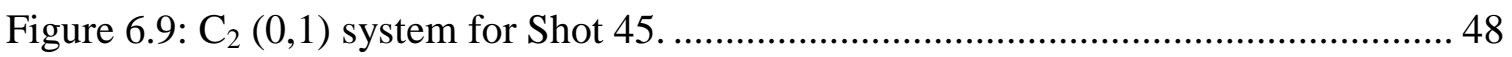

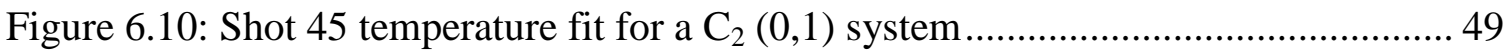

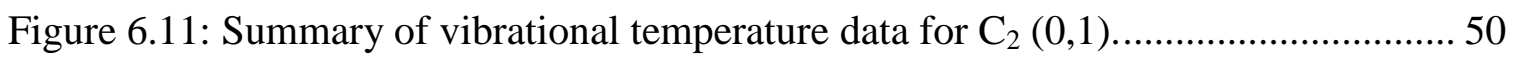

Figure 6.12: Calibrated Shot 36 with cross section taken at $5.35 \mathrm{~cm}$........................... 51

Figure 6.13: Temperature as a function of shock position............................................ 52

Figure 6.14: Summary of rotational temperatures for the $\mathrm{C}_{2}$ and $\mathrm{CN}$ systems................ 53

Figure A.1: Fabrication drawing for the Arc Driver Liner......................................... 57

Figure A.2: Fabrication drawing for the D2 Primary Cal Mount .................................. 58

Figure A.3: Fabrication drawing for the D2 Calibration Slider Plate............................. 58

Figure A.4: Fabrication drawing for the D2 Calibration Bracket..................................5 59

Figure A.5: Fabrication drawing for the D2 Calibration Clamp...................................59

Figure A.6: Fabrication drawing for the I-sphere Primary Cal Mount ............................ 60

Figure A.7: Fabrication drawing for the I-sphere Adapter Flange ................................ 60 


\section{Chapter 1}

\section{Introduction}

During Hypersonic entry into planetary atmospheres, free stream kinetic energy is converted into internal energy of the gas as it moves across the bow shock that is formed on the spacecraft. As a result, the high gas temperature behind the shockwave creates ionization and dissociation within the gas (Panesi, Babou, \& Chazot, 2008). Radiation specific to the atoms and molecules present, is then emitted by the gas. This radiation gives rise to a radiative flux that can be theoretically or experimentally calculated across the spectrum.

Hypersonic planetary entry has been a scientific challenge for most spacecraft designs throughout time. Traditional spacecraft are developed based on historical capsule designs like that of the Apollo program. The spacecraft consists of an aeroshell that protects the payload. Upon entry into a planetary atmosphere, a bow shock is formed just ahead of the spacecraft, that highly influences design specifications for the spacecraft's thermal protection system (TPS). Design considerations for appropriate TPS must be considered to account for shockwave characteristics associated with planetary entry. Some characteristics associated with this type of shockwave are boundary layer effects, viscous interactions, surface recombination, dissociation-ionization, transition to turbulent, ablation, shock-shock interaction, and radiation (Cruden, Martinez, Grinstead, \& Olejniczak, 2009). Radiation is an important factor that is associated with TPS design and can be calculated and analyzed experimentally. 
Thermal energy associated with planetary entry must be absorbed or dissipated by the TPS. A portion of the thermal energy that the spacecraft experiences, comes from radiative heat transfer. Blackbody radiative heat transfer scales are shown in Equation (1.1), although a much higher dependence on velocity is seen in the EAST Facility.

$$
\rho r_{n} V^{8}
$$

In Equation (1.1), $\rho$ is the free stream density, $r_{n}$ is the nose radius of the spacecraft, and $V$ is the entry velocity. As we see through Equation (1.1), radiative heating becomes relevant for larger vehicles (larger $r_{n}$ ) and/or high entry velocities $(V)$.

The EAST Facility is a test facility that provides test data for the development and validation of kinetic models of shock radiation used in entry radiative heating analysis (Cruden, et al., 2009). The EAST facility currently supports various projects, including NASA's Fundamental Aeronautics Program (Hypersonics), the CEV Aerosciences Project (CAP) and the In-Space Propulsion Technology Program. Shock radiation measurements have been performed in the EAST Facility for all of these programs. Spacecraft designs under consideration for future Mars systems will be larger and enter the atmosphere at higher velocities, which will result in significant shock layer radiation (Grinstead, et al., 2008).

The EAST Facility at NASA-ARC has the capability of creating shockwaves representative of the Mars and Venus missions of the future. These conditions are specified by entry trajectory velocities and expected atmospheric pressure conditions. Comprehensive radiation testing was performed for various Mars and Venus entry conditions, in order to gain a better understanding for the radiative heating properties of 
these tests. Once this experimental data is post-processed, it is compared to theoretical predictions and results are quantified based on experimental and theoretical comparisons.

In the shock tube, the non-equilibrium gas is approximated by a one-dimensional shockwave. This type of test is representative of the shock heated gas behind the shockwave on a flight vehicle. Only flow divergence and boundary layer terms must be neglected for this particular type of shock tube test (Grinstead, et al., 2008). As a result of these assumptions, radiation emitted by the gas behind the shockwave is a source of data validation for the development of analytical calculations and physical models in Computational Fluid Dynamics (CFD). These comparisons allow for better predictions of aero-thermal environments for spacecraft entry into a given atmosphere and help with the development of TPS.

New Mars systems under consideration are larger than previous generations, making shock layer radiation an important portion of the heating environment for these types of missions. Venus systems will enter the atmosphere in the order of 10 to 11 kilometers per second $(\mathrm{km} / \mathrm{s})$, which is dictated by the orbital mechanics of the orbit transfer (Grinstead, et al., 2008). Peak radiative heating occurs in the lower atmosphere representative of an atmospheric pressure of 1 to 2 Torr for these Venus mission systems. At such velocities and pressures, radiation is expected to be a significant portion of the heating environment for all types of potential entry probes. 


\section{Chapter 2}

\section{Experimental Facility Description}

The EAST Facility at NASA-ARC was developed for the purpose of using an experimental facility to create high enthalpy conditions and shock heated gas simulating entry for hypersonic vehicles entering different planetary atmospheres (Grinstead, et al., 2008). High enthalpy conditions in the EAST Facility can vary from 20 to $70 \mathrm{MJ} / \mathrm{kg}$. Test times are in the order of microseconds but depend on the velocity of the shockwave. The facility has a broad range of uses but is mostly used for shock radiation, ionization, and gas kinetics research associated with hypersonic entry into planetary atmospheres. The EAST Facility was developed in the mid-1960s in conjunction with the Apollo program. Since then, it has supported various space programs for NASA.

A picture of the EAST Facility is shown in Figure 2.1. Current testing is being conducted in the smaller of the two shock tubes, of which the shock tube driven diameter, $\mathrm{D}$, is $10.16 \mathrm{~cm}$. The total length of the driven tube, which is measured from the main diaphragm to the dump tube, is approximately $8.2 \mathrm{~m}$. The arc driver energy is delivered from a capacitor bank and will be further explained. 


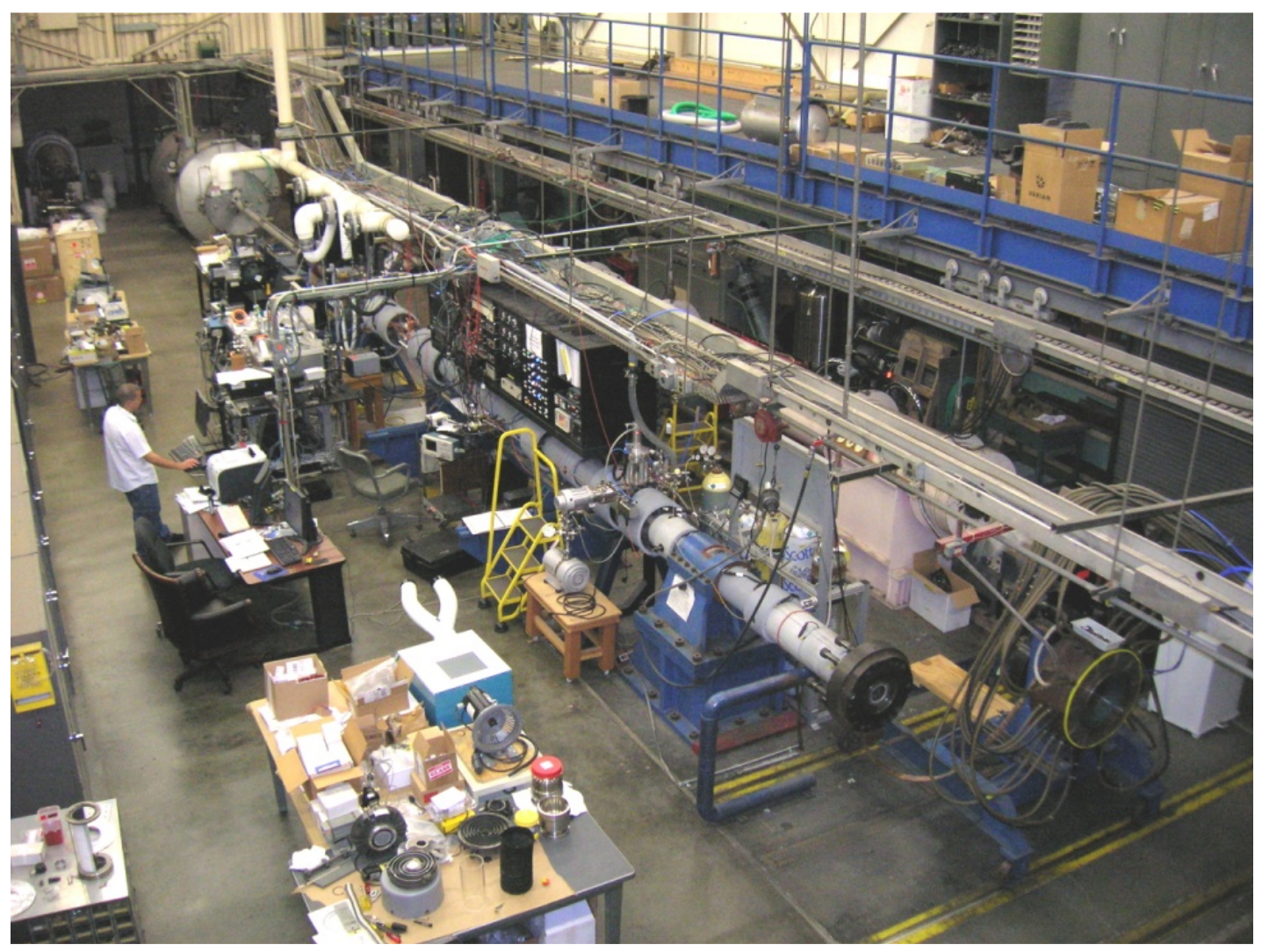

Figure 2.1. The EAST Facility at NASA Ames Research Center.

The energy for the arc driver discharge is supplied by a 6-tier capacitor capacitance bank, which is located in a separate room adjacent to the shock tube. The capacitor bank has a maximum energy storage of $1.2 \mathrm{MJ}$, with a total capacitance that can range from 149 to $6126 \mu \mathrm{F}$. The maximum capacitance for $40 \mathrm{kV}$ operation (used in current tests) is $1530 \mu \mathrm{F}$ (Grinstead, et al., 2008). The system inductance is $0.26 \mu \mathrm{H}$ and the system resistance is $1.6 \mathrm{~m} \Omega$. A picture of the capacitor bank is shown in Figure 2.2. Capacitor bank test voltage set points depend on desired target shock velocities for the given test. Shock velocities vary on a test-by-test basis dictated by project needs. 


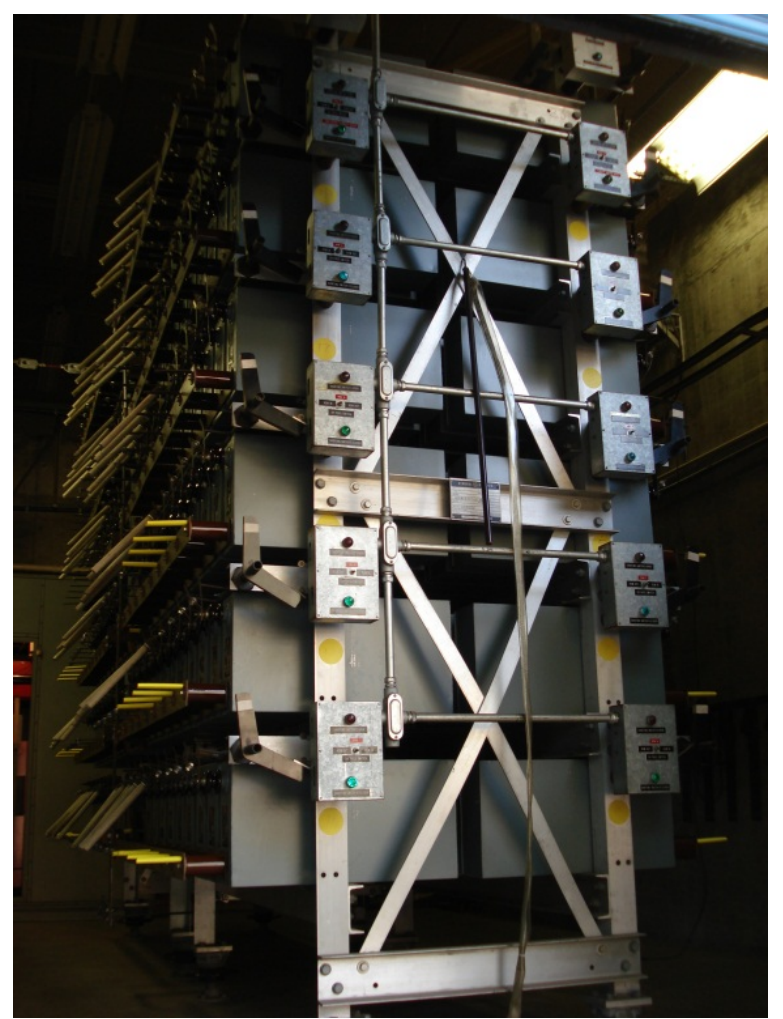

Figure 2.2. The 6-tier capacitor capacitance bank.

EAST Facility instrumentation falls into two categories, facility performance instrumentation and spectroscopic instrumentation. Spectroscopic instrumentation is designed to capture spectrally and spatially resolved shock radiance as the shockwave passes through the facility test section. Vital instruments for the EAST Facility are imaging spectrographs that capture spatially resolved shock radiation spectra throughout the shock layer. Shockwave tests are performed by imaging the shock layer with timegated detectors. These shock layer tests are only possible with the design of an optical system that correctly magnifies and focuses the shock radiance on the corresponding spectrometer and detector setup. Imaging spectroscopy is possible in this facility from the deep VUV (120 to $200 \mathrm{~nm}$ ) through the UV/visible (200 to $800 \mathrm{~nm}$ ) and IR (800 to $1700 \mathrm{~nm}, 3000$ to $5000 \mathrm{~nm}$ ) regions of the spectrum. 


\section{Chapter 3}

\section{The EAST Facility Upgrade Project}

The EAST Facility has been operational since the late 1960s. In 2008, there was a need for a modernization of the facility, since the facility was still being operated with "legacy" equipment. As a result, a major modernization upgrade project took place for both facility and testing related equipment and instrumentation used in the EAST Facility.

\subsection{Facility and Instrumentation Upgrades}

Multiple motivations drove the EAST Facility upgrade project. One of the goals of the upgrade project was to replace the legacy equipment and modernize facility operations by automating various portions of operational techniques. A second goal was to further enable spectroscopy studies, with an emphasis to make spectrally and spatially resolved measurements into the VUV. A computer aided design (CAD) model of the EAST Facility upgrades and modifications is shown in Figure 3.1. 


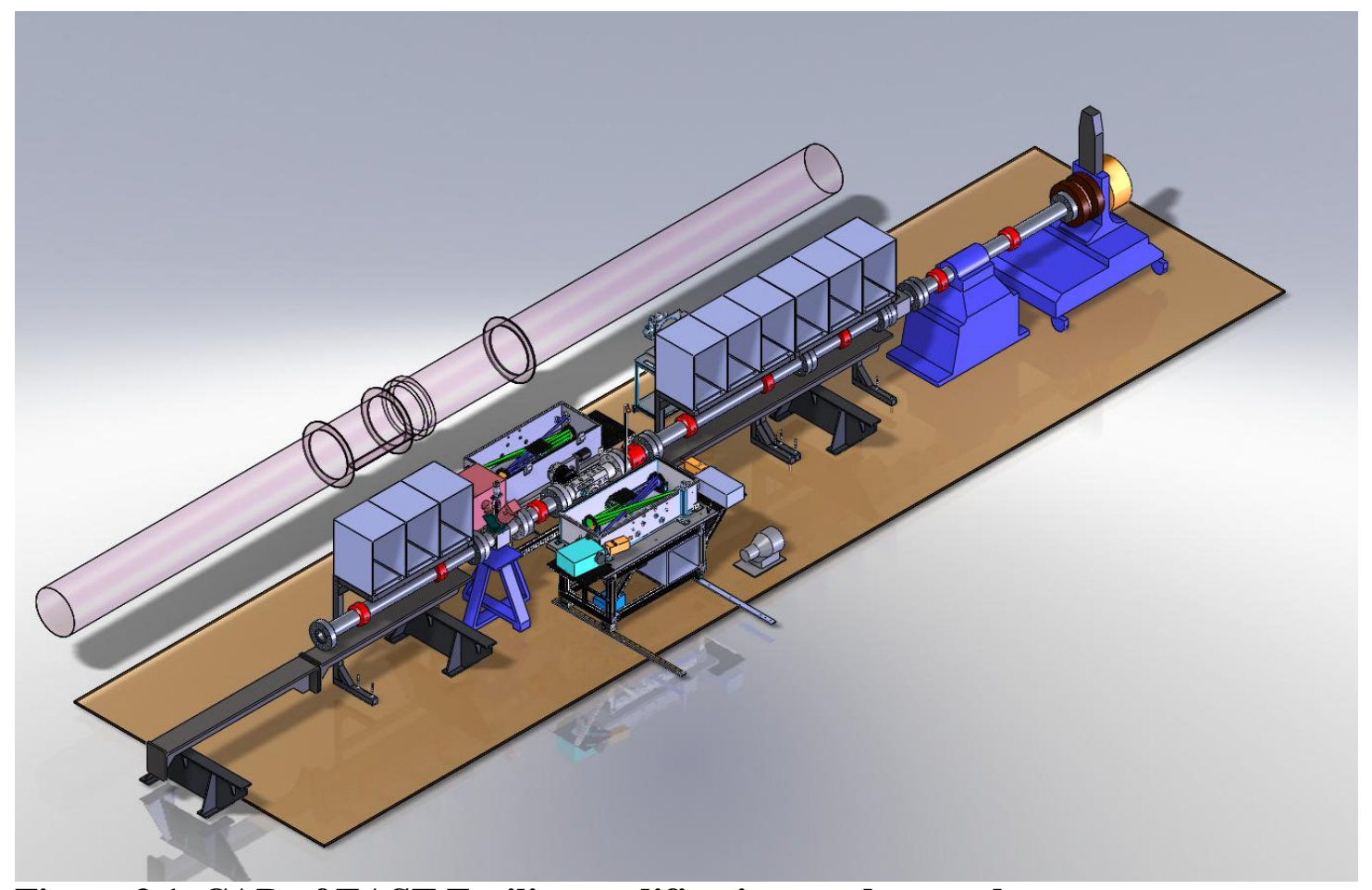

\section{Figure 3.1. CAD of EAST Facility modifications and upgrades.}

Radiative heating is observed and predicted to be significant in the VUV portion of the spectrum for various hypersonic entry applications (Bose, et al., 2008). For both $\mathrm{CO}_{2}$ and Air applications, no good experimental data had been captured for radiation measurements in the deep VUV, due to instrument and facility limitations. In preupgrade EAST testing, this type of deep VUV measurement was not possible. Due to difficulties associated with enclosing optics in a vacuum atmosphere, VUV data was collected without imaging optics. As a result, data obtained were only spectrally resolved. In order to enable imaging into the deep VUV, new Lithium Fluoride (LiF) windows had to be designed and manufactured. Also, the VUV spectrometer was upgraded as part of the modernization of the facility. The EAST upgrade accommodated previous VUV issues and now enables deep VUV measurement. 
The new optical configuration is now enclosed in a high vacuum chamber and a vacuum grade spectrometer and detector are attached to this chamber. A solid model of the new setup is shown in Figure 3.2. Once calibrations for the upcoming test are performed, the vacuum box is then coupled to the shock tube and the entire system is brought down to high vacuum conditions. Radiation measurements are then able to be measured down to $120 \mathrm{~nm}$, through the use of the $\mathrm{LiF}$ windows.

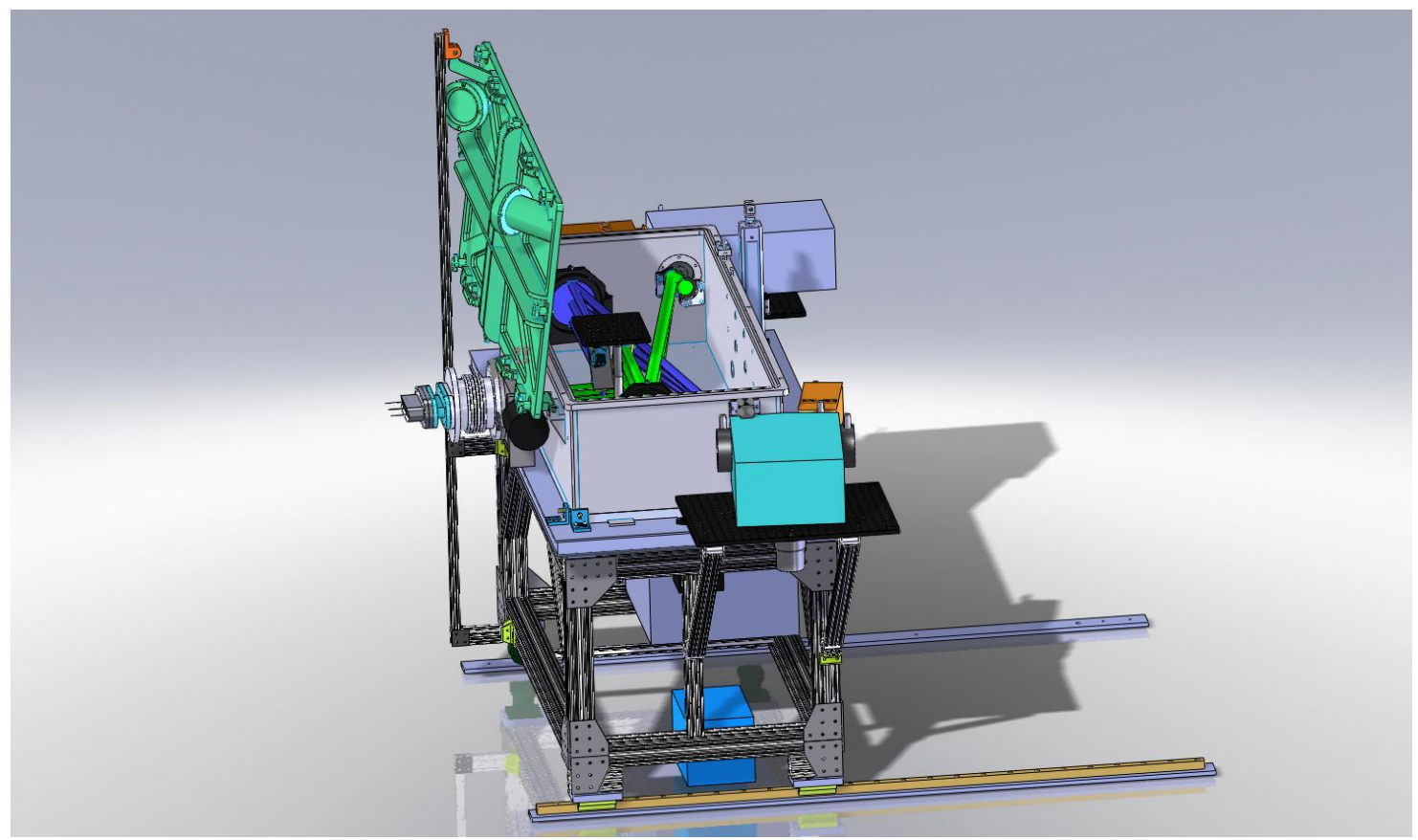

Figure 3.2. Solid model of the vacuum box with imaging system integrated.

There are two vacuum boxes, which have four spectrometer/camera systems attached, that are able to take measurements from the VUV to IR portions of the spectrum. The coupled system is shown in Figure 3.1. The new vacuum box setup allows for simultaneous measurements of shockwave radiance, via the four spectrometers, all at the same axial location of the shock tube. Fully automated 
spectrometers allow us to change grating and slit widths with relative ease, via a software program by the name of Winspec. A summary of the imaging spectrograph locations, along with important parameters for each system, is summarized in Table 3.1.

Table 3.1. Imaging spectrograph specifications after EAST upgrade.

\begin{tabular}{|c|c|c|c|c|}
\hline System & VUV & UV/VIS (Blue) & $\begin{array}{c}\text { VIS/NIR } \\
(\text { Red) }\end{array}$ & NIR/IR \\
\hline $\begin{array}{c}\text { Spectral Range } \\
(\mathrm{nm})\end{array}$ & $120-450$ & $185-650$ & $500-900$ & $535-1700$ \\
\hline Detector & ICCD & ICCD & ICCD & VisGaAs \\
\hline Array size & 1024 X 1024 & 1024 X 1024 & 512 X 512 & 320 X 256 \\
\hline $\begin{array}{c}\text { Gate width, shot } \\
\text { conditions }(\mu \mathrm{s})\end{array}$ & $0.1-1$ & $0.1-1$ & $0.1-1$ & $0.5,1$ \\
\hline $\begin{array}{c}\text { Spectrograph } \\
\text { model }\end{array}$ & VM-504 & SP2500i & SP2500i & SP2500i \\
\hline \begin{tabular}{c} 
Focal length (m) \\
\hline $\begin{array}{c}\text { Slit } \\
\text { width }(\mu \mathrm{m})\end{array}$
\end{tabular} & $\begin{array}{c}10-3000(\text { non- } \\
\text { motorized }\end{array}$ & $10-3000$ & $10-3000$ & $10-3000$ \\
\hline
\end{tabular}

Also as part of the EAST upgrade, two pumping stations were modified and implemented. The main facility valve was modified to increase conductance and oil free mechanical pumps were implemented. These modifications allow the driven tube to be evacuated to pressures in the $10^{-6}$ Torr range, prior to filling the test gas during testing operations. These pumping stations provide the most contamination free simulated atmosphere in the shock tube during the test. These upgrades further eliminate water and carbon dioxide contamination in the system. An automated overnight pumping procedure controls pumping operations, heat, and purging cycles that reduce contamination levels. As a result, the facility is able to achieve pressures in the $10^{-6}$ Torr range after overnight pumping, which in pre-upgrade EAST pumping, took approximately 40 hours to achieve. 
An automated gas loading system was also implemented. This system allows the shock tube to have pressure and gas mixtures preset prior to testing. This gas loading system is interfaced with the shock tube firing system and allows the shock tube to be filled with the test gas during the charging sequence. A very important contribution to the EAST upgrade was the implementation of the use of an oxygen plasma cleaning source. The cleaning source creates $\mathrm{O}$ radicals which help remove surface carbon from the shock tube walls. This method of cleaning has been shown to be successful in the reduction of carbon and hydrogen contamination (Cruden, et al., 2009). The cleaning device is pictured in Figure 3.3. This cleaning device is used during the overnight pumping and purge cycles.



Figure 3.3. The oxygen plasma cleaning source installed in the shock tube.

New Photo Multiplier Tubes (PMTs) and Pressure Transducers (PCBs) were also implemented as part of the upgrade project. PMTs and PCBs are part of the Time of Arrival (TOA) system used to measure shock arrival times, and hence, velocity, for EAST testing. The new configuration of the EAST Facility has port locations for the new 
type of sensors at 18 different locations along the shock tube. Nine of these locations are clustered around the test section and are shown in Figure 3.4. These nine locations are directly around the viewing area where radiation measurements are taken for all 4 spectrometer and camera systems. PCBs and PMTs are used to characterize pressure and broadband radiance traces both as a function of time. PCBs are installed on the bottom of the test section with blue wires as shown. PMTs are connected with orange fiber optic cables and can be seen installed in the test section in Figure 3.4 as well. PMTs are used as part of the shot trigger system for shock imaging instrumentation. This system allows us to capture the shockwave arrival in the field of view of the camera. Both PMT and PCB outputs are fed to the Data Acquisition System (DAS), which measures various parameters for the given test including but not limited to driver voltage, current, camera trigger traces, PMT and PCB traces at different locations.

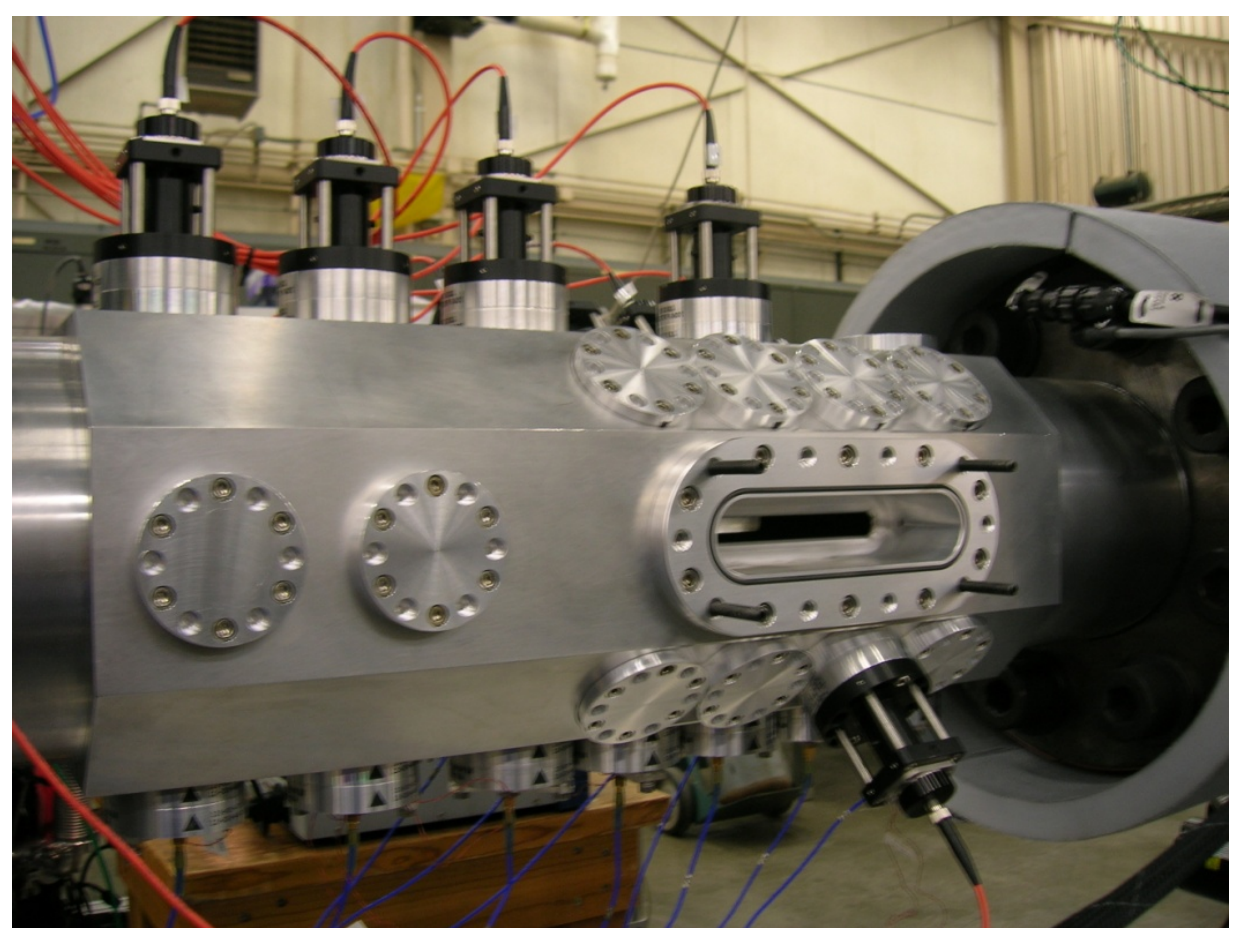

Figure 3.4. The new EAST Facility test section with PCBs and PMTs installed. 


\subsection{Design Work}

Throughout work during the EAST upgrade project, many different parts required design work to accommodate features of the new setup. As a result, there was design work associated with the EAST Facility upgrade that was instrumental to the EAST upgrade project. The following entails design work that was done on recommendation of the EAST upgrade project.

\subsubsection{Arc Driver Liner}

A solid model of the Arc Driver Liner that is used in the EAST Facility is seen in Figure 3.5. This part is essential to EAST facility operations, as it is an integral part to the EAST Arc Driver assembly. This Arc Driver assembly must be taken apart and reassembled prior to each shot. The CAD model was designed based off of "legacy" drawings in the facility, but a need arose for the creation of a solid model. This solid model is now distributed to vendors and is used for the manufacturing and fabrication of the part. It is currently used to create Teflon material driver liners for the EAST Arc Driver. However, there has been discussion on making a possible material change to try to reduce carbon contamination in the shock tube. The CAD model shown in Figure 3.5 is a cross-sectioned portion of the full CAD model that was designed in SolidWorks. It is sectioned in this particular case for easy viewing. 


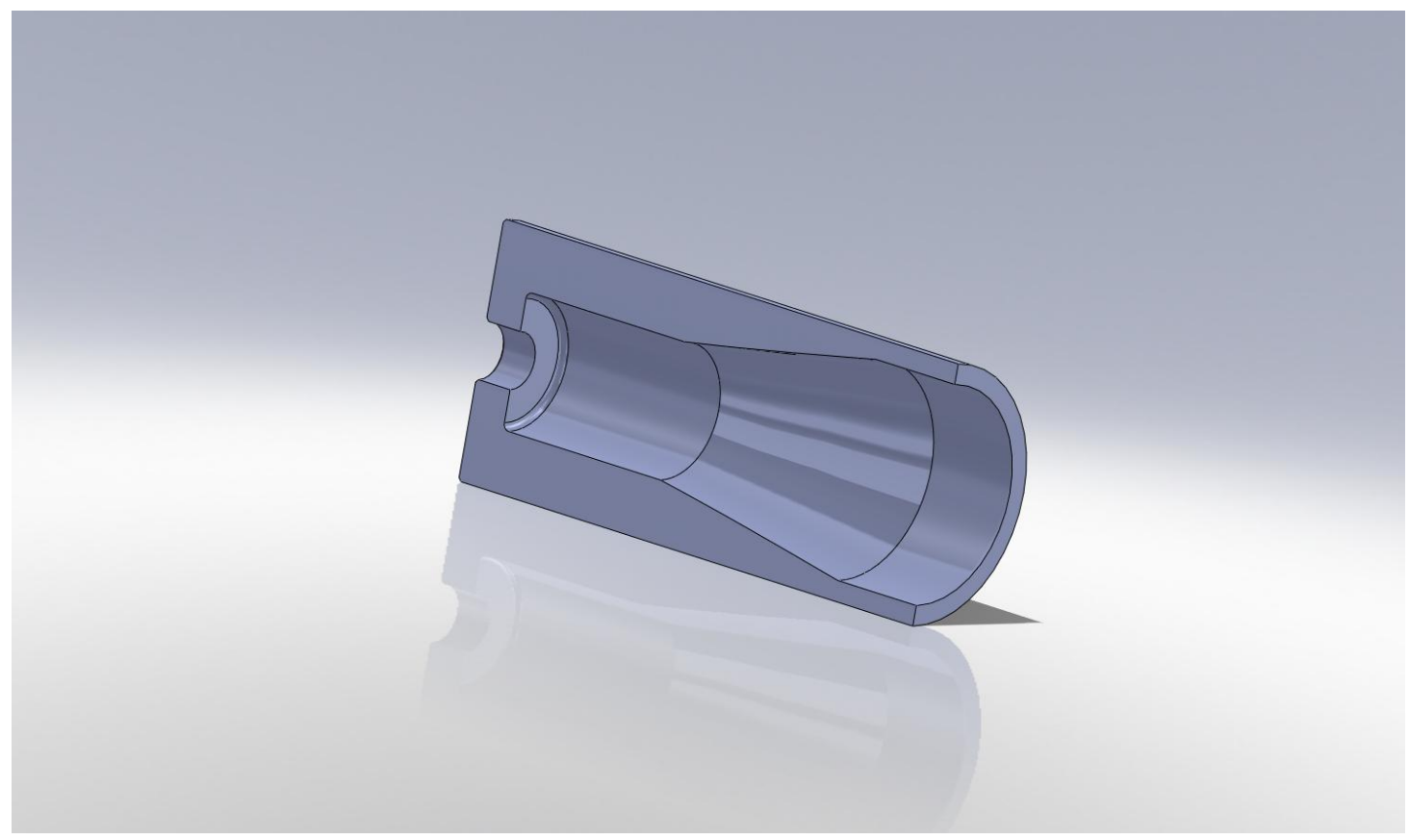

Figure 3.5. CAD model for the Arc Driver Liner.

Upon being tasked to produce the solid model for the Arc Driver Liner, a fabrication drawing must accompany the model. This fabrication drawing is sent to manufacturers along with the solid model for fabrication purposes. This fabrication drawing is shown in the Appendix.

\subsubsection{Calibration Mounts}

Since the upgrade required major changes to the facility, different techniques for calibration had to be considered. The implementation of a new optical setup, a new test section, and new spectrometer mounting systems, required new calibration techniques to be developed. To accommodate these facility changes, new calibration systems had to be considered. 


\subsubsection{Deuterium $\left(\mathrm{D}_{2}\right)$ Lamp Calibration Mounts}

Using the $\mathrm{D}_{2}$ lamp for calibration enables us to make deep VUV measurements. Since the $\mathrm{D}_{2}$ lamp calibration image only fills a small portion of the imaging area on the camera, there existed a need to design a system that could mechanically move along the window, and take corresponding images at pre-determined points along the window.

This system allows for more accurate calibration of the system and is explained in detail in Chapter 4. In Figure 3.6, the CAD for the design of the $\mathrm{D}_{2}$ lamp calibration mounting assembly is shown. The fabrication drawings are shown in the Appendix.

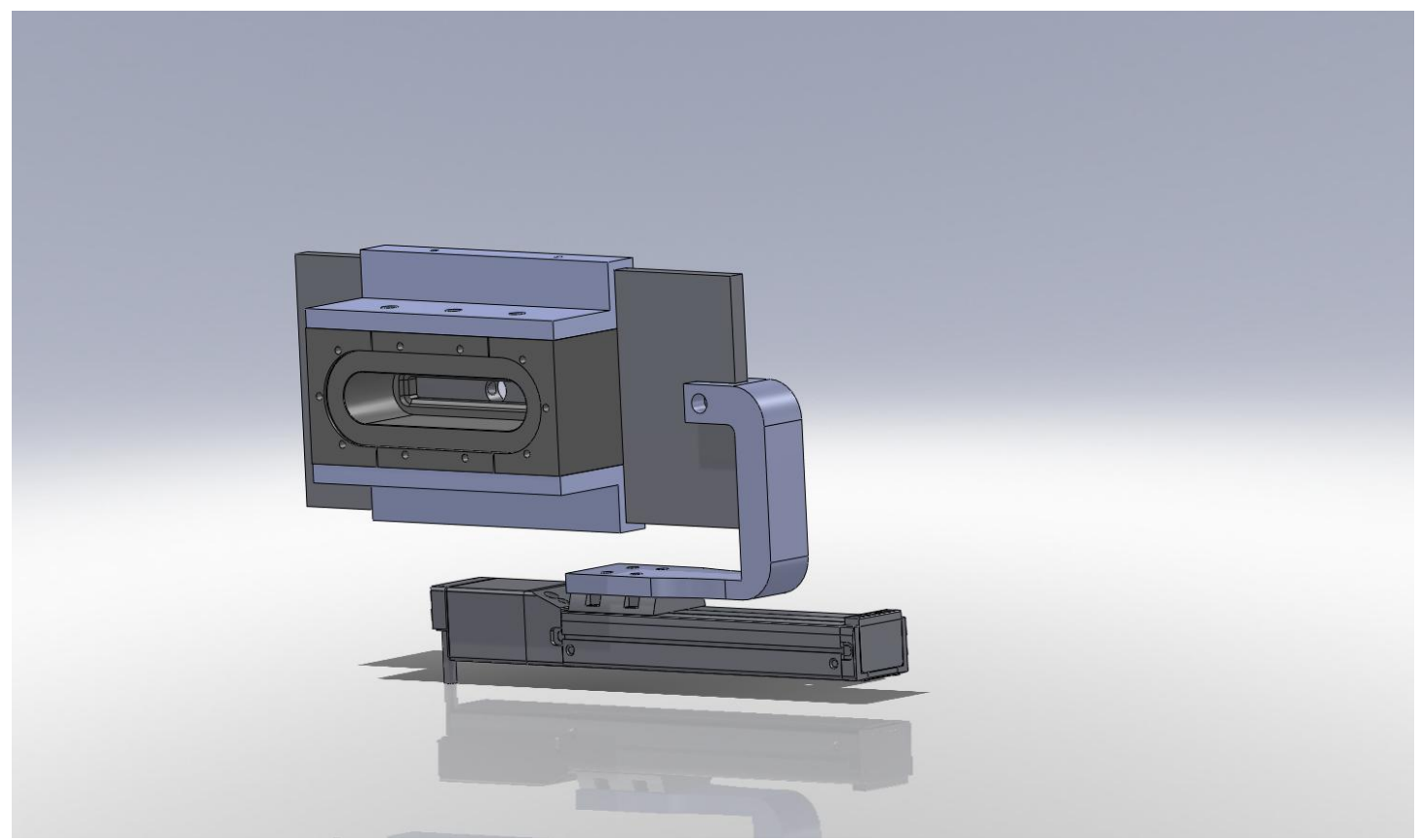

Figure 3.6. CAD model for the $\mathrm{D}_{2}$ Lamp Calibration Mounting Assembly.

\subsubsection{I-sphere Calibration Mounts}

Using the Integrating (I) sphere for calibration, enables calibration from the 300 to $1700 \mathrm{~nm}$ portions of the spectrum. Since radiation emitted from the I-sphere could have potentially hazardous levels of ultraviolet radiation, the adapter flange needed to be 
able to move simultaneously with the I-sphere. This adapter flange allows full field calibration, while preventing radiation produced from the calibration lamp to be leaked out to people in the nearby vicinity. In Figure 3.7, the CAD for the new design of the Isphere calibration mounting assembly is shown. The fabrication drawings are also seen in the Appendix.

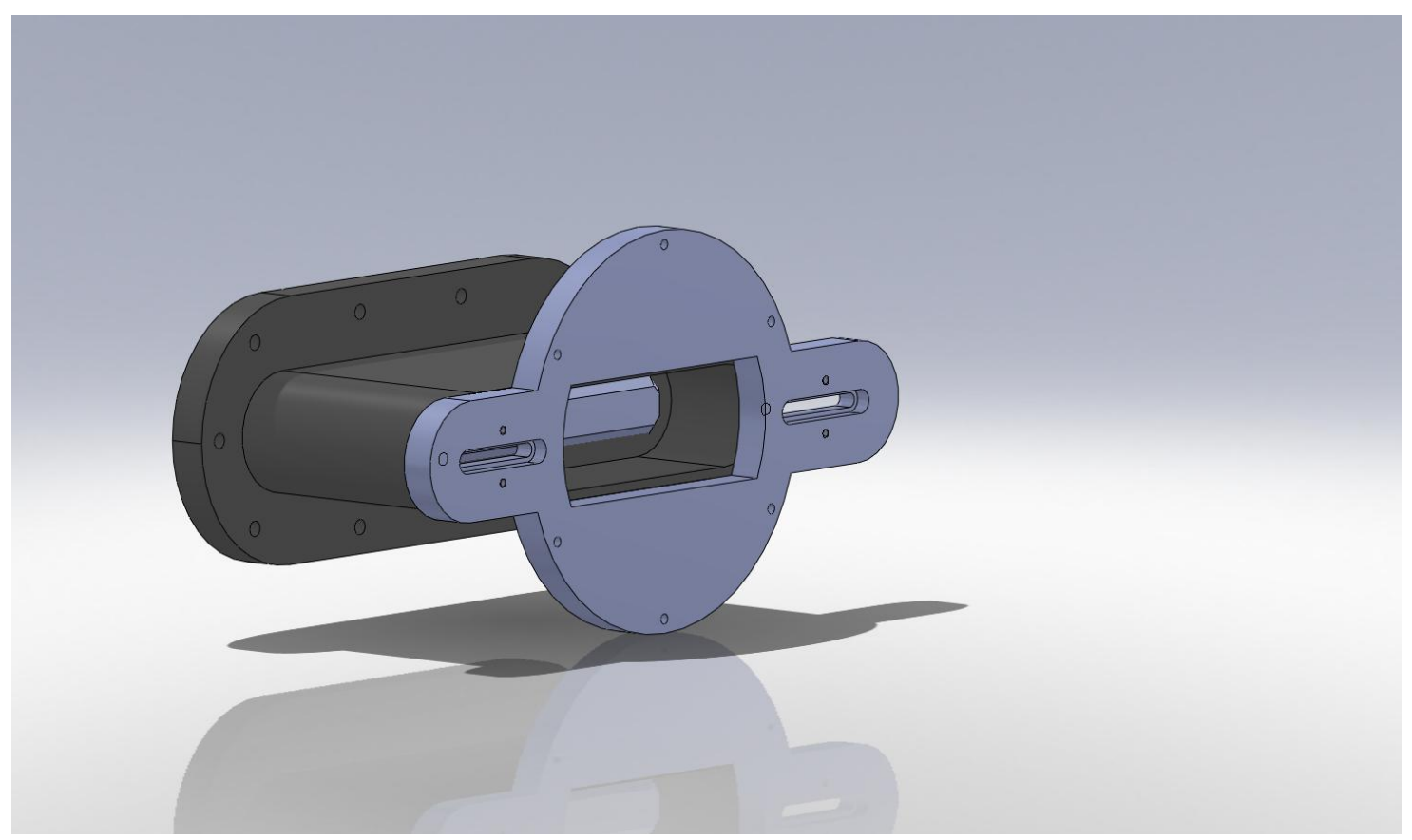

Figure 3.7. CAD model for the I-sphere Calibration Mounting Assembly. 


\section{Chapter 4}

\section{Calibration Techniques}

Pre-upgrade, one of the most time consuming activities in a shot to shot basis, was the calibration of appropriate spectroscopic and camera setups. One of the purposes of the upgrade was to reduce calibration time, yet keep quality of calibrations and consistency within calibrations. In the new system, implemented spectrometers hold wavelength calibrations over extended periods of time. Now, a more opticalmechanically stable system, allows us to see minimal changes in calibrations on a day to day basis.

\subsection{I-sphere Calibration}

The I-sphere has been introduced to the facility as the method of calibration for the 300 to $1700 \mathrm{~nm}$ wavelength range. The I-sphere has a 4 inch diameter port, which has a peak radiance near $1100 \mu \mathrm{W} / \mathrm{cm}^{2}$-sr-nm. It is used as the primary absolute radiance calibration source for the Visible through IR wavelength range. Since the 4 inch diameter port of the I-sphere does not cover the entire viewing area of the optical window, we must take calibrations at different locations covering the entire span of the optical window. These are known as I-sphere calibrations taken at the center, upstream, and downstream positions of the window. Examples of such calibrations are shown in Figures 4.1-4.3 and correspond to the Red (Vis/NIR) system in the EAST Facility. Here the horizontal axis on the calibration image is the spectral axis (wavelength) while the vertical axis is the spatial axis (strip) as shown below. 


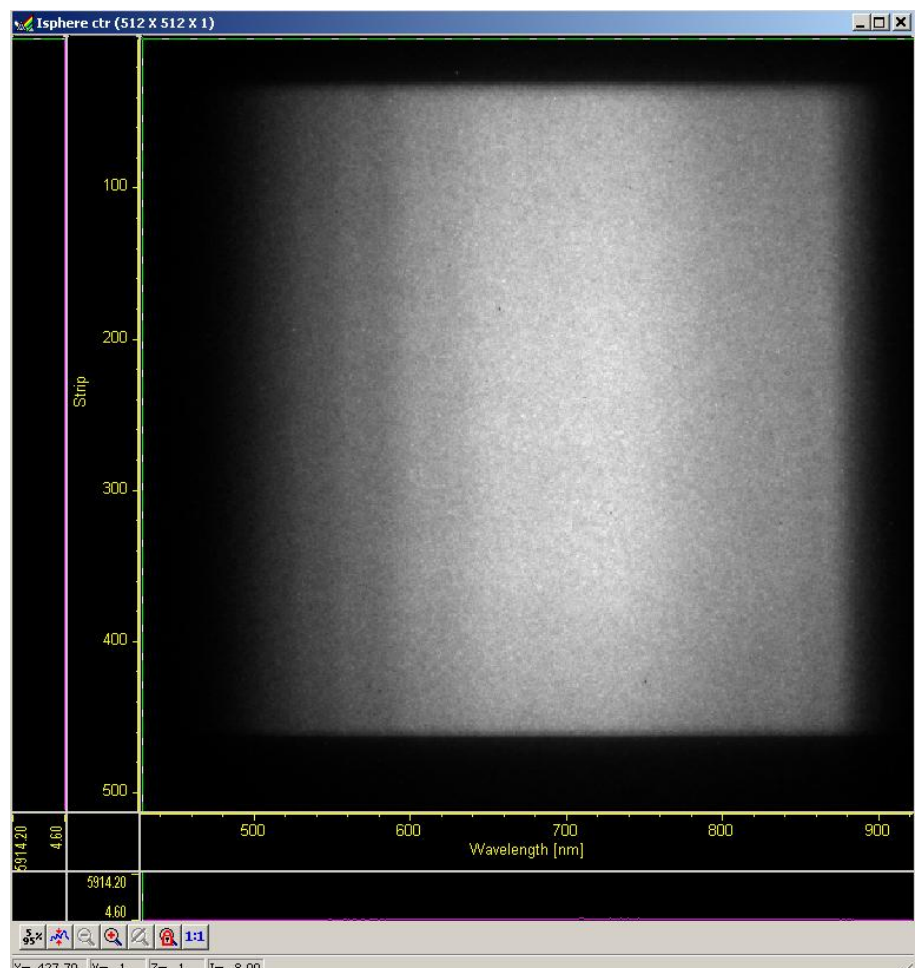

Figure 4.1. I-sphere calibration taken at the center location.

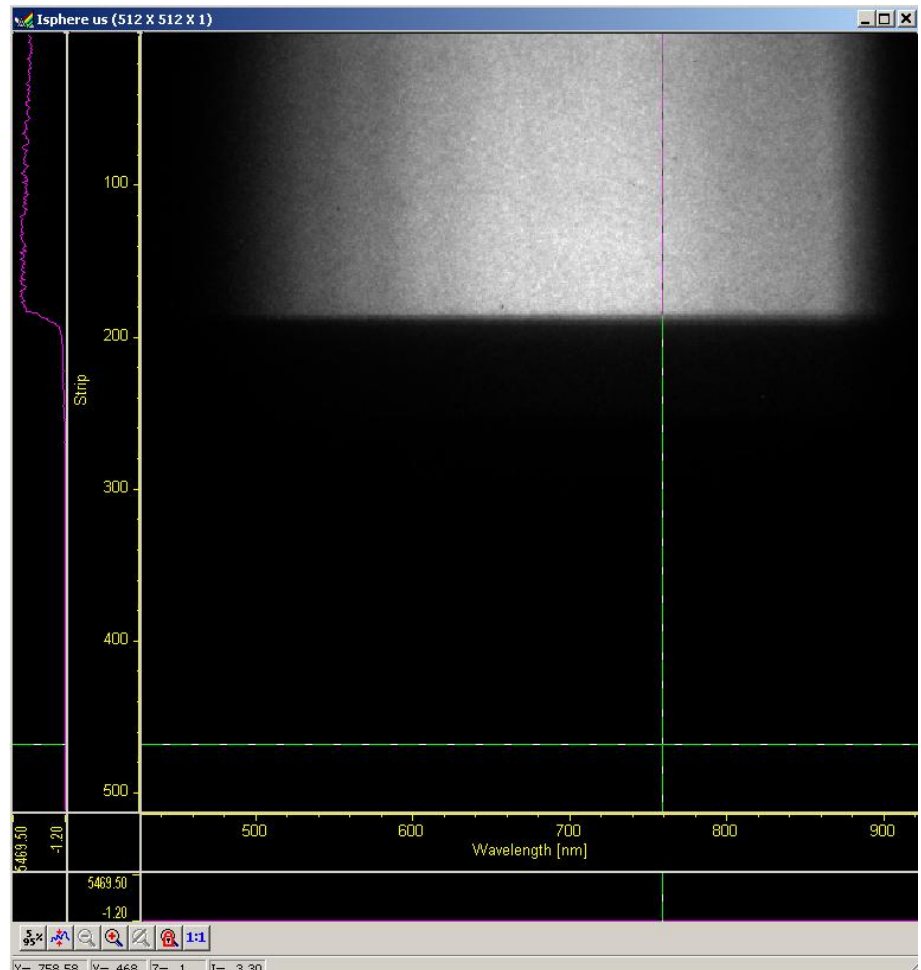

Figure 4.2. I-sphere calibration taken at the upstream location. 


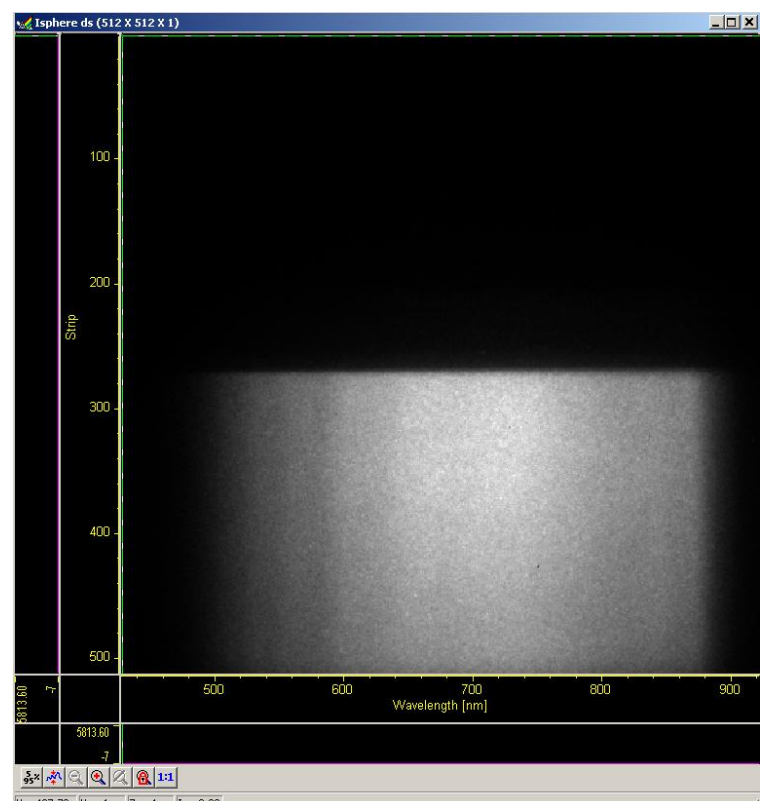

\section{Figure 4.3. I-sphere calibration taken at the downstream location.}

A flatfield is then created for calibration purposes using the center, upstream, and downstream data. An example flatfield is shown in Figure 4.4. This flatfield is an averaged depiction of the calibrations at the three locations described. This calibration method allows a full field calibration for the entire span of the optical window.

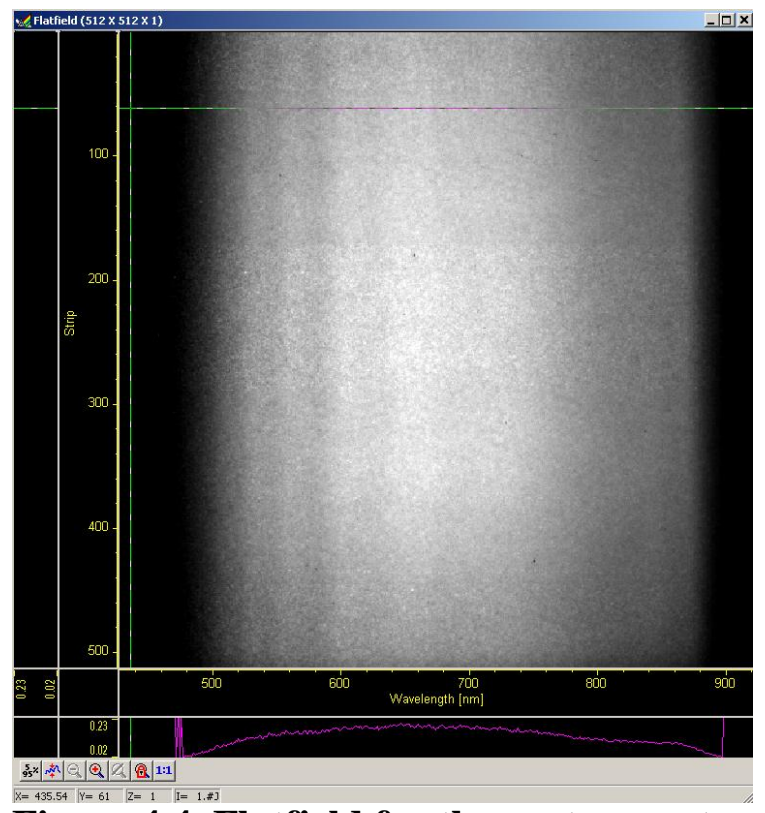

Figure 4.4. Flatfield for the center, upstream, and downstream calibrations. 


\section{2 $\quad \mathrm{D}_{2}$ Lamp Calibration}

In regions below the $300 \mathrm{~nm}$ range, a $\mathrm{D}_{2}$ lamp is used for calibration. This lamp is used to obtain calibration measurements at multiple positions along the optical path of the window. When taking calibration measurements with the $\mathrm{D}_{2}$ lamp, a calibration image must be taken at the shot condition. This data must be then correlated to a reference position taken with both the $\mathrm{D}_{2}$ lamp and the I-sphere at the same wavelength location. An example of a $\mathrm{D}_{2}$ lamp calibration at a single position is shown in Figure 4.5.

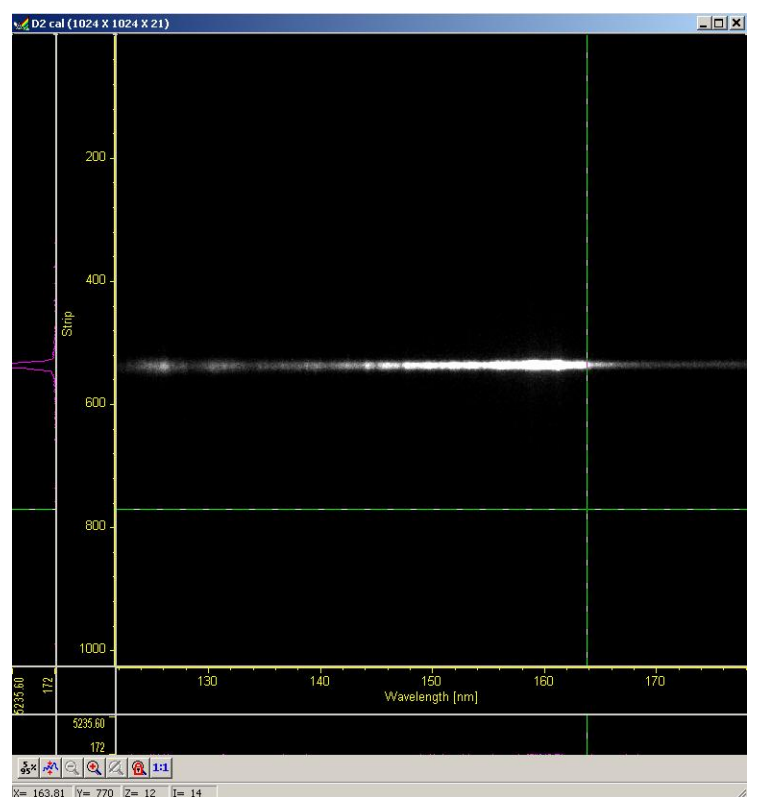

\section{Figure 4.5. $D_{2}$ lamp calibration for the VUV system at a single position.}

These calibration sources and methods are designed to provide the most hassle free and straightforward setup to allow calibrations to be done in a timely manner, on a shot by shot (i.e. daily) basis. The calibrations sources, along with new opticalmechanical mounting techniques, have dramatically decreased calibration time in comparison to pre-upgrade testing. Typical shot calibrations require approximately 4 hours of calibration time in the modernized EAST Facility. 


\section{Chapter 5}

\section{Mars and Venus Test Results}

Experiments in the EAST Facility require three essential parameters to describe the test environment. Test gas, test gas pressure, and shock velocity are key parameters in characterizing shockwaves that are created in the shock tube. Spectral features vary vastly based on the combination of these three parameters.

\subsection{Testing Parameters}

Test gas is a parameter that is controlled externally and is dictated by testing needs. Experiments done for Mars entry conditions consist of $96 \% \mathrm{CO}_{2}$ and $4 \% \mathrm{~N}_{2}$ by volume. Experiments done for Venus entry conditions consist of $96.5 \% \mathrm{CO}_{2}$ and $3.5 \%$ $\mathrm{N}_{2}$ by volume. These gases are representative of Mars and Venus entry conditions into the planet's atmosphere. Test gas pressure is controlled externally with the use of a gas loading system and pressure measurement instrumentation used in the facility. These

settings are dictated by test specific needs for each given test. Typical tests for Mars and Venus entry conditions performed varied from 0.1 to 2.0 Torr atmospheric pressure.

Shock velocity is a semi-controllable parameter that is based on the charge voltage applied in the capacitance bank that is chosen by the experimenter. Based on shock tube theory in Anderson (2003), shock velocity can be calculated in a shock tube using the following relations:

$$
M s=\frac{W}{a_{1}}
$$


where $M s$ is defined to be the Mach number, $W$ is the shock wave velocity and $a_{1}$ is the local speed of sound defined to be:

$$
a_{1}=\sqrt{\gamma_{1} R T_{1}}
$$

where $\gamma_{1}$ is the ratio of specific heats, $R$ is the specific gas constant and $T_{1}$ is the ambient temperature. $M s$ can be further simplified and is shown by the following relation:

$$
M s=\sqrt{\frac{\gamma_{1}+1}{2 \gamma_{1}}\left(\frac{p_{2}}{p_{1}}-1\right)+1}
$$

where $\frac{p_{2}}{p_{1}}$ is defined to be the pressure ratio across the shock wave. Combining Equations (5.1) and (5.3) yields our theoretical shock velocity calculation given by;

$$
W=a_{1} \sqrt{\frac{\gamma_{1}+1}{2 \gamma_{1}}\left(\frac{p_{2}}{p_{1}}-1\right)+1}
$$

Equation (5.4) would be sufficient to characterize shock velocities theoretically, if the problem were steady state. $p_{2}$ is an experimental value which is difficult to measure and shockwaves traveling down the shock tube experience significant changes in $\frac{p_{2}}{p_{1}}$ and $\gamma_{1}$. As a result, Equation (5.4) is not sufficient for shockwave velocity calculations pertaining to EAST Testing.

Shock velocities must be calculated from TOA sensor data, comprised of experimental measurements of shock arrival times at different positions in the shock tube based on either pressure or broadband radiance data.

The data presented shows a series of shots performed for Mars entry testing done in the EAST Facility. These shots give us sufficient data points to create a complete data set for the 0.25 Torr and $8 \mathrm{~km} / \mathrm{s}$ nominal shockwave velocity condition. 


\subsection{Test Condition: 0.25 Torr, $8 \mathrm{~km} / \mathrm{s}$ (Nominal)}

To complete a data set for any given test condition one shot is not sufficient to capture the entire 120 to $1700 \mathrm{~nm}$ portion of the spectrum. Thus, multiple shots are combined in order to complete a data set for a given nominal test condition. As an example, a single shot in the Mars test series is described, with additional data points shown to complete the nominal data test condition. The target velocity for Shot 39 was 8 $\mathrm{km} / \mathrm{s}$. The test gas used for this shot was $96 \% \mathrm{CO}_{2}$ and $4 \% \mathrm{~N}_{2}$ by volume and the atmospheric simulated pressure in the shock tube is 0.25 Torr. Based off of previous tests with similar conditions, the voltage control set point for the capacitance bank was set to $13.5 \mathrm{kV}$. The following are various pressure parameters that were measured and associated with Shot 39 .

Table 5.1. EAST Facility pressure readings for Shot 39.

\begin{tabular}{|l|c|}
\hline \multicolumn{1}{|c|}{ Parameter Measured } & Pressure (Torr) unless otherwise noted \\
\hline Base pressure & $2.90 \mathrm{E}-06$ \\
\hline Rate of Rise at 1 min & $1.00 \mathrm{E}-05$ \\
\hline Pre-shot base pressure & $3.30 \mathrm{E}-06$ \\
\hline Vacuum box pressure & $1.30 \mathrm{E}-07$ \\
\hline VM504 spectrometer pressure & $3.10 \mathrm{E}-06$ mbarr \\
& \\
\hline Pressure control set point & 0.25 \\
\hline Driver gas pressure & $100 \mathrm{psi}$ \\
\end{tabular}


Base pressure is dictated by a mid-tube gauge reading which provides a baseline for the pressure of the tube after pre-shot pumping sequences. The rate of rise at $1 \mathrm{~min}$ parameter is used as a reference point to determine impurity levels in the shock tube arising from outgassing or vacuum leaks. The pre-shot base pressure is recorded as the last recorded base pressure before the test occurs and the test gas is loaded, in order to better assess contamination. The contamination level in the tube can be estimated as:

$$
\frac{P_{\text {ror }}-P_{\text {base }}+P_{\text {preshot }}}{P_{\text {test }}} \times 10^{6} \mathrm{ppm}
$$

For this example the contamination level is $10.4 \mathrm{ppm}$.

Vacuum box pressure and VM504 spectrometer pressure are parameters that dictate whether the vacuum box is at appropriate vacuum levels for the test. In general, a vacuum box pressure of $10^{-5}$ Torr would result in a $1 \%$ absorption of radiation in the vacuum ultraviolet, so these values ensure the absorption is approximately 2 orders of magnitude less than that. The pressure control set point dictates the test gas pressure that is loaded into the tube prior to shooting. This set point is known as our simulated atmospheric pressure condition.

\subsubsection{Shock Velocity Measurement}

From Young and Freedman (2004), it is known that velocity is a function of both distance and time. Therefore the following relation is defined:

$$
V=\frac{d x}{d t}
$$

where $V$ is velocity, and $d x / d t$ is the rate of change in distance $x$. This equation can be directly applied to experimental shock tube velocity calculations with the following relation: 


$$
V_{s}=\frac{d x_{t o a}}{d t_{s a}}
$$

where $V_{s}$ is shock velocity, $d x_{\text {toa }}$ is the rate of change in distance between TOA sensors and $d t_{s a}$ is the rate of change in time based off of shock arrival between TOA sensors.

A PMT trace for Shot 39 is shown in Figure 5.1. PMTs specify the time the shockwave passes the given PMT, by exhibiting a spike in broadband radiance. As shown in Figure 5.1, the shock passes PMT M at $877 \mu$ s after the initial arc strike.

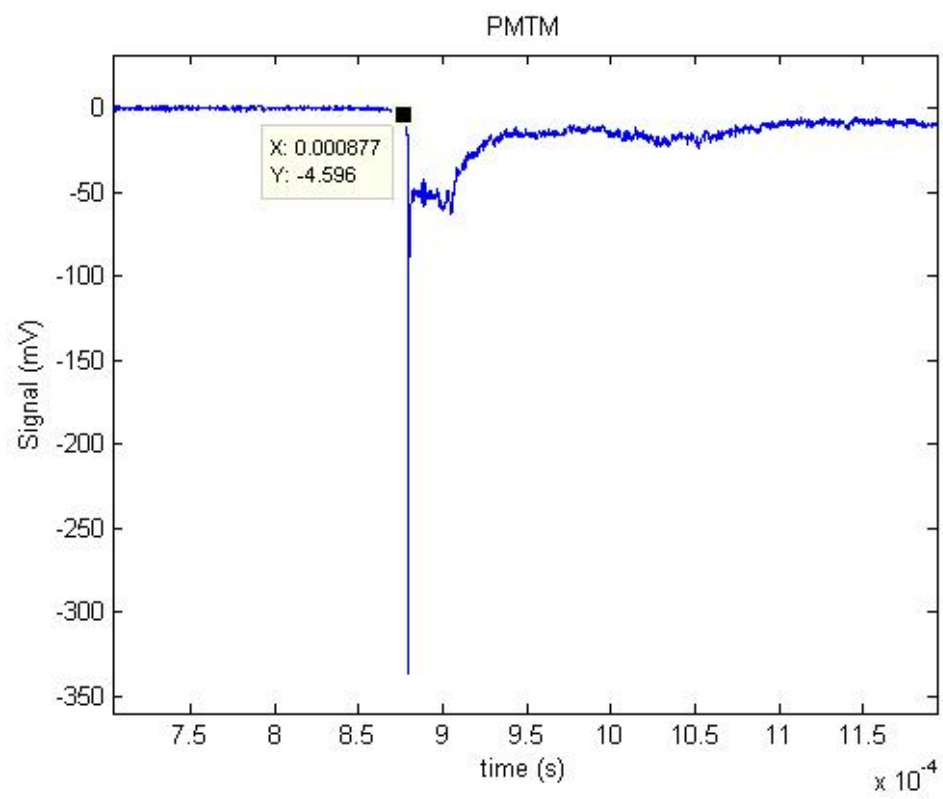

Figure 5.1. PMT M trace for Shot 39.

Figure 5.2 is the pressure trace at location O (PCB O) for Shot 39. As we see a sharp rise in pressure around $887.6 \mu \mathrm{s}$, we mark this as the point of shock arrival at PCB O. PCB O is a critical point, as it is the location of the camera trigger, and hence will correspond to the shock front location imaged on the spectrometers during the test. The determination of shock arrival can be applied for all individual TOA sensor locations for each shot. Table 5.2 summarizes all the TOA locations along the shock tube in distance 
$(\mathrm{cm})$ and the time it took for the shockwave to reach the TOA location in $(\mu \mathrm{sec})$ for Shot 39.

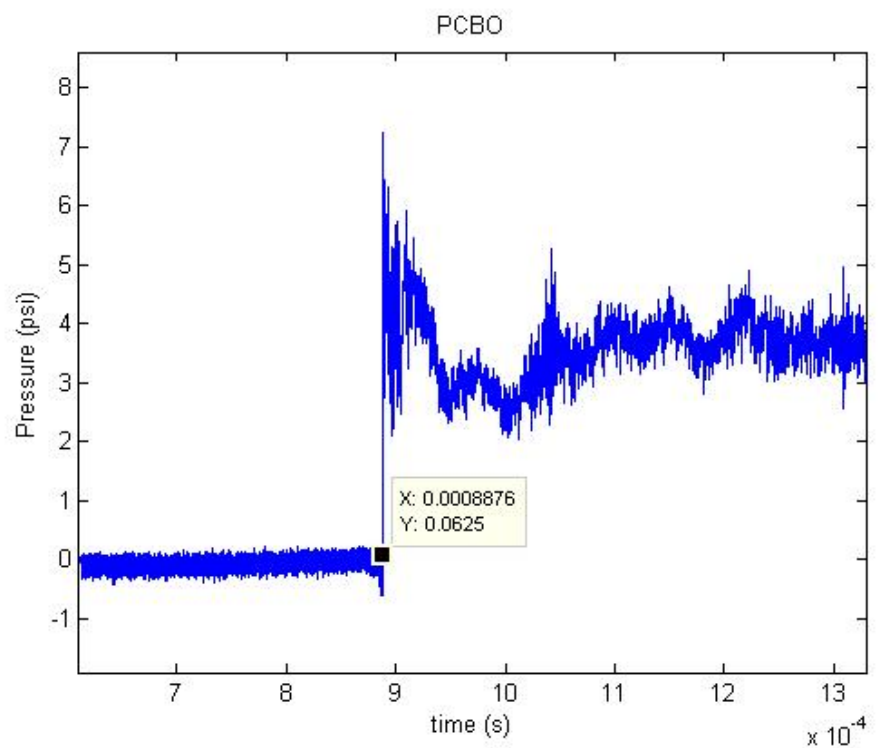

Figure 5.2. Time of shock arrival for PCB O, Shot 39.

Table 5.2. TOA locations and shock arrival times based on Shot 39 data.

\begin{tabular}{|c|c|c|}
\hline Position Along Shock Tube & Position (cm) & TOA ( $\boldsymbol{\mu s e c})$ \\
\hline F & 699.9 & 777.50 \\
\hline G & 710.1 & 789.76 \\
\hline H & 756.6 & 846.90 \\
\hline I & 764.9 & 857.26 \\
\hline J & 773.1 & 867.58 \\
\hline K & 776.3 & 871.58 \\
\hline L & 779.5 & 875.66 \\
\hline M & 782.6 & 883.68 \\
\hline N & 785.8 & 887.60 \\
\hline O & 789 & 891.72 \\
\hline P & 792.2 & 895.70 \\
\hline Q & 795.3 & \\
\hline
\end{tabular}


Using data in Table 5.2, we are able to construct a shock velocity measurement that was experimentally obtained using appropriate TOA sensors. Converting TOA locations from centimeters to kilometers and TOAs for the shockwave from microseconds to seconds lets us construct a relation to output shock velocity in our desired (km/s) units. Solving Equation (5.7) experimentally lets us construct a TOA vs. distance plot as shown in Figure 5.3.



Figure 5.3. TOA vs. distance data with a second order polynomial fit for Shot 39.

Upon fitting a second order polynomial to the data presented in Table 5.2, we are able to calculate our shock velocity at position $\mathrm{O}$ in the test section. Applying Equation (5.7), we are able to compute $V_{s}$ by;

$$
x=-1895 t^{2}+11.24 t-0.0006
$$

Differentiating the equation yields our velocity equation given by;

$$
V_{s}(x)=-3790 t+11.24
$$

Calculating the velocity at $T O A_{p c b o}$ yields; 


$$
\begin{gathered}
V_{s}\left(\text { TOA } A_{p c b o}\right)=-3790\left(\text { TOA }_{p c b o}\right)+11.24 \\
V_{s}(0.000888 \mathrm{sec})=-3790(0.000888 \mathrm{sec})+11.24 \\
V_{s}=7.87 \mathrm{~km} / \mathrm{s}
\end{gathered}
$$

\subsubsection{Calibrated Shock Intensity}

Upon characterizing the shock velocity for the given shot, we then are able to calculate the calibrated shock intensity and analyze spectral features that are associated with the shockwave. With the use of our 4 spectrometer and camera setups, we are able to resolve shock radiance both spatially and spectrally. Using Equation (5.8), we are able to compute shock intensity.

$$
B_{r}=\frac{I_{\text {raw }}-I_{\text {dark }}}{\tau_{\text {shot }}} K
$$

where $B_{r}$ is the calibrated shot image in form of (W/cm3- $\left.\mu \mathrm{m}-\mathrm{sr}\right), I_{\text {raw }}$ is the raw shot image in counts, $I_{\text {dark }}$ is the dark shot image in counts, $K$ is the calibration factor and $\tau_{\text {shot }}$ is the shot image exposure time. The calibration factor $K$ is defined to be:

$$
K=\frac{r_{\tau} L_{l} \tau_{c}}{I_{l, r}-I_{l, d}} \frac{1}{D}
$$

where $r_{\tau}$ is the reciprocity factor between $\tau_{\text {shot }}$ and $\tau_{c}, L_{l}$ is the calibration lamp absolute radiance, $\tau_{c}$ is the calibration lamp image exposure time, $D$ is defined to be the shock tube diameter, $I_{l, r}$ is the raw lamp calibration image in counts and $I_{l, d}$ is the dark calibration image in counts.

Instrumentation used to characterize shock radiance comes by the use of four distinct spectrometer and camera setups. In Table 5.3, the four spectrometer and camera set points are shown for Shot 39. 
Table 5.3. Spectrometer and camera set points for Shot 39 .

\begin{tabular}{|c|c|c|c|c|c|c|}
\hline $\begin{array}{c}\text { Spectrometer } \\
\text { settings }\end{array}$ & Grating & Range(nm) & $\begin{array}{c}\text { Exposure } \\
(\boldsymbol{\mu s})\end{array}$ & Filter & $\begin{array}{c}\text { Slit } \\
\text { Width } \\
(\boldsymbol{\mu m})\end{array}$ & $\begin{array}{c}\text { Temp } \\
(\mathbf{C})\end{array}$ \\
\hline VUV & $600 / 150$ & $165-218$ & 0.5 & N/A & 30 & -20 \\
\hline $\begin{array}{c}\text { UV/VIS } \\
\text { (Blue) }\end{array}$ & $150 / 300$ & $328-502$ & 0.1 & $\# 3$ & 30 & -20 \\
\hline $\begin{array}{c}\text { VIS/NIR } \\
\text { (Red) }\end{array}$ & $50 / 600$ & $480-900$ & 0.1 & $\# 3$ & 30 & -20 \\
\hline IR & $150 / 1200$ & $850-1050$ & 1 & $\begin{array}{c}\# 3 \\
(450 n m \text { cutoff })\end{array}$ & 60 & 0 \\
\hline
\end{tabular}

Figures 5.4-5.7 are the calibrated images for Shot 39 using the method outlined in Equations (5.8) and (5.9). Data reduction for these calibrated shots is done in-house with an automated data reduction program in MATLAB. The data analysis technique is addressed in part in Cruden, et al. (2009). The program outputs the calibrated shot data as spectral radiance versus position and wavelength. Cross sections of the 2-D image may be selected to obtain an integrated radiance profile in (W/cc-sr) in the spatial direction, and an averaged spectral radiance profile in (W/cc-sr- $\mu \mathrm{m})$ in the spectral direction. 

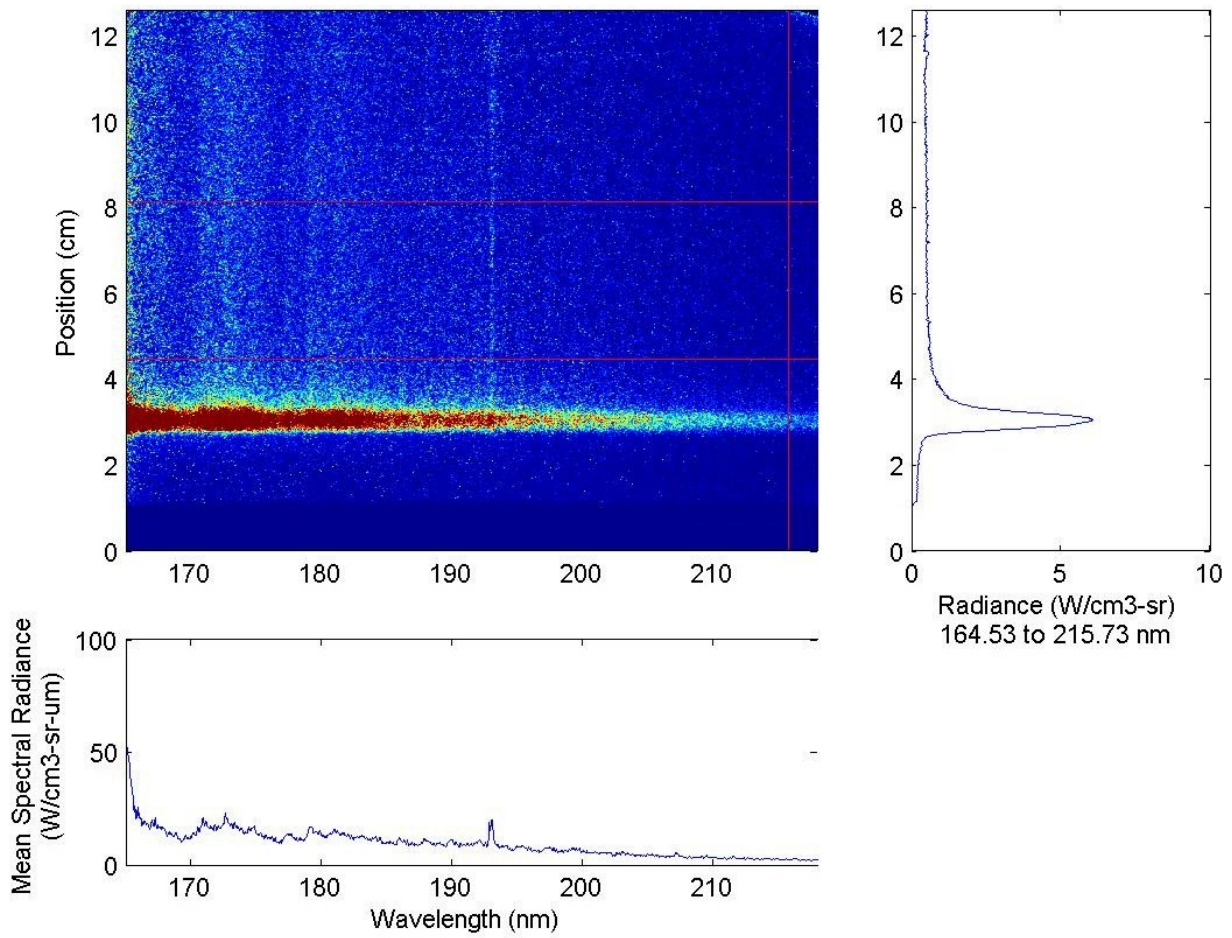

164.53 to $215.73 \mathrm{~nm}$

Figure 5.4. VUV calibrated shot data for Shot 39.
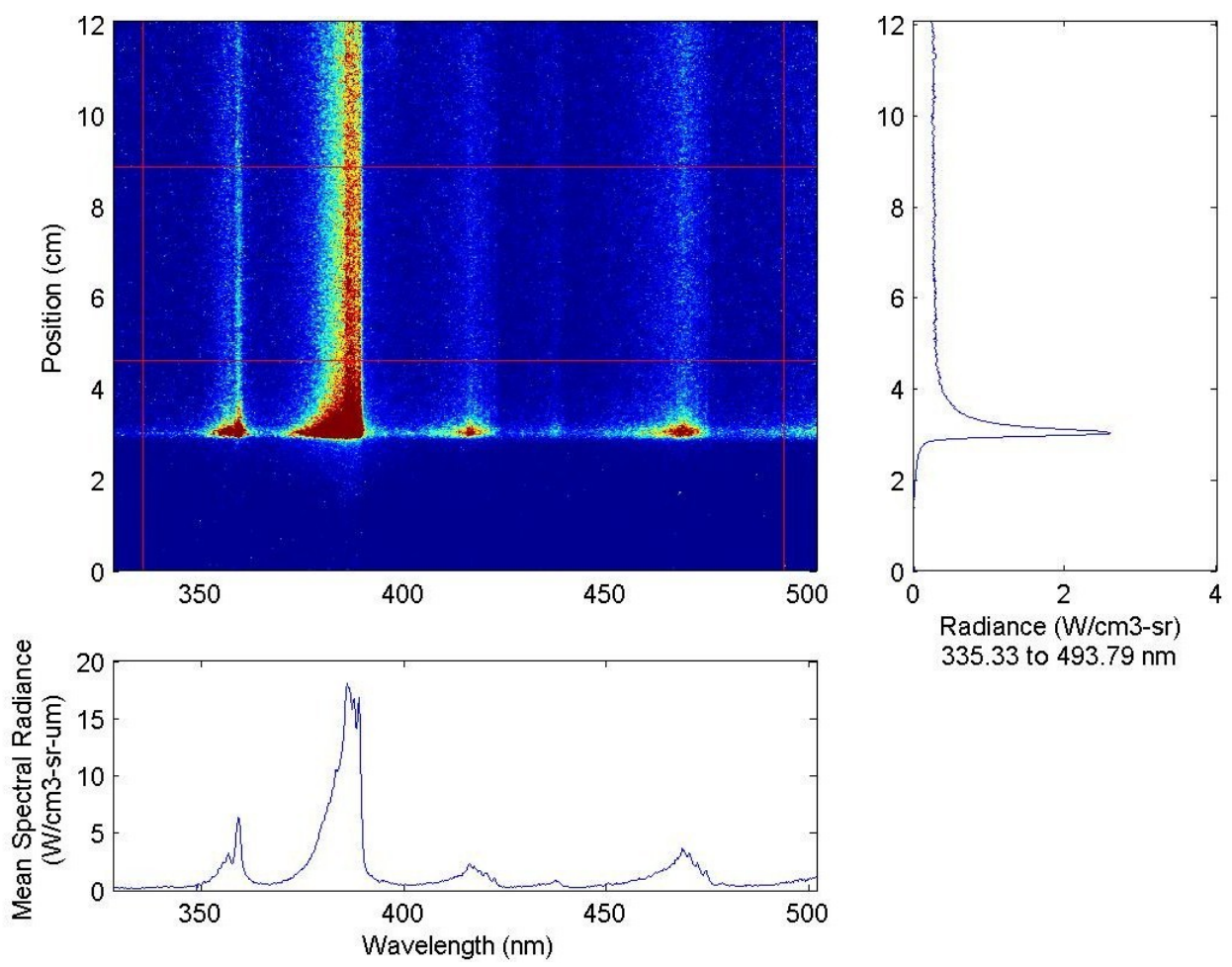

335.33 to $493.79 \mathrm{~nm}$

Figure 5.5. Blue calibrated shot data for Shot 39 . 

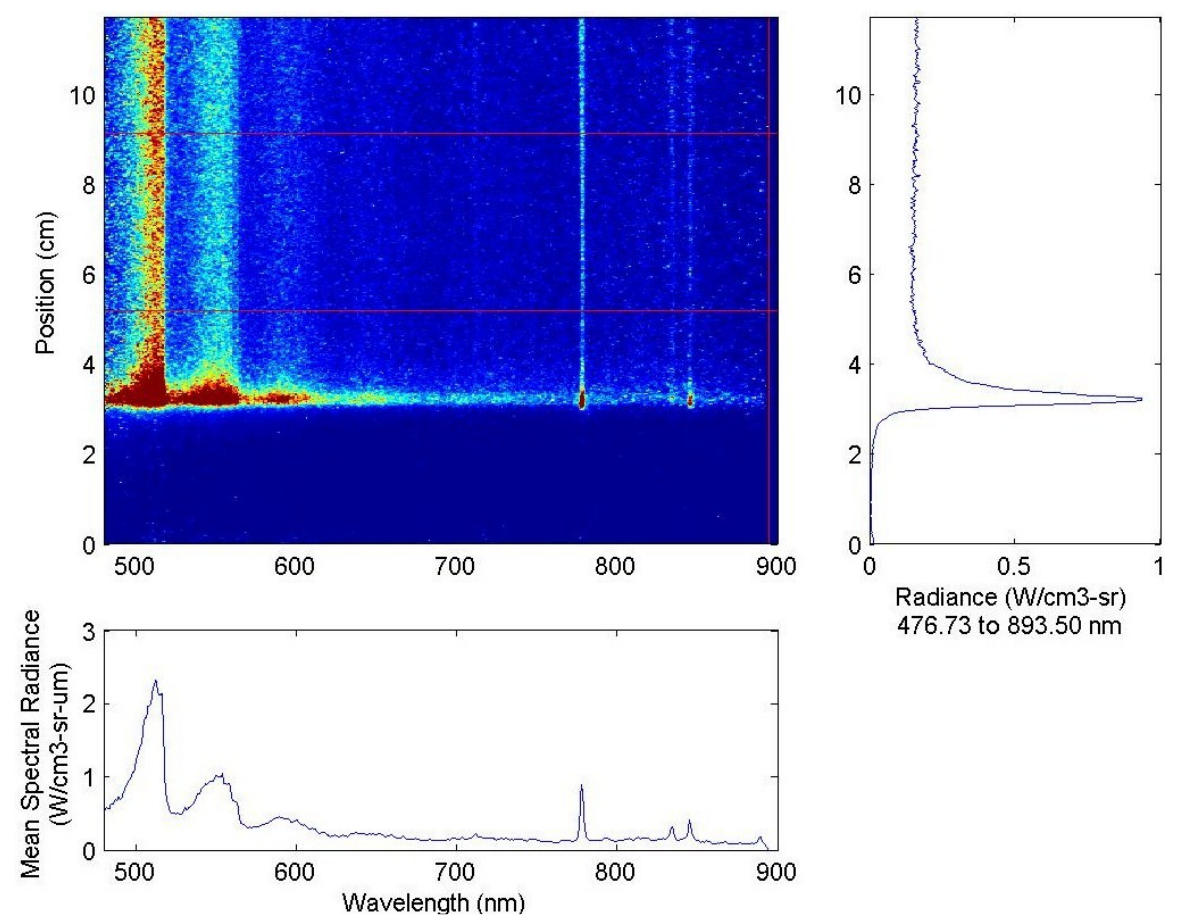

Figure 5.6. Red calibrated shot data for Shot 39.
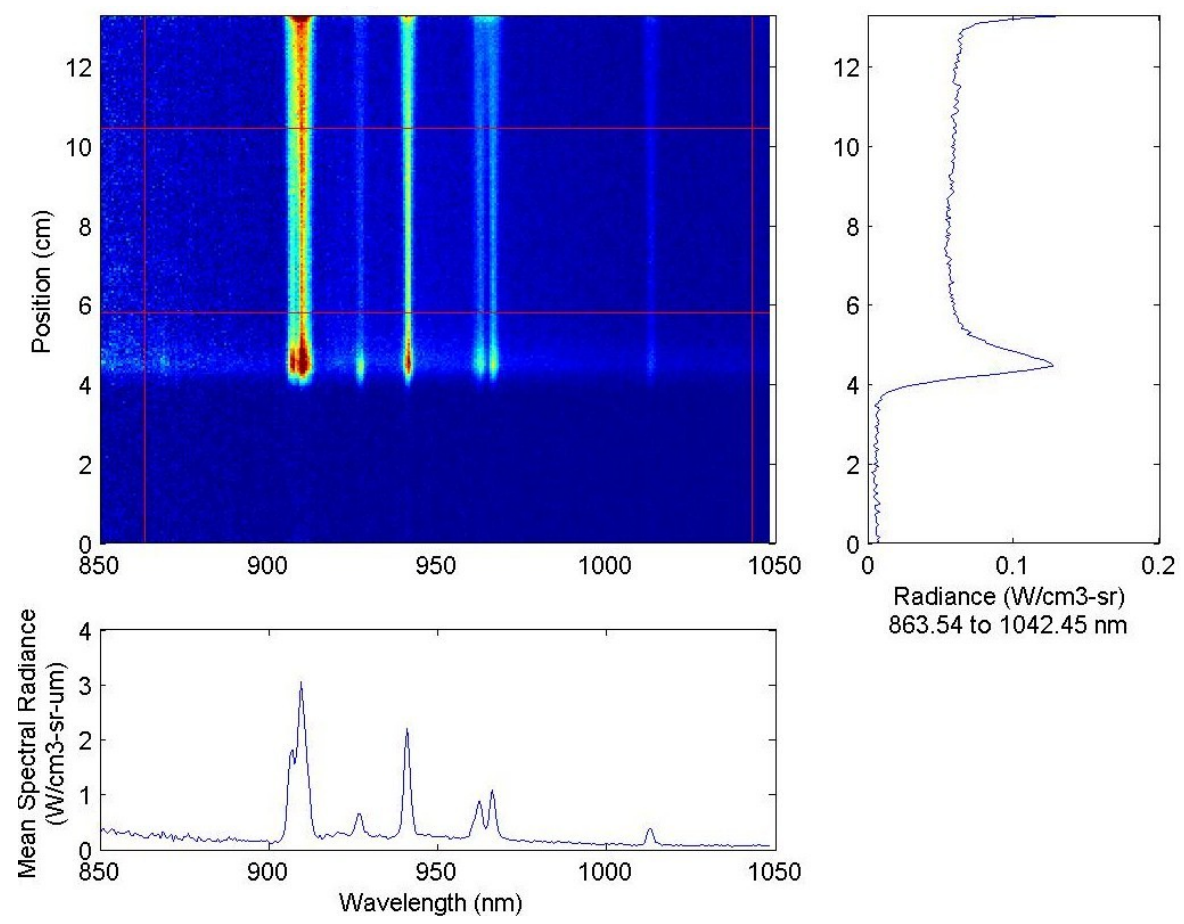

Figure 5.7. IR calibrated shot data for Shot 39. 
One shot however is not enough to cover the entire 120 to $1700 \mathrm{~nm}$ data range. In order to complete the data for the nominal test condition, we must take data from other shots and combine it with the data from Shot 39. Key parameters such as test gas pressure and shockwave velocity must compare to less than $1 \%$ for this method to be considered valid. As a result, we can combine Shot 39 with Shot 44 data, due to the fact that Shot 44 data is tested in the same test gas, has a velocity of $V_{s}=7.88 \mathrm{~km} / \mathrm{s}$, and was tested at a pressure of 0.25 Torr. Methods for determining $V_{s}$ and test gas pressure are similar to the example of Shot 39 that was previously discussed. Spectrometer and camera set points for Shot 44 are shown in Table 5.4.

Table 5.4. Spectrometer and camera set points for Shot 44.

\begin{tabular}{|c|c|c|c|c|c|c|}
\hline $\begin{array}{c}\text { Spectrometer } \\
\text { settings }\end{array}$ & Grating & $\begin{array}{c}\text { Range } \\
(\mathbf{n m})\end{array}$ & $\begin{array}{c}\text { Exposure } \\
(\boldsymbol{\mu s})\end{array}$ & $\begin{array}{c}\text { Filter } \\
\text { Width } \\
(\boldsymbol{\mu m})\end{array}$ & $\begin{array}{c}\text { Temp } \\
(\mathbf{C})\end{array}$ \\
\hline VUV & $600 / 150$ & $120-170$ & 0.5 & N/A & 30 & -20 \\
\hline $\begin{array}{c}\text { UV/VIS } \\
\text { (Blue) }\end{array}$ & $150 / 300$ & $190-350$ & 0.1 & $\# 1$ & 30 & -20 \\
\hline $\begin{array}{c}\text { VIS/NIR } \\
(\text { Red })\end{array}$ & $1200 / 750$ & $769-785$ & 0.25 & $\# 3$ & 30 & -20 \\
\hline IR & $150 / 1200$ & $1050-1250$ & 1 & $(450 \mathrm{~nm}$ cutoff $)$ & & \\
\hline
\end{tabular}

The calibrated shot data is shown in Figures 5.8-5.10. This completes the data set, with the exception of the IR data, for the nominal $8 \mathrm{~km} / \mathrm{s}, 0.25$ Torr condition in Mars entry testing. 

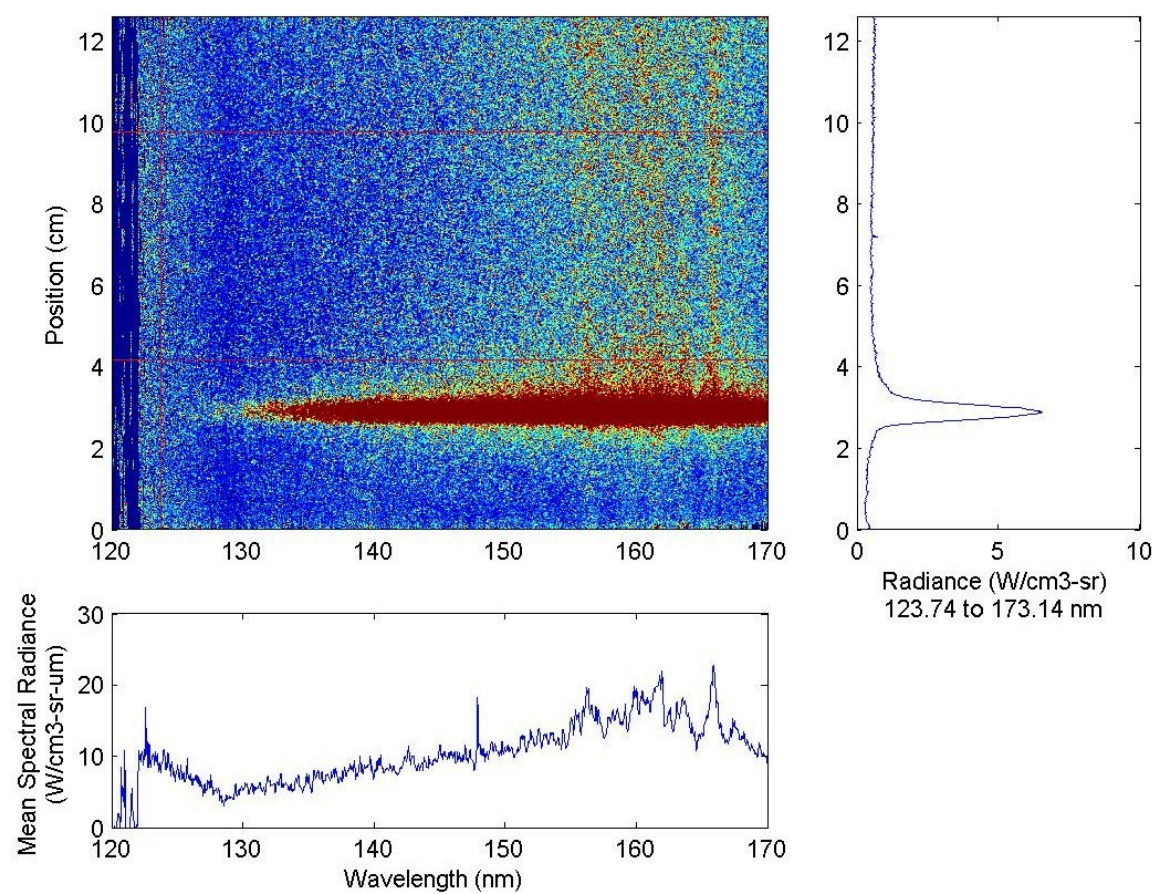

Figure 5.8. VUV calibrated shot data for Shot 44 .
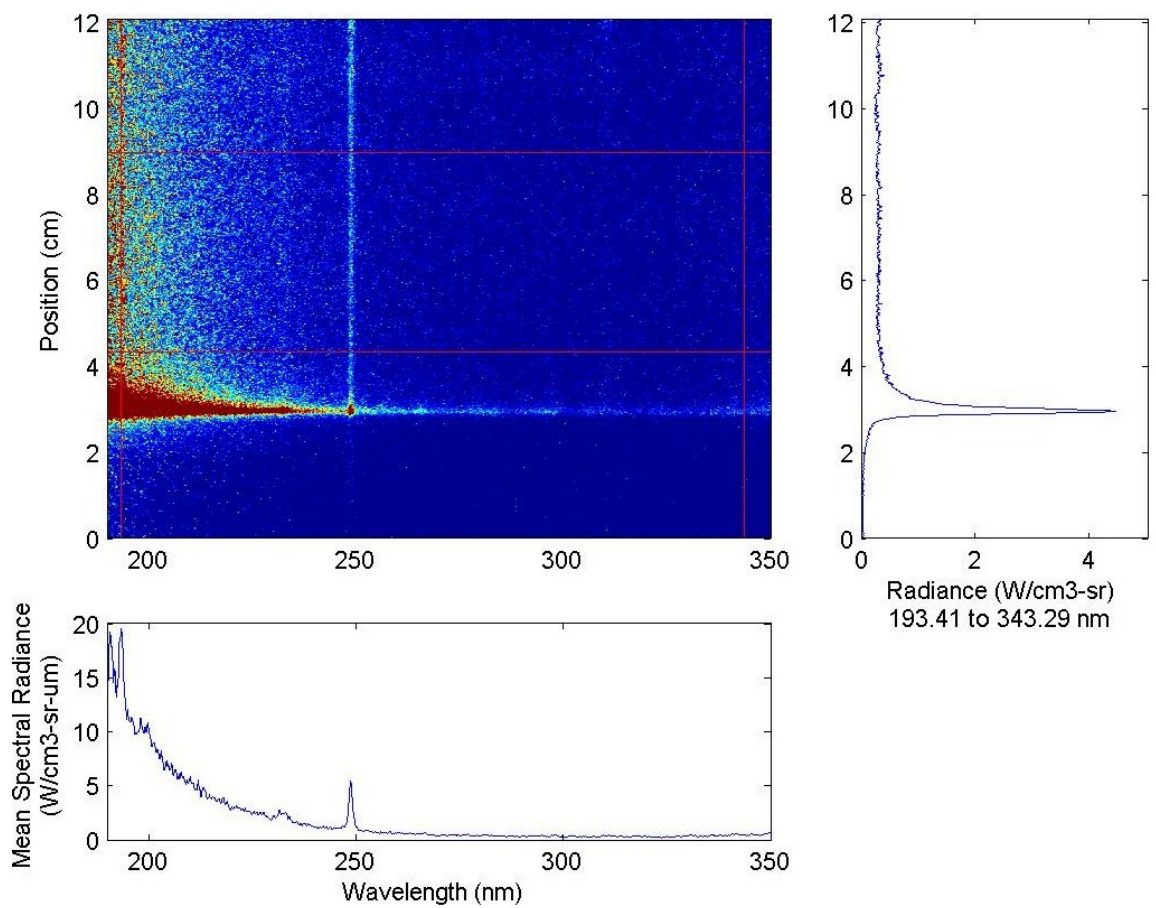

193.41 to $343.29 \mathrm{~nm}$

Figure 5.9. Blue calibrated shot data for Shot 44 . 

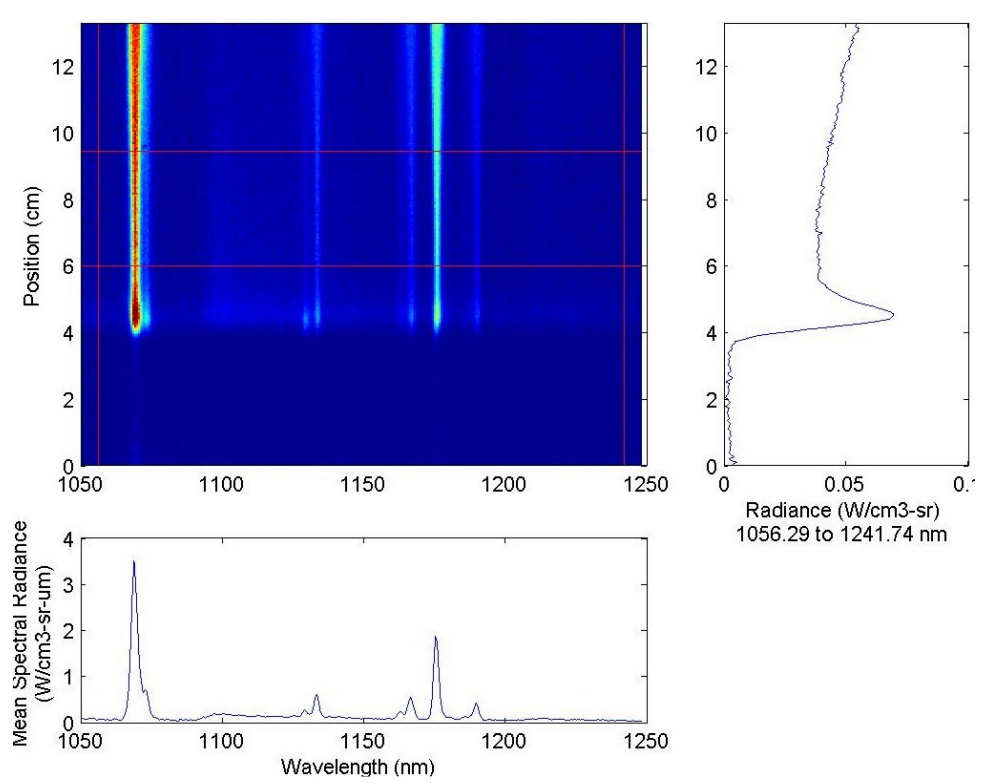

1056.29 to $1241.74 \mathrm{~nm}$

Figure 5.10. IR calibrated shot data for Shot 44 .

The need for two additional IR calibrated shot data images are needed to complete the nominal data test condition. The additional data is needed due to the low wavelength coverage of the IR camera during these tests. The following shot data is taken from Shot 42 and 45 . These two additional data points are required to complete the composite spectrum in the IR. They can be seen in Figures 5.11 and 5.12.
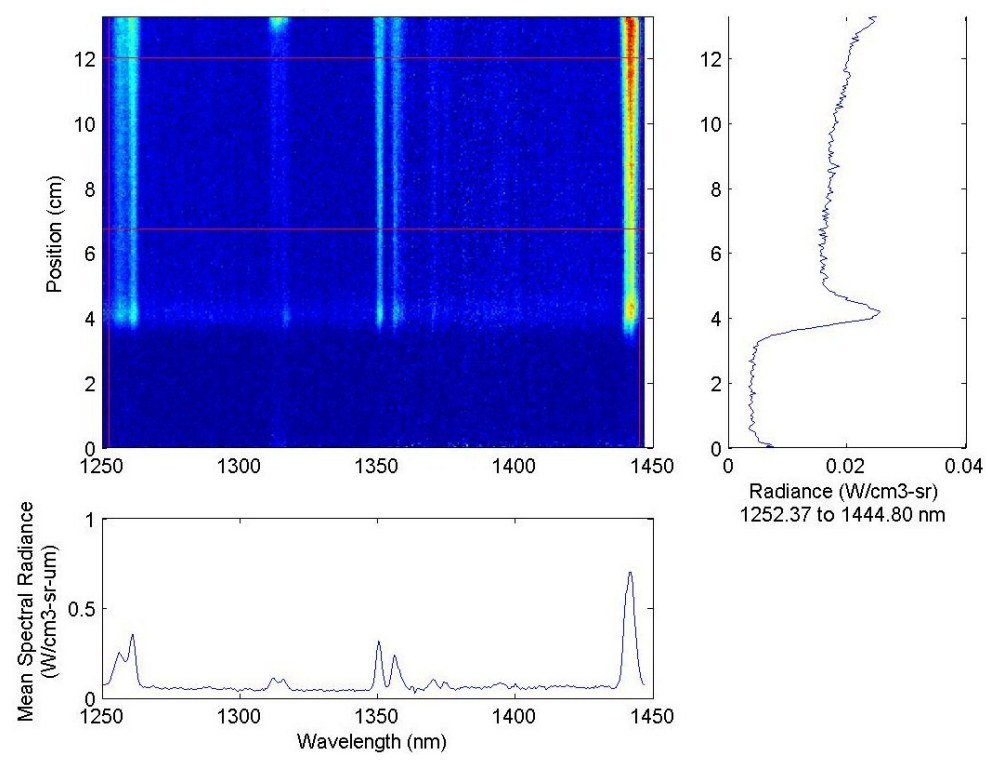

1252.37 to $1444.80 \mathrm{~nm}$

Figure 5.11. IR calibrated shot data for Shot 45 . 

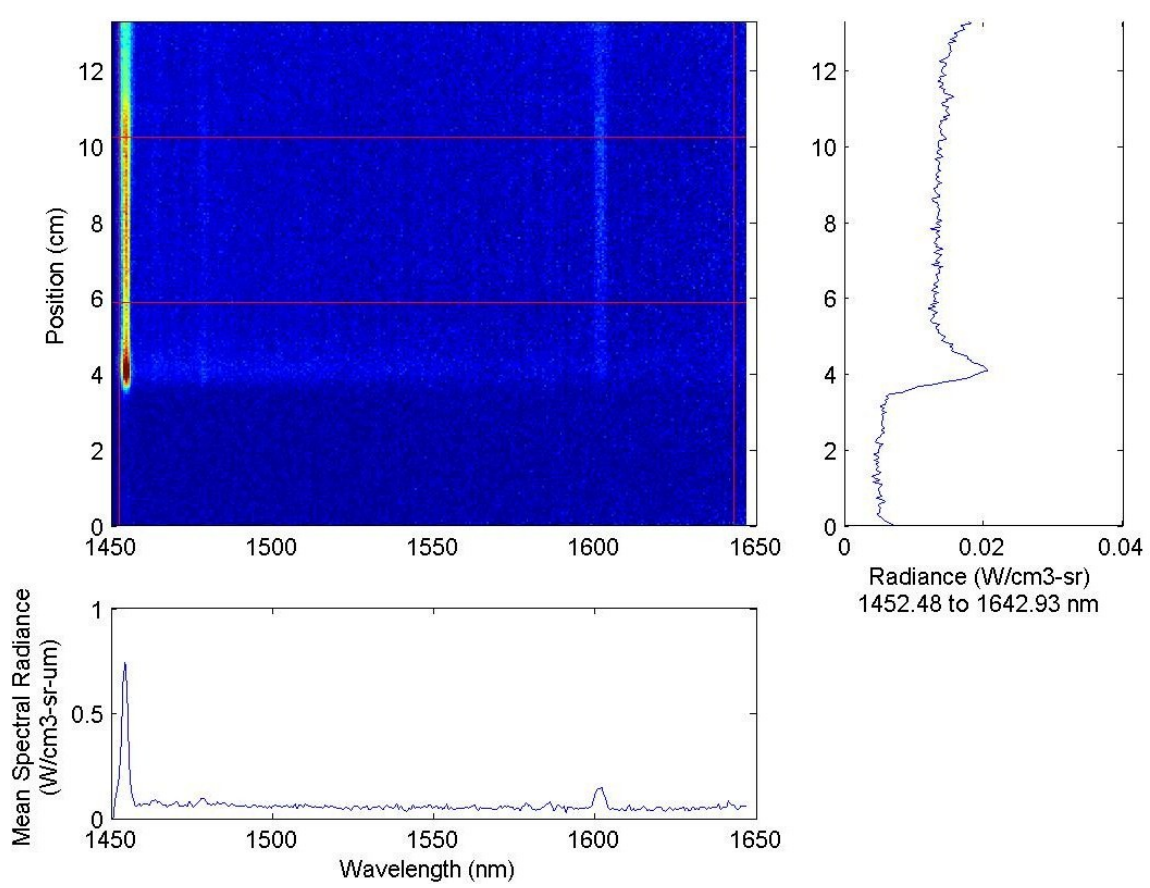

1452.48 to $1642.93 \mathrm{~nm}$

Figure 5.12. IR calibrated shot data for Shot 42.

\subsubsection{Composite Spectrum}

The purpose of the Mars entry condition shot analysis was to gain a better understanding of how shock layer radiation behaves under the given circumstances. By testing in $96 \% \mathrm{CO}_{2}$ and $4 \% \mathrm{~N}_{2}$, at a simulated atmosphere of 0.25 Torr and a nominal shock velocity of $8 \mathrm{~km} / \mathrm{s}$, we gain a better experimental characterization of the shock layer radiation that occurs under the tested conditions.

By creating a shot composite spectrum and combining Shots 39, 42, 44, and 45, we are able to characterize the shock layer radiation that occurs. This data gives us a better understanding of shock layer radiation from the 120 to $1700 \mathrm{~nm}$ portion of the spectrum under the tested nominal entry condition. 


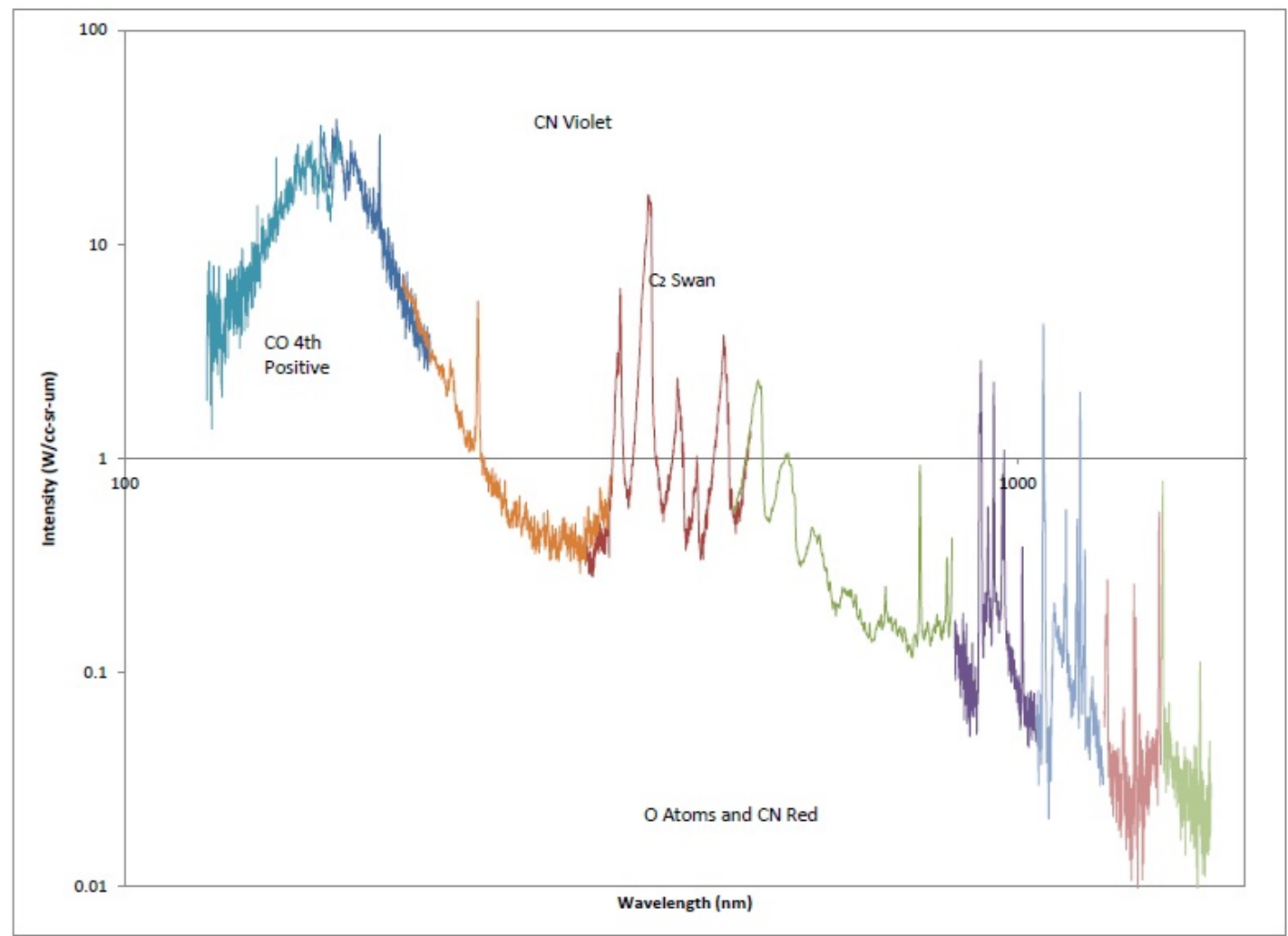

Figure 5.13. Mars composite spectrum at 0.25 Torr, 8 km/s nominal shock velocity.

As seen in Figure 5.13, the VUV-UV portion of the spectrum constitutes a significant amount of the shock layer radiation for Mars entry in the tested conditions. The VUV (120 to $200 \mathrm{~nm}$ ) is dominated by the CO (4+) system, and shows that it exceeds all other spectral features in the spectrum, as expected. This $\mathrm{CO}(4+)$ system is the most intense across the composite spectrum. The spectrum also shows two atomic carbon lines at $193 \mathrm{~nm}$ and $248 \mathrm{~nm}$.

We also see the vibrational manifold of the $\mathrm{CN}$ Violet system and the $\mathrm{C}_{2}$ Swan system showing up in the UV-VIS portion of the spectrum. These manifolds also account for a significant portion of the shock layer radiation emitted under the tested entry condition. 
In the NIR-IR portion of the spectrum, we see relatively weak peaks as compared to the other portions of the spectrum. This portion of the spectrum consists of various $\mathrm{O}$ atom emissions and a much weaker CN Red system.

\subsection{Composite Spectrum for Various Test Conditions in Mars and Venus}

Figure 5.14 shows a combined composite spectrum for 6 nominal test conditions in Mars and Venus test gas. The data is combined and reduced in a similar fashion as shown in Section 5.2. The nominal test conditions that were tested in Mars and Venus entry conditions are depicted in Figure 5.14. This updated work is based off of previous work shown in Cruden, et al. (2010). The updated data is reflected in the VUV and IR portions of the spectrum. Each spectrum is composed of multiple shots.

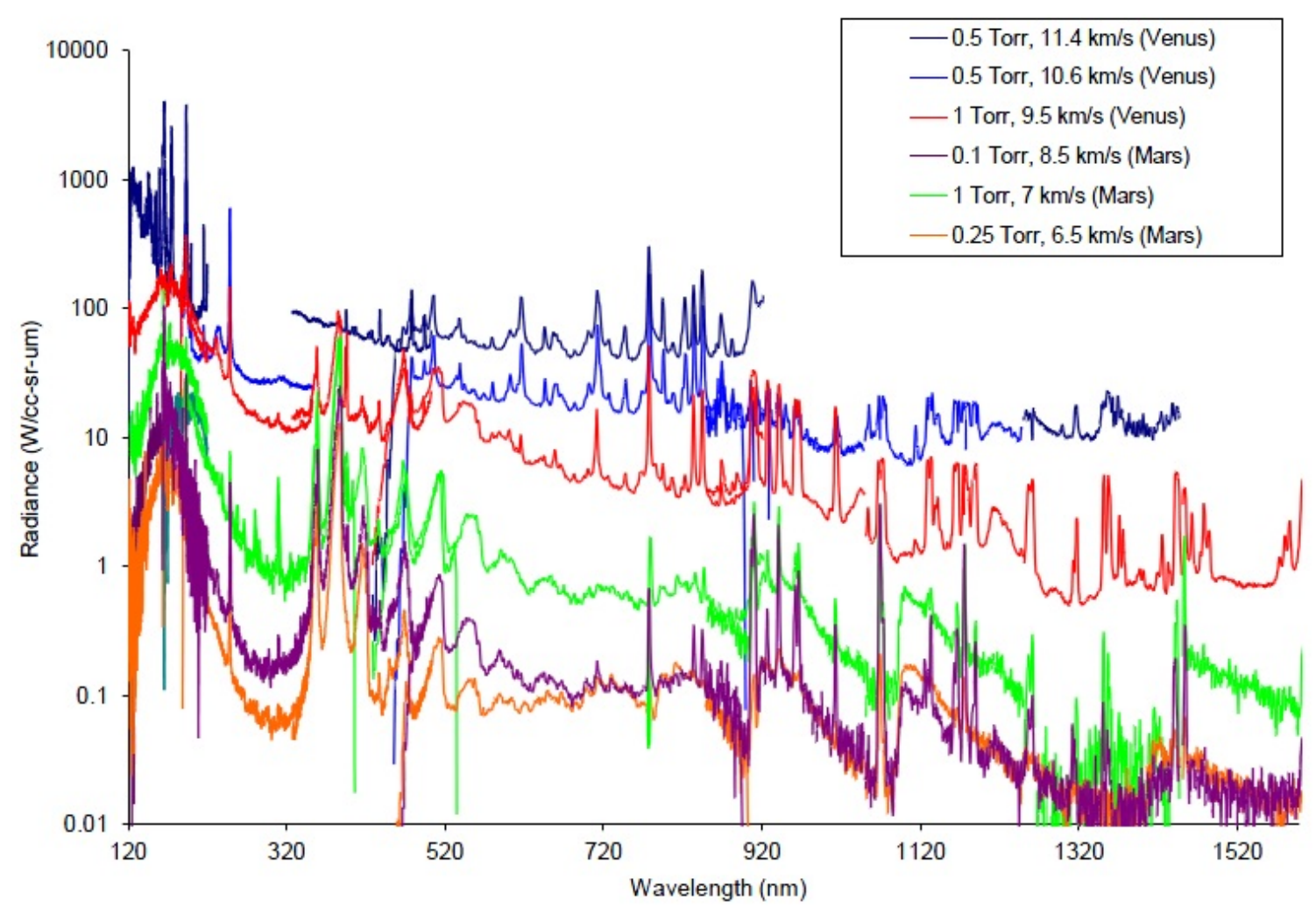

Figure 5.14. Mars and Venus combined composite spectrum. 


\section{Chapter 6}

\section{Mars and Venus Temperature Analysis}

The EAST Facility is also capable of taking higher resolution spectroscopic data. Specific to each spectroscopic setup, both medium and higher resolution images are able to be captured for each shock tube test. This higher resolution data allows us to capture and analyze relevant parameters such as gas temperature through non-intrusive spectroscopic diagnostics. Medium resolution images of $\mathrm{CN}$ and $\mathrm{C}_{2}$ band systems were captured. These measurements were used to analyze for rotational and vibrational temperatures. These estimates are performed by fitting a rotational band of the appropriate diatomic species in the emission. Both the $\mathrm{CN}$ and $\mathrm{C}_{2}$ emission bands are fit simultaneously for rotational and vibrational temperatures. Vibrational temperature $\left(T_{v i b}\right)$ is determined by fitting the integrated band intensity $\left(I_{v^{\prime}} v^{\prime \prime}\right)$ to;

$$
I_{v^{\prime} v^{\prime \prime}} \alpha v^{4} S_{v^{\prime} v^{\prime \prime}} \exp \left(-\frac{E_{v^{\prime}}}{k T_{v i b}}\right)
$$

where $E_{v^{\prime}}$ is the energy of the excited state, $v$ is the frequency of the light emitted, $k$ is the Boltzmann constant and $S_{v^{\prime} v^{\prime \prime}}$ is the band strength for that transition (Cruden, Rao, Sharma, \& Meyyappan, 2002). Upon fitting these bands, there are various assumptions made. We assume that the rotational population of the species that is being looked at is thermally equilibrated or close enough for non-equilibrium characteristics to be negligible. Another assumption is that the rotational temperature of the excited state that emits is equilibrated with the ground state temperature. 


\section{1 $\quad \mathbf{C N}(0,0),\left(B^{2} \Sigma^{+}-X^{2} \Sigma^{+}\right)$}

The following is an analysis technique used for calculating rotational and vibrational temperatures ( $T_{\text {rot }}$ and $T_{v i b}$ ) of a $\mathrm{CN}$ system in both Mars and Venus test gas. The analysis is done for test conditions that are applicable in Mars and Venus entry conditions. These conditions are a function of test gas pressure and shockwave velocity. The structure and routine that is used for this analysis is outlined in Cruden, et al. (2002).

\subsubsection{CN $(0,0),\left(B^{2} \Sigma^{+}-X^{2} \sum^{+}\right)$in Equilibrium}

The $\mathrm{CN}$ that is present in the system is due to the interaction of carbon and nitrogen in the shock tube. This $\mathrm{CN}$ system is known as the $\mathrm{CN}\left(B^{2} \Sigma^{+}-X^{2} \Sigma^{+}\right)$ transition. The $(\mathrm{n}, \mathrm{n})$ progression spans from approximately the 370 to $390 \mathrm{~nm}$ portion of the spectrum and is seen in Figure 6.1. The strongest band is the $(0,0)$ vibrational transition, with other transitions being described by $(v, v)$, which are also seen in the spectrum. In this particular work, $v$ values vary from 0 to 8 . These $(v, v)$ values are fit to the spectrum based on band strength measurements, which are determined by FrankCondon factors. The band strengths are taken from Danylewych and Nicholls (1978). The Boltzmann population is determined using the lower state rotational constants.

The following is an example of a calibration shot image, of a medium resolution $\mathrm{CN}(0,0)$ system that was used for gas temperature analysis. In Figure 6.1 the calibrated data is shown with a spectral radiance profile and a positional radiance profile. 


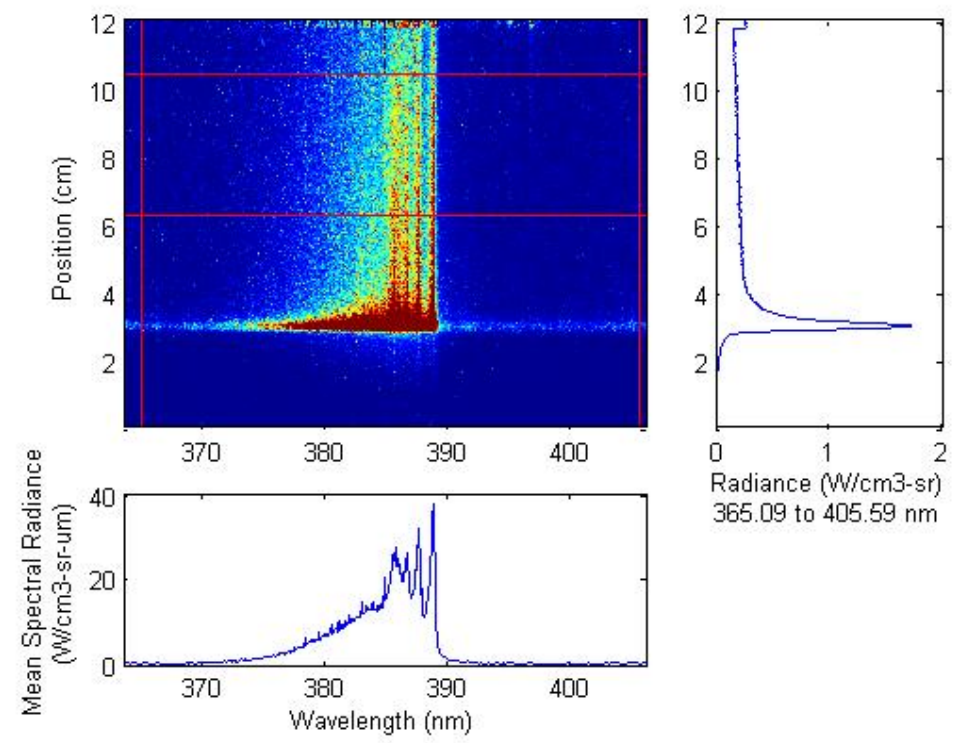

Figure 6.1. CN system for Shot 45.

Figure 6.2 shows the spectral radiance spectrum for Shot 45 . This spectrum is fit to a temperature synthetic spectrum, which was calculated using the "fminsearch" function in MATLAB.

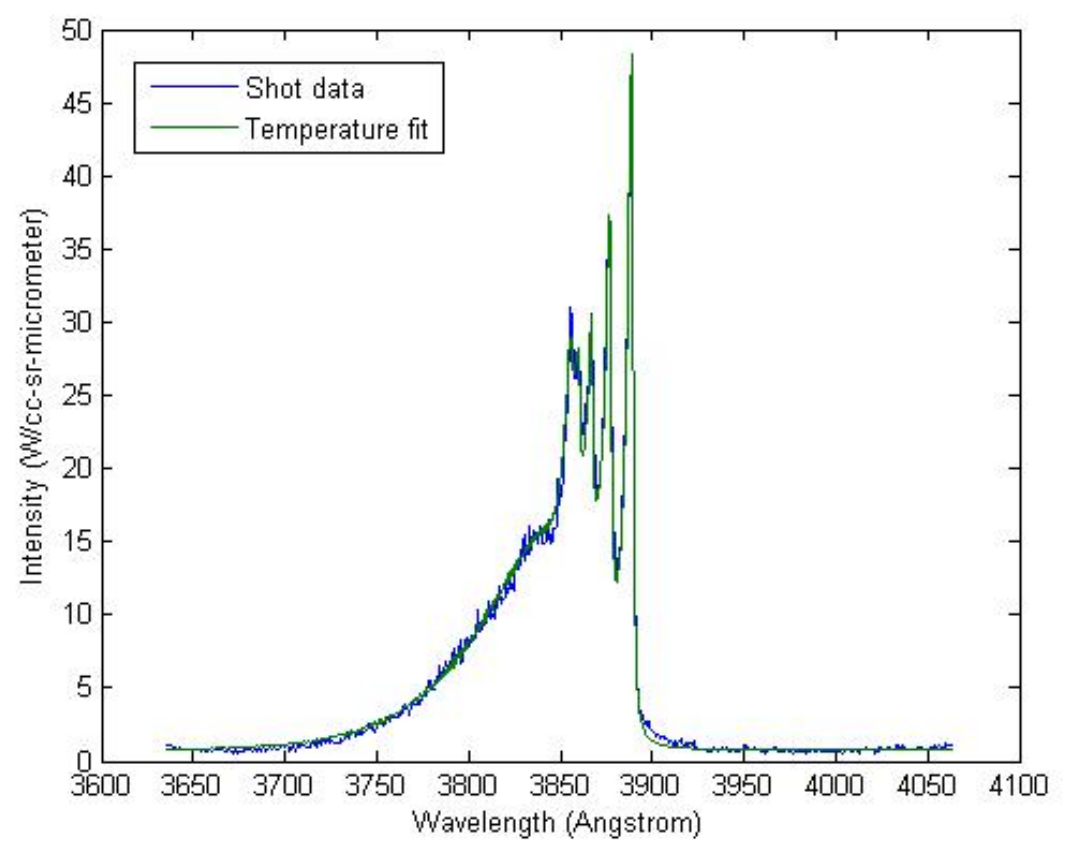

Figure 6.2. Shot 45 temperature fit for a $\mathrm{CN}(0,0)$ system. 
Only one spectrum and temperature fit is presented. However, a comprehensive data set is depicted in Table 6.1. This data represents all applicable $\mathrm{CN}(0,0)$ measurements that were used for gas temperature analysis for Mars and Venus entry conditions.

Table 6.1. Rotational and Vibrational temperature fits for various $\mathrm{CN}(0,0)$ systems.

\begin{tabular}{|l|c|c|c|c|}
\hline Shot & P (Torr) & $\mathbf{V ~ ( k m / s )}$ & Trot (K) & Tvib (K) \\
\hline Mars & & & & 7930 \\
\hline 7 & 0.993 & 6.82 & 6630 & 8640 \\
\hline 8 & 0.993 & 8.19 & 6910 & 7150 \\
\hline 28 & 0.25 & 6.7 & 6250 & 7820 \\
\hline 36 & 0.1 & 8.39 & 6590 & 6980 \\
\hline 41 & 0.251 & 7.5 & 6500 & 7740 \\
\hline 45 & 0.251 & 8.06 & 6810 & 9230 \\
\hline Venus & & & & 7740 \\
\hline 14 & 0.994 & 9.15 & & \\
\hline
\end{tabular}

\subsubsection{CN $(0,0),\left(B^{2} \Sigma^{+}-X^{2} \Sigma^{+}\right)$Temperature vs. Position}

The following measurements and calculations were taken using the same technique and routine as previously discussed in Section 6.1.1. However, the spectral radiance measurements for this analysis are not taken in the "equilibrium" region of the shock. The purpose of this analysis is to gain a better understanding of gas temperature as a function of spatial location along the shock. Figure 6.3 is the calibrated shot data for Shot 41 . 

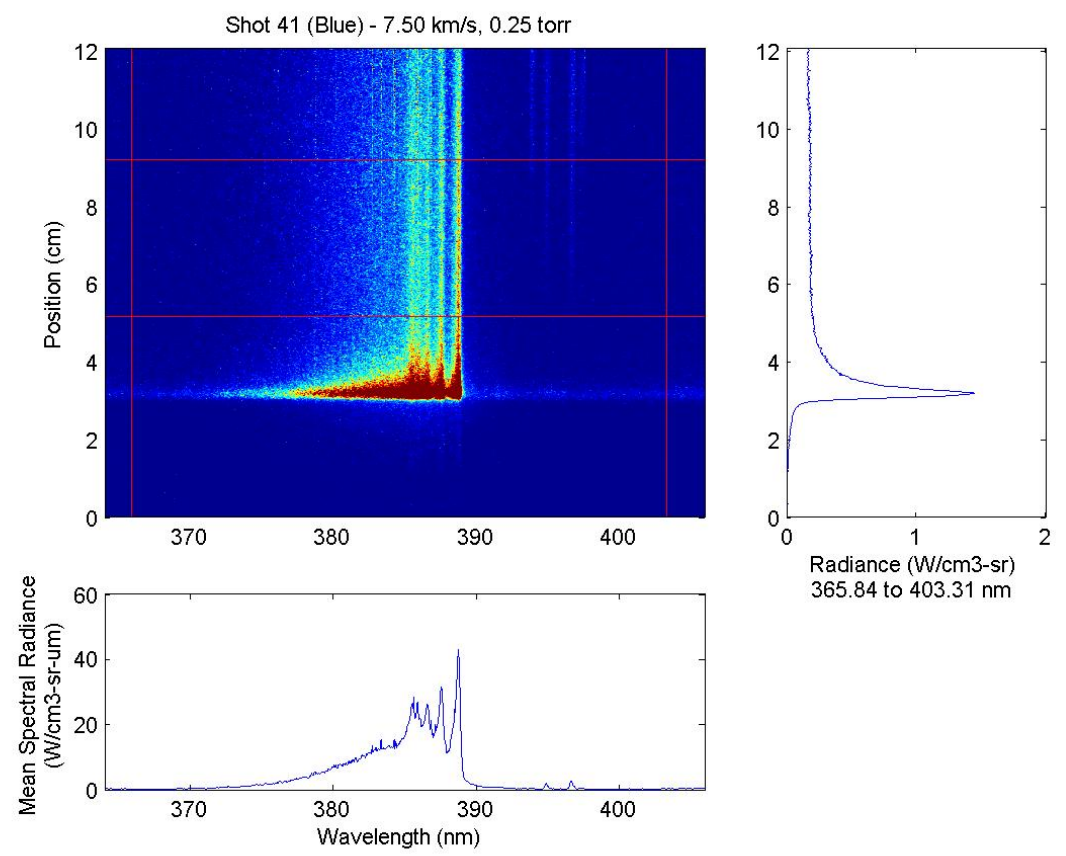

Radiance $(\mathrm{W} / \mathrm{cm} 3-\mathrm{sr})$

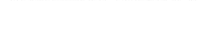

Figure 6.3. CN (0,0) system for Shot 41.

Using these calibrated data points, various horizontal transverse sections are taken along the position axis. The data yields radiance measurements along the position axis of the shock, which can be analyzed for temperature data. The spatial resolution of the fit is limited to the viewing angle of the optics and the charge blur on the camera. Due to each data point being taken on an average of a 10 pixel section, the data corresponds to 1.2 $\mathrm{mm}$. Since the exposure time of the camera was $0.25 \mu$ s for this particular shot, the data results in a $1.9 \mathrm{~mm}$ spatial blur (Cruden, et al., 2010). The blur effect associated with the data is most significant in regions where the radiation changes rapidly. In this particular case, the blur effect is seen at the front of the shock. It is difficult to obtain a decent spectrum at the rising edge of the shock due to this blur effect. However, the relaxation portion of the shock can be characterized. 
Thus various spectra are taken across the spatial direction of the shockwave and a temperature fit is applied to each position. This method allows the problem to be characterized for gas temperature as a function of position along the shockwave. The following is a temperature fit for a spectrum taken at a position of $3.42 \mathrm{~cm}$.

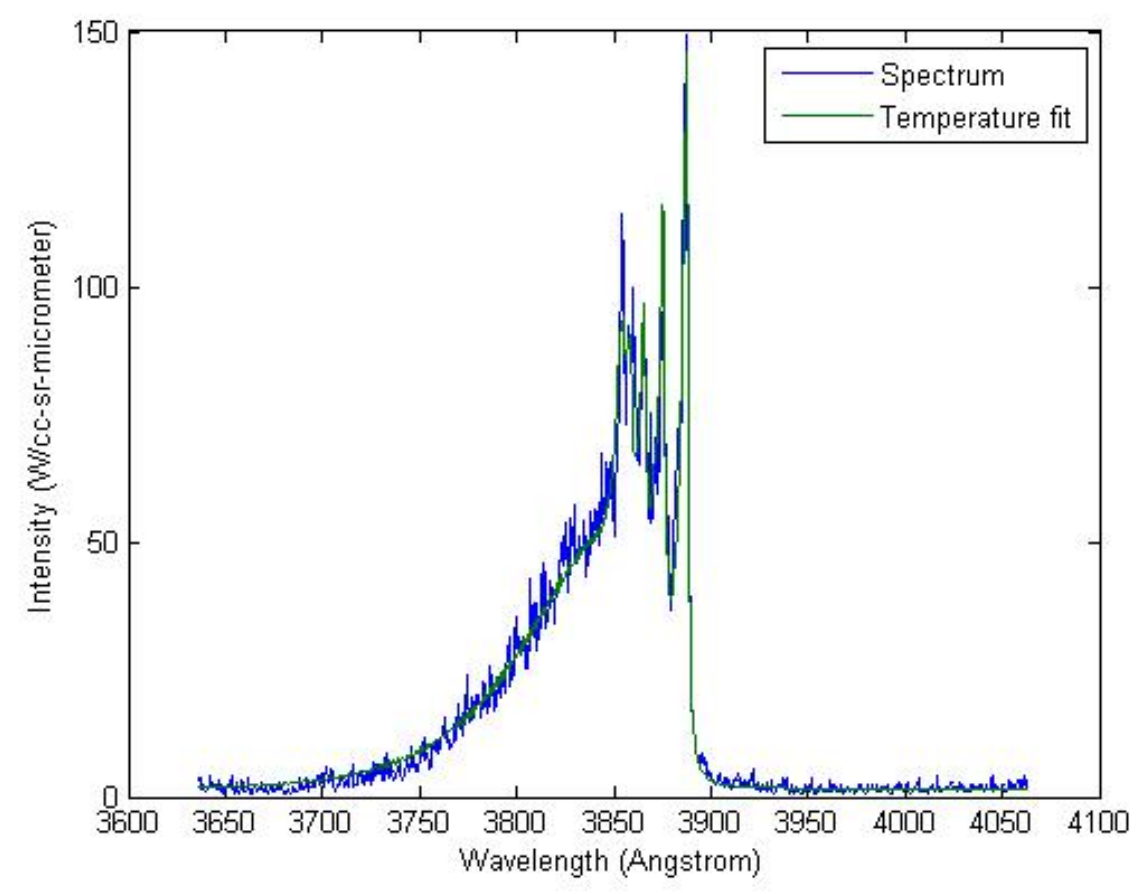

Figure 6.4. Temperature fit for Shot 41 at a position of $3.42 \mathrm{~cm}$.

Figure 6.5 equates various rotational and vibrational temperatures as a function of position along the shockwave. The shock front is seen at a position of $2.95 \mathrm{~cm}$. These data points are representative of a 0.25 Torr and $7.5 \mathrm{~km} / \mathrm{s}$ case. The high vibrational temperature near the shock front is expected. However, the rotational temperature is not predicted well in the relaxation portion of the shock compared to predicted twotemperature models, which suggests that there could be rotational-vibrational energy coupling in this portion of the shock. 


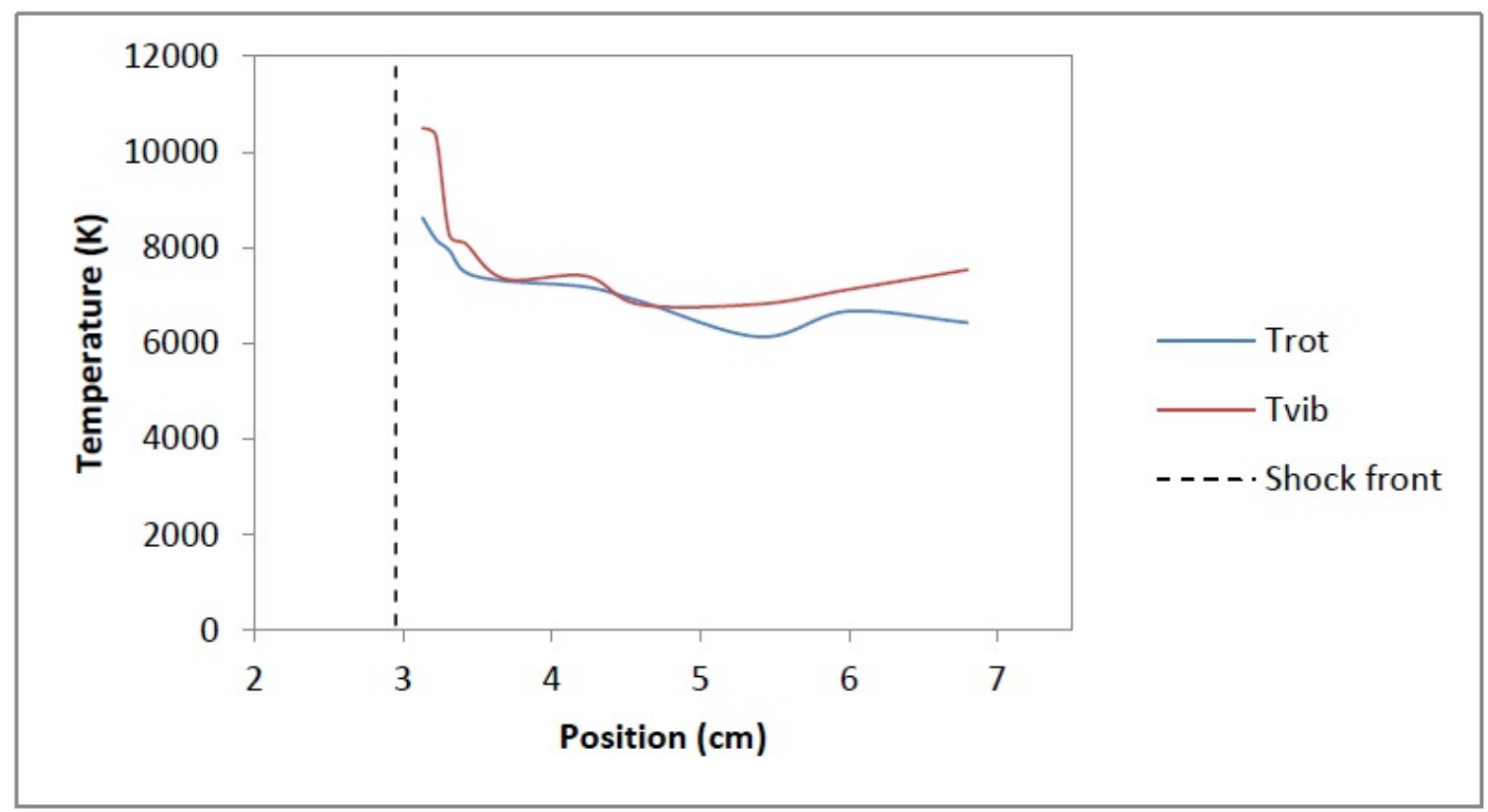

Figure 6.5. Vibrational and Rotational temperature as function of shock position.

6.2 $\quad C_{2}(0,0),\left(d^{3} \Pi_{g}-a^{3} \Pi_{u}\right)$

The following is an analysis technique used for calculating rotational temperature $\left(T_{\text {rot }}\right)$ of a $\mathrm{C}_{2}$ system in both Mars and Venus test gas. The analysis is for all tests in Mars and Venus entry conditions which view the $\mathrm{C}_{2}(0,0)$ system. The temperature data is presented as a function of test gas pressure and shockwave velocity. All calculations for $T_{\text {rot }}$ in this section are assumed to be done in the "equilibrium" region of the shock. The structure and routine that is used for this analysis is outlined in Cruden, et al. (2002).

The $\mathrm{C}_{2}$ that is present in the system is attributed to the excited triplet states of $\mathrm{C}_{2}$. The $\mathrm{C}_{2}$ systems are known as the $\mathrm{C}_{2}\left(d^{3} \Pi_{g}-a^{3} \Pi_{u}\right)$ Swan band transitions and are observed in the 500 to $560 \mathrm{~nm}$ portions of the spectrum. An example of the $\mathrm{C}_{2}(0,0)$ system is seen in Figure 6.6. 


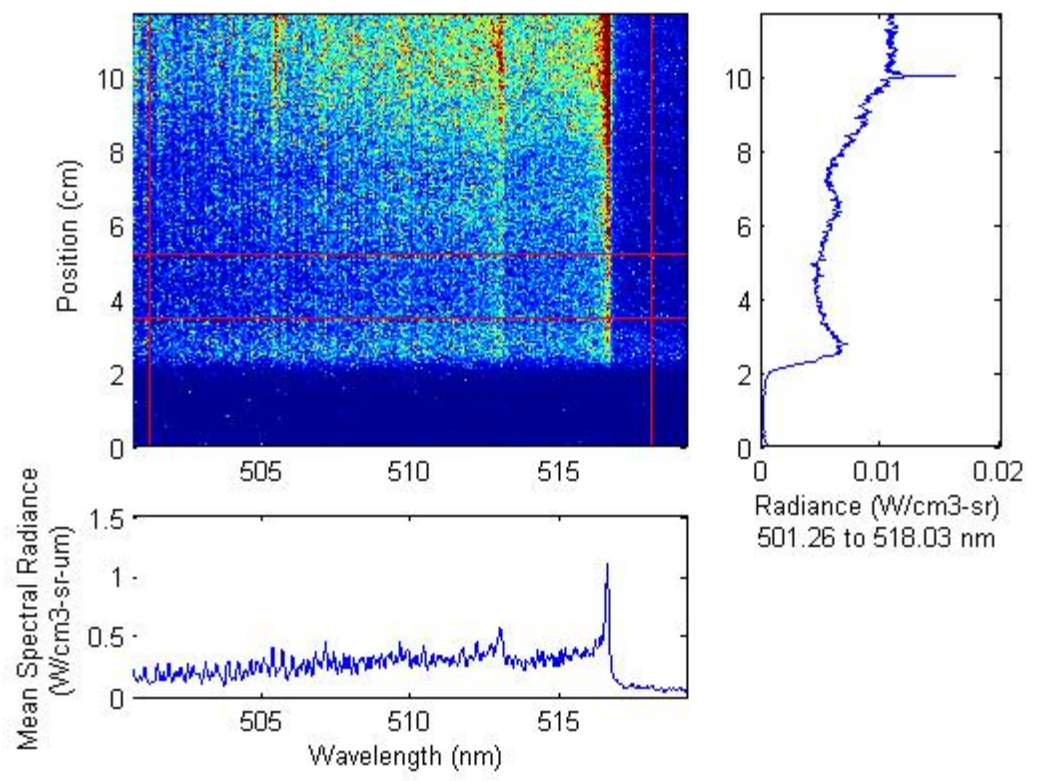

Figure 6.6. $\mathrm{C}_{2}(0,0)$ system for Shot 29.

The energy levels for this work were calculated using updated constants from Tanabashi, Hirao, Amano, and Bernath (2007). In this particular work, v values vary from 0 to 4 . These $(v, v)$ values are fit to the spectrum based on band strength measurements, which are used from updated measurements in Rodio (2010), which also vary from 0 to 4 . The $S$ values vary in range from $S_{11}$ to $S_{44}$. The $(0,0)$ band is the most prominent, although it is overlapped by various other bands including the $(1,1)$ band. The Boltzmann population is also determined using the upper state constants in Tanabashi et al. (2007).

The instrument line shape (ILS) was determined by fitting an empirical line shape to known atomic lines observed in the spectrum close to the test wavelengths. The ILS was empirically calculated and fit using a mixed Gaussian and Lorentzian function. An example of the ILS fit for a $20 \mu \mathrm{m}$ slit case is seen in Figure 6.7. An HgAr pin lamp is 
used and the reference atomic line that is fitted is a $\mathrm{HgAr}$ line at a center of $546.07 \mathrm{~nm}$. In Mars and Venus testing, shot settings dictated tests to be done in $20 \mu \mathrm{m}, 30 \mu \mathrm{m}$, and $60 \mu \mathrm{m}$ slit widths. Since slit width is essential to calculating ILS properties for a given test, ILS values were calculated for each slit width used during these tests. These values were then implemented into the temperature fitting routine based on which slit width was used for the particular test being analyzed.

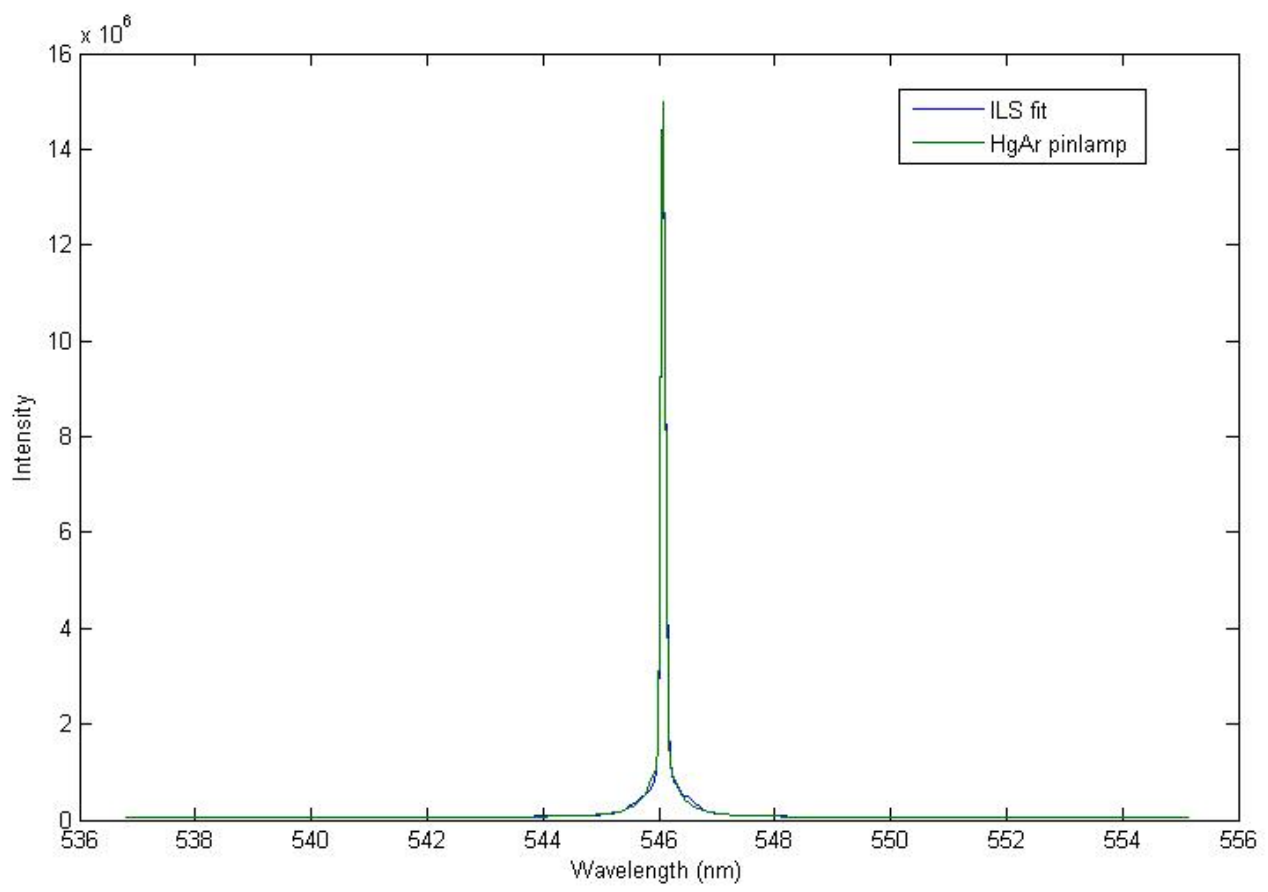

Figure 6.7. ILS fit for $20 \mu \mathrm{m}$ slit.

The following is a radiance spectrum and temperature fit for Shot 29. The data is seen in Figure 6.8. A comprehensive data set for all $\mathrm{C}_{2}(0,0)$ tests performed in Mars and Venus entry conditions is depicted in Table 6.2. The vibrational temperatures seem to be over predicted, possibly due to the spectrum not being in complete equilibrium and a wavelength shift in the 501 to $504 \mathrm{~nm}$ portion of the spectrum, thus are not presented. 


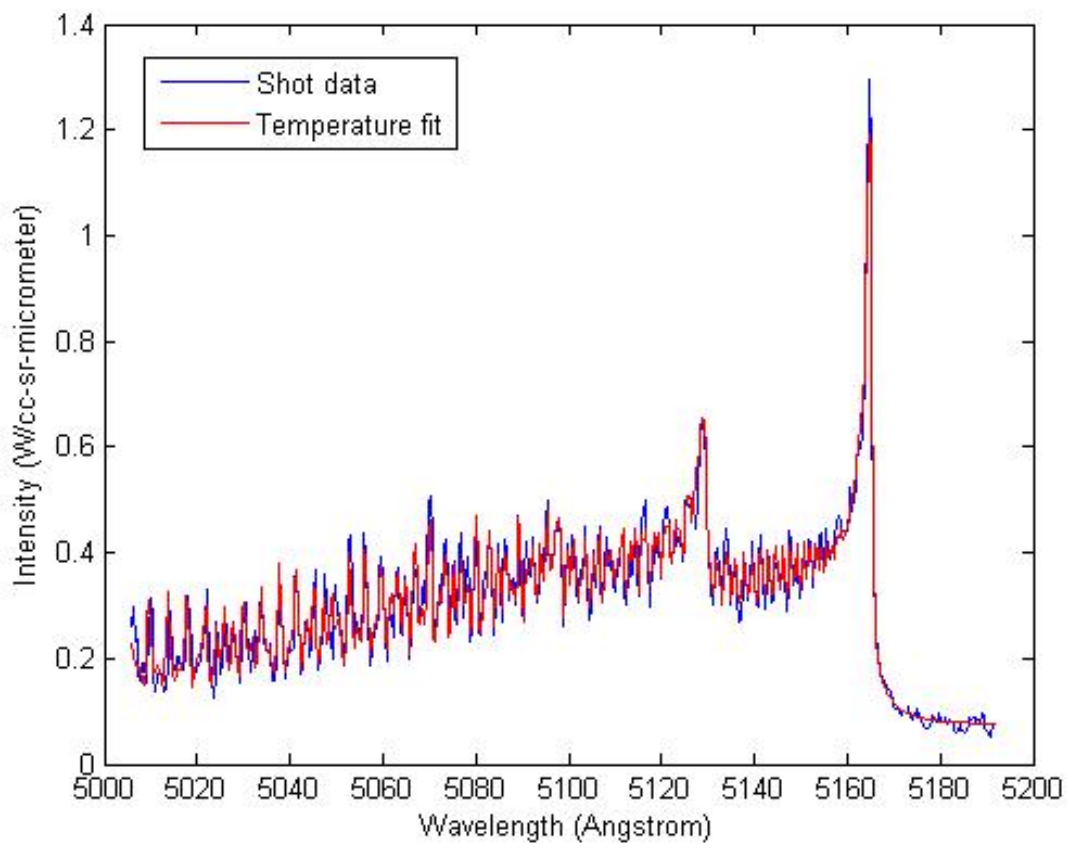

Figure 6.8. Shot 29 temperature fit for a $C_{2}(0,0)$ system.

Table 6.2. Rotational temperature fits for various $C_{2}(0,0)$ systems.

\begin{tabular}{|l|c|c|c|}
\hline Shot & P (Torr) & V (km/s) & T rot (K) \\
\hline Mars & & & \\
\hline 7 & 0.993 & 6.82 & 5276 \\
\hline 8 & 0.993 & 8.19 & 6397 \\
\hline 29 & 0.25 & 6.5 & 6005 \\
\hline 37 & 0.1 & 8.43 & 5937 \\
\hline 42 & 0.251 & 8.09 & 6077 \\
\hline Venus & & 8.78 & 6918 \\
\hline 9 & 0.991 & 8.95 & 7100 \\
\hline 10 & 0.999 & 9.15 & \\
\hline 14 & 0.994 & & \\
\hline
\end{tabular}




\section{3 $\quad \mathrm{C}_{2}(0,1),\left(d^{3} \Pi_{g}-a^{3} \Pi_{u}\right)$}

This analysis accounts for all applicable tests in Mars entry conditions that view the $\mathrm{C}_{2}(0,1)$ system as a function of test gas pressure and shockwave velocity. The structure and routine that is used for this analysis is outlined in Cruden, et al. (2002).

\subsection{1 $\mathrm{C}_{2}(0,1),\left(d^{3} \Pi_{g}-a^{3} \Pi_{u}\right)$ in Equilibrium}

An example of a $\mathrm{C}_{2}(0,1)$ system is seen in Figure 6.9. This data is representative of Shot 45 in the Mars testing series. The energy levels for this work were calculated using updated constants from Tanabashi et al. (2007). In this particular work, $v$ values vary from 0 to 6 . Values are fit to the spectrum based on updated band strength measurements which were determined in Rodio (2010). These $S$ values vary in range from $S_{12}$ up to $S_{67}$. The Boltzmann population is also determined using the upper state constants. The ILS fit procedures are the same as shown in Section 6.2.

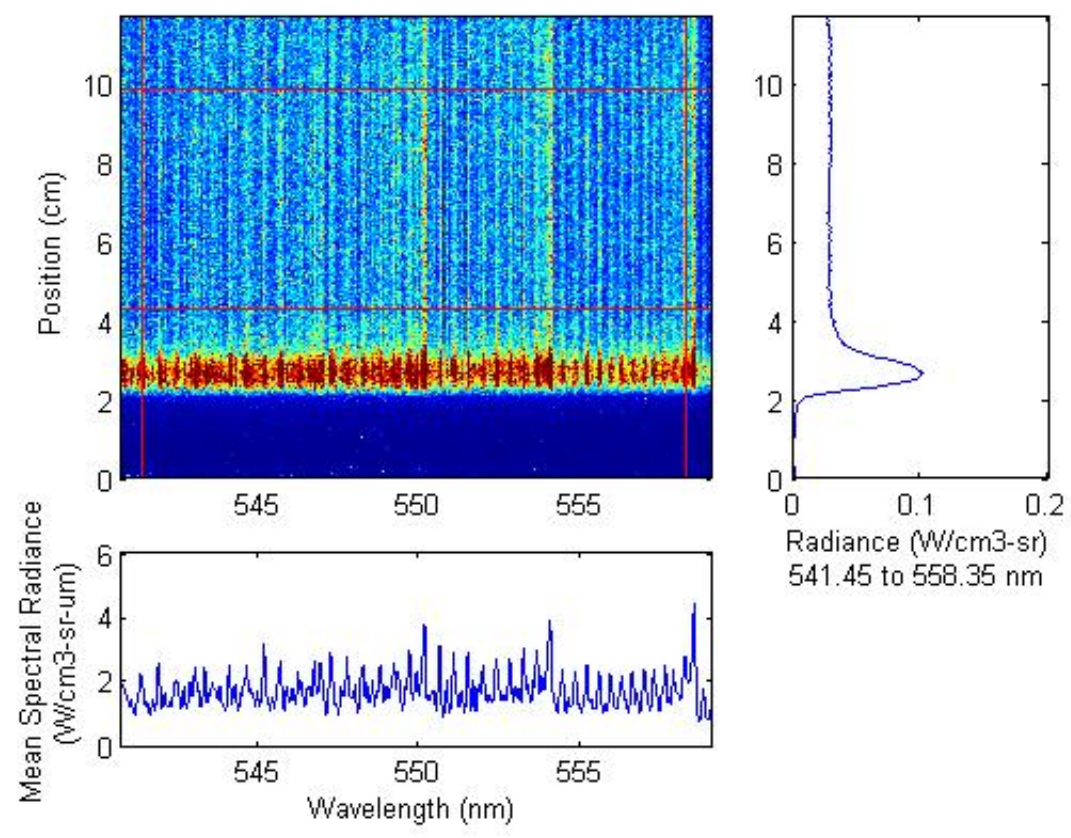

Figure 6.9. $C_{2}(0,1)$ system for Shot 45. 
The following is a radiance spectrum and temperature fit for Shot 45 . This data is seen in Figure 6.10. A comprehensive data set for all $\mathrm{C}_{2}(0,1)$ tests performed in Mars entry conditions are depicted in Table 6.3. The vibrational and rotational temperatures seem to agree fairly well suggesting close to equilibrated spectrum as well as sufficient bands being implemented into the routine. Table 6.3 summarizes all temperature fit data for the $\mathrm{C}_{2}(0,1)$ systems as a function of test gas pressure and shockwave velocity.

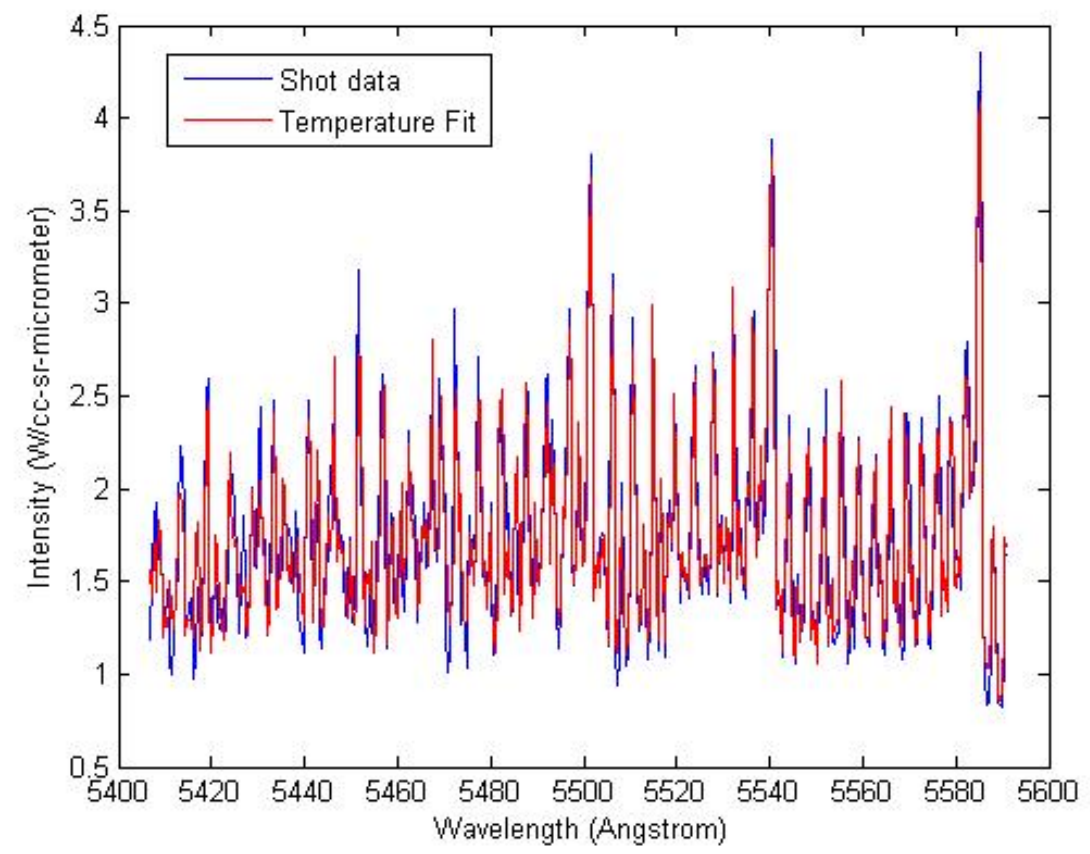

Figure 6.10. Shot 45 temperature fit for a $C_{2}(0,1)$ system.

Table 6.3. Rotational and Vibrational temperature fits for various $C_{2}(0,1)$ systems.

\begin{tabular}{|l|c|c|c|c|}
\hline Shot & P (Torr) & $\mathbf{V}(\mathbf{k m} / \mathbf{s})$ & T rot $(\mathbf{K})$ & T vib (K) \\
\hline Mars & & & & \\
\hline 9 & 0.99 & 7.89 & 6611 & 6409 \\
\hline 12 & 0.99 & 7.03 & 6419 & 6969 \\
\hline
\end{tabular}




\begin{tabular}{|l|c|c|c|c|}
\hline 28 & 0.25 & 6.7 & 5671 & 6652 \\
\hline 36 & 0.10 & 8.39 & 6551 & 6908 \\
\hline 41 & 0.25 & 7.5 & 6135 & 7010 \\
\hline 45 & 0.25 & 8.06 & 6630 & 7154 \\
\hline
\end{tabular}

The following is a graphical representation that summaries vibrational temperature fits versus pressure and shock velocity for various $C_{2}(0,1)$ systems. Figure 6.11 shows a representative set of error bars that is associated with the data. Error bars indicate a confidence level of $\pm 10 \%$. Shown as solid lines, are predicted equilibrium temperature data points for these conditions. As seen in Figure 6.11, a stronger dependence is shown with velocity in comparison to pressure. All data shown agrees within the confidence limit that is described.

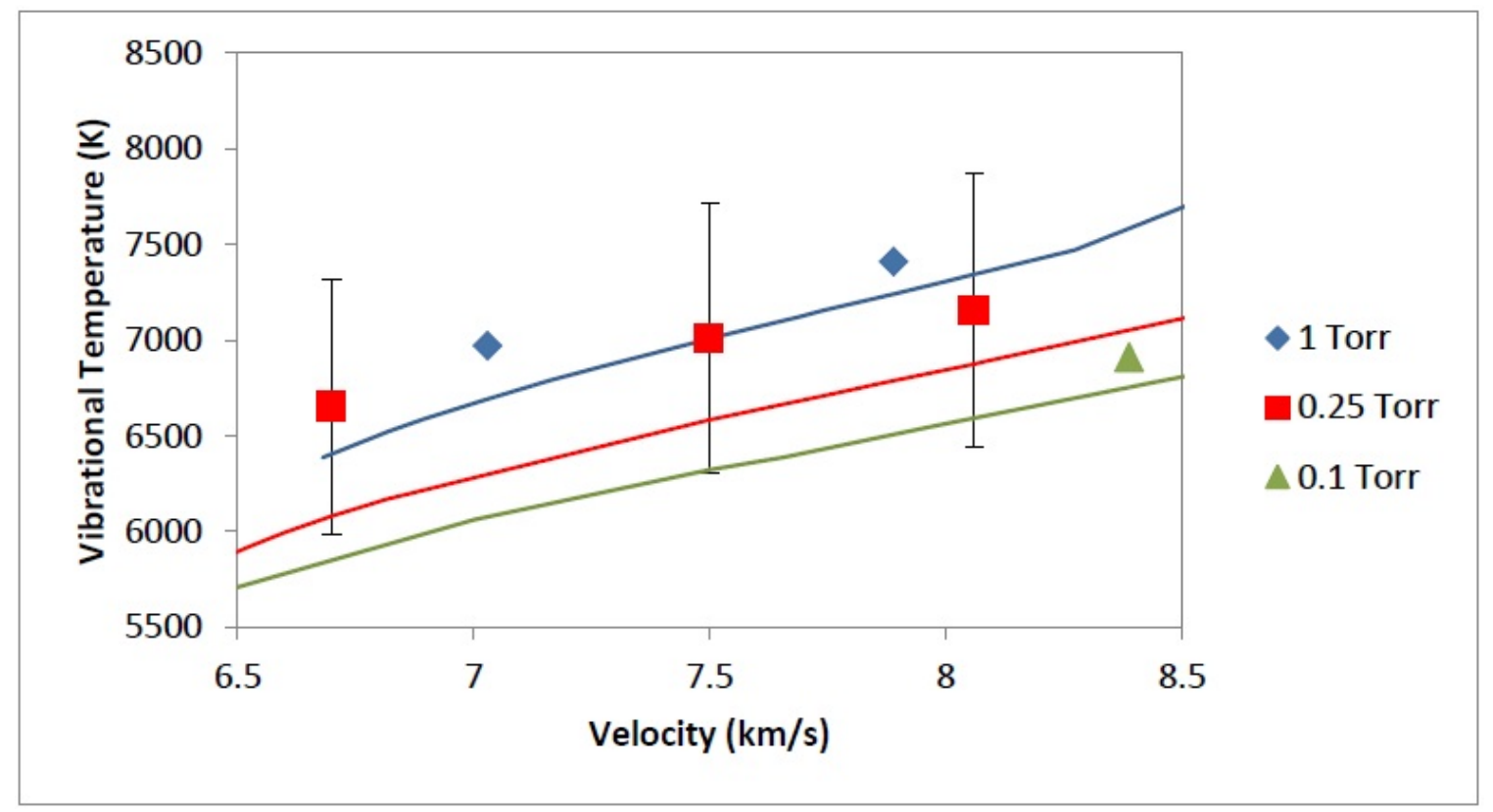

Figure 6.11. Summary of vibrational temperature data for $C_{2}(0,1)$. 


\subsection{2 $C_{2}(0,1),\left(d^{3} \Pi_{g}-a^{3} \Pi_{u}\right)$ Temperature vs. Position}

The following measurements and calculations were taken using the same technique and routine as previously discussed in Section 6.3.1. However, the spectral radiance measurements for this analysis are not taken in the "equilibrium" region of the shock. The purpose of this analysis is to gain a better understanding of gas temperature as a function of spatial location along the shock. Figure 6.12 is the calibrated shot image for Shot 36 with a cross section taken at $5.35 \mathrm{~cm}$.


Figure 6.12. Calibrated Shot 36 with cross section taken at $5.35 \mathrm{~cm}$.

Using these calibrated data points, various horizontal transverse sections are taken along the position axis. This method yields various radiance measurements along the position axis of the shock, which can be analyzed for temperature data. The spatial resolution of the fit is limited to the viewing angle of the optics and the charge blur on the camera. Due to each section being taken on an average of a 10 pixel section, this data 
corresponds to $1.2 \mathrm{~mm}$. Thus, the rising edge shock is difficult to capture. However, the relaxation portion of the shock is able to be characterized and fit.

Various spectra are calculated across the spatial direction of the shockwave and a temperature fit is applied to each position. This method allows the problem to be characterized for gas temperature, as a function of position along the shockwave.

Figure 6.13 equates various rotational and vibrational temperatures. The shock front is seen at a position of $2.2 \mathrm{~cm}$. This data is representative of a 0.1 Torr and $8.4 \mathrm{~km} / \mathrm{s}$ shock velocity case. The high vibrational temperature near the shock front is expected. However, the rotational temperature is not predicted well in the relaxation portion of the shock compared to predicted two-temperature models.

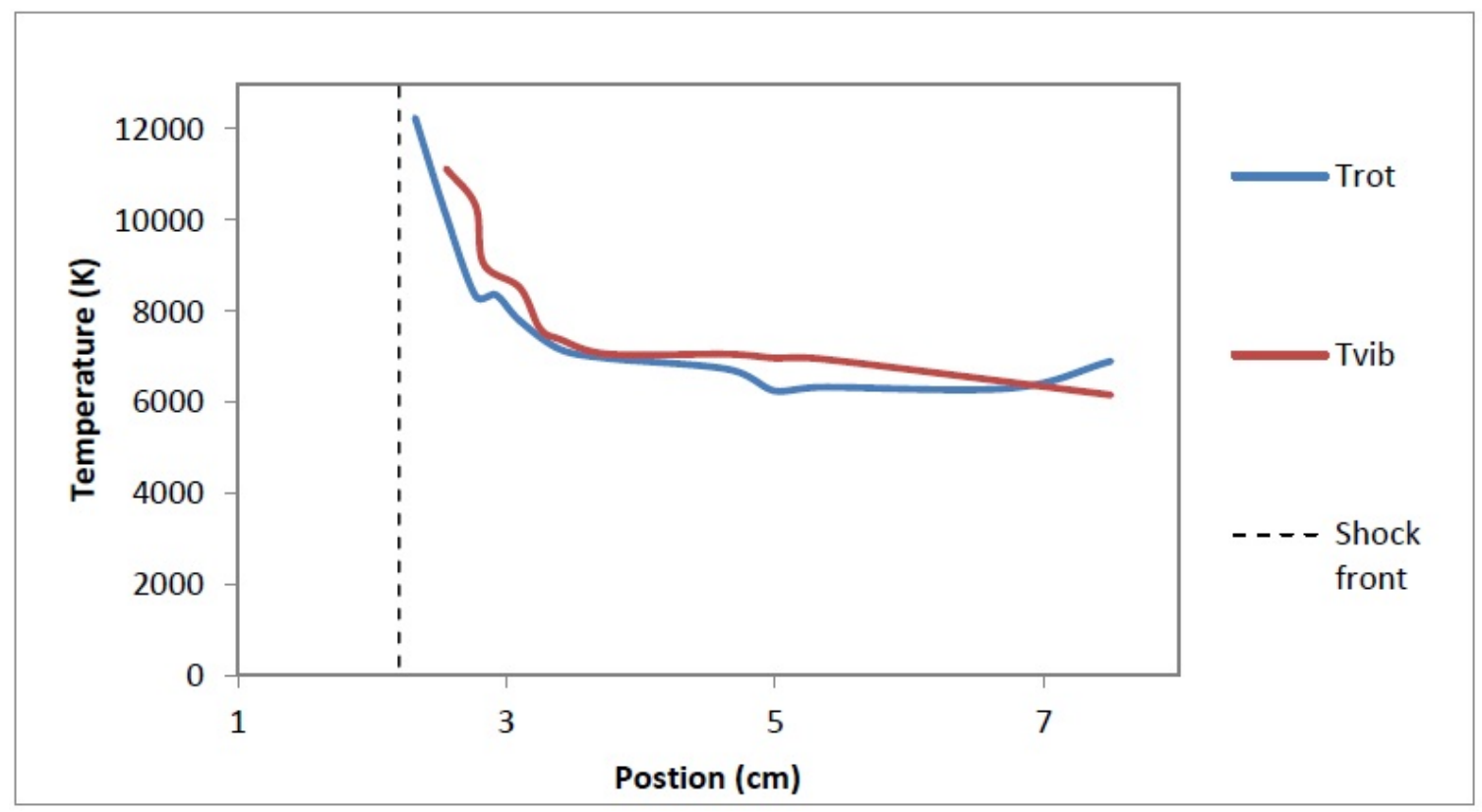

Figure 6.13. Temperature as a function of shock position. 


\subsection{Temperature Results}

Figure 6.14 summarizes all $\mathrm{C}_{2}$ and $\mathrm{CN}$ rotational temperature fits versus pressure and shock velocity. Solid markers indicate fit temperature data from the $\mathrm{C}_{2}(0,0)$ systems. Open markers indicate fit temperature data from the $\mathrm{C}_{2}(0,1)$ systems. Open markers with a horizontal line indicate fit temperature data from the $\mathrm{CN}(0,0)$ systems. A representative set of error bars is shown, indicating confidence limits of $\pm 10 \%$. Shown as solid lines are equilibrium predicted temperatures for these conditions. Most data agrees well within the confidence limits with the exception of 1 Torr, $\mathrm{C}_{2}(0,0)$ systems. These are indicated in the plot by solid blue markers. All other data for the $\mathrm{C}_{2}$ and $\mathrm{CN}$ systems described are within confidence of the error limits. As seen in the data, there is a stronger dependence on velocity than pressure. Figure 6.14 captures all rotational temperature data that was analyzed and that was experimentally captured for Mars and Venus entry conditions.

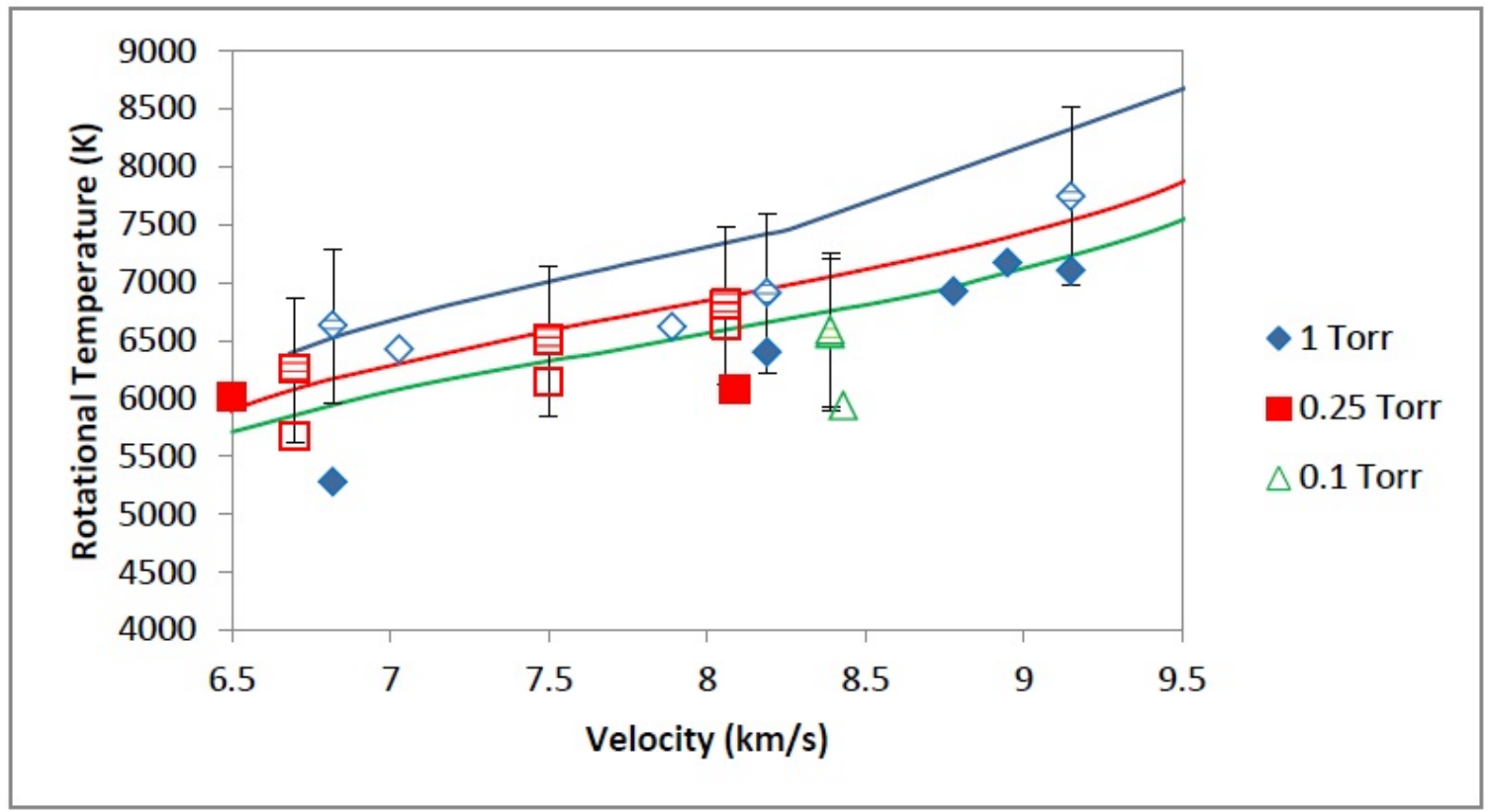

Figure 6.14. Summary of rotational temperatures for the $C_{2}$ and $C N$ systems. 


\section{Chapter 7}

\section{Conclusions}

Presented was a background investigation showing why shock layer radiation testing is important both at an experimental and analytical level. A description of the EAST Facility was shown to facilitate the reader in understanding basic facility operational and instrumentation techniques used. A summary of major EAST upgrades is shown, which allows the reader to gain a more in-depth knowledge of current operations in the EAST Facility. Experimental procedures are characterized to learn calibration and analysis techniques employed in EAST testing. These procedures and analysis techniques show the relevance of shock layer radiation testing taking place in the EAST Facility. A composite spectrum was presented to give an overview of a typical nominal data set in Mars test gas. A more comprehensive composite spectrum data set is shown for Mars and Venus testing, with recent updates to the VUV and IR portions of the spectrum. Temperature analysis was performed and data was presented to characterize gas temperature as a function of test gas pressure and shock velocity. This experimental data has the potential to be compared to analytical data, which can be incorporated into CFD models to assist and better understand shock layer radiation. These comparisons are influential and useful in the creation of a TPS system for a future spacecraft. 


\section{References}

Anderson, J. D. (2003). Modern compressible flow with historical perspective, $3^{\text {rd }}$ Ed. McGraw Hill.

Brandis, A., Cruden, B., Prabhu, D., Bose, D., McGilvray, M., Morgan, R. (2010). Analysis of Air Radiation Measurements Obtained in the EAST and X2 Shocktube Facilities. $10^{\text {th }}$ AIAA/ASME Joint Thermophysics and Heat Transfer Conference. pp. AIAA 2010-4510.

Bose, D., McCorkle, E., Bogdanoff, D., Allen, G. (2009). Comparisons of Air Radiation Model with Shock Tube Measurements. 47th AIAA Aerospace Sciences Meeting. pp. AIAA 2009-1030.

Bose, D., McCorkle, E., Thompson, C., Bogdanoff, D., Prahbu, D., Allen, G., and Grinstead, J. (2008). Analysis and Model Validation of Shock Layer Radiation in Air. 46th AIAA Aerospace Sciences Meeting. pp. AIAA 2008-1246.

Çengel, Y. A. (2007). Heat and Mass Transfer, $3^{\text {rd }}$ Ed. McGraw Hill.

Cruden, B., Prabhu, D., Martinez, R., Le, H., Bose, D., Grinstead, J. (2010). Absolute Radiation Measurement in Venus and Mars Entry Conditions. $10^{\text {th }}$ AIAA/ASME Joint Thermophysics and Heat Transfer Conference. pp. AIAA 2010-4508.

Cruden, B., Martinez, R., Grinstead, J., Olejniczak, J. (2009). Simultaneous Vacuum Ultraviolet through Near IR Absolute Radiation Measurement with Spatiotemporal Resolution in an Electric Arc Shock Tube. 41st AIAA Thermophysics Conference. pp. AIAA 2009-4240.

Cruden, B., Martinez, R., Grinstead, J., Olejniczak, J. (2009). Simultaneous Vacuum UV through Near IR Absolute Radiation Measurement with Spatiotemporal Resolution in an Electric Arc Shock Tube. 41st AIAA Thermophysics Conference. Conference presentation.

Cruden, B. A., Rao, M. V. V. S., Sharma, S. P., and Meyyappan, M. (2002). Neutral gas temperature estimates in an inductively coupled CF4 plasma by fitting diatomic emission spectra. J Appl Phys Vol. 91. pp. 8955-8964.

Danylewych, L., Nicholls, R. (1978). Proc. R. Soc. London, Ser. A 360, 557.

Grinstead, J. H. (2010). Advanced spectroscopic and thermal imaging instrumentation for shock tube and ballistic range facilities. VKI Lecture Series RTO-AVT 186 Aerothermodynamics design, review on ground testing and CFD. 
Grinstead, J. H., Wilder, M. C., Wright, M. J., Bogdanoff, D. W., Allen, G. A., Dang, K., and Forrest, M. J. (2008). Shock Radiation Measurements for Mars Aerocapture Radiative Heating Analysis. 46th AIAA Aerospace Sciences Meeting. pp. AIAA 2008-1272.

Grinstead, J. H., Wilder, M. C., Olejniczak, J., Bogdanoff, D. W., Allen, G. A., Dang, K., and Forrest, M. J. (2008). Shock-heated Air Radiation Measurements at Lunar Return Conditions. 46th AIAA Aerospace Sciences Meeting. pp. AIAA 20081244.

Panesi, M., Babou, Y., Chazot, O. (2008). Predictions of Nonequilibrium Radiation: Analysis and Comparison with EAST Experiments. 40th AIAA Thermophysics Conference. pp. AIAA 2008-3812.

Rodio, J. (2010). Spectroscopic Data for the Diatomic Molecules: C2, CN, and CO. North Carolina State University, Raleigh, NC.

Tanabashi, A., Hirao, T., Amano, T., Bernath, P. (2007). The Swan System Of C2: A Global Analysis Of Fourier Transform Emission Spectra. The Astrophysical Journal Supplement Series, Vol. 169, pp. 472-484.

Thompson, C., Fletcher, D., Bose, D. (2008). Analysis of Spectrally Resolved ShockLayer Emission for Lunar Trajectory Conditions. 40th AIAA Thermophysics Conference. pp. AIAA 2008-3813.

Young, H. D., Freedman, R. A. (2004). University Physics with Modern Physics, $11^{\text {th }}$ Ed. Pearson Addison Wesley. 


\section{Appendix:}

\section{Fabrication Drawings}

The Appendix shows fabrication drawings associated with Section 3.2.

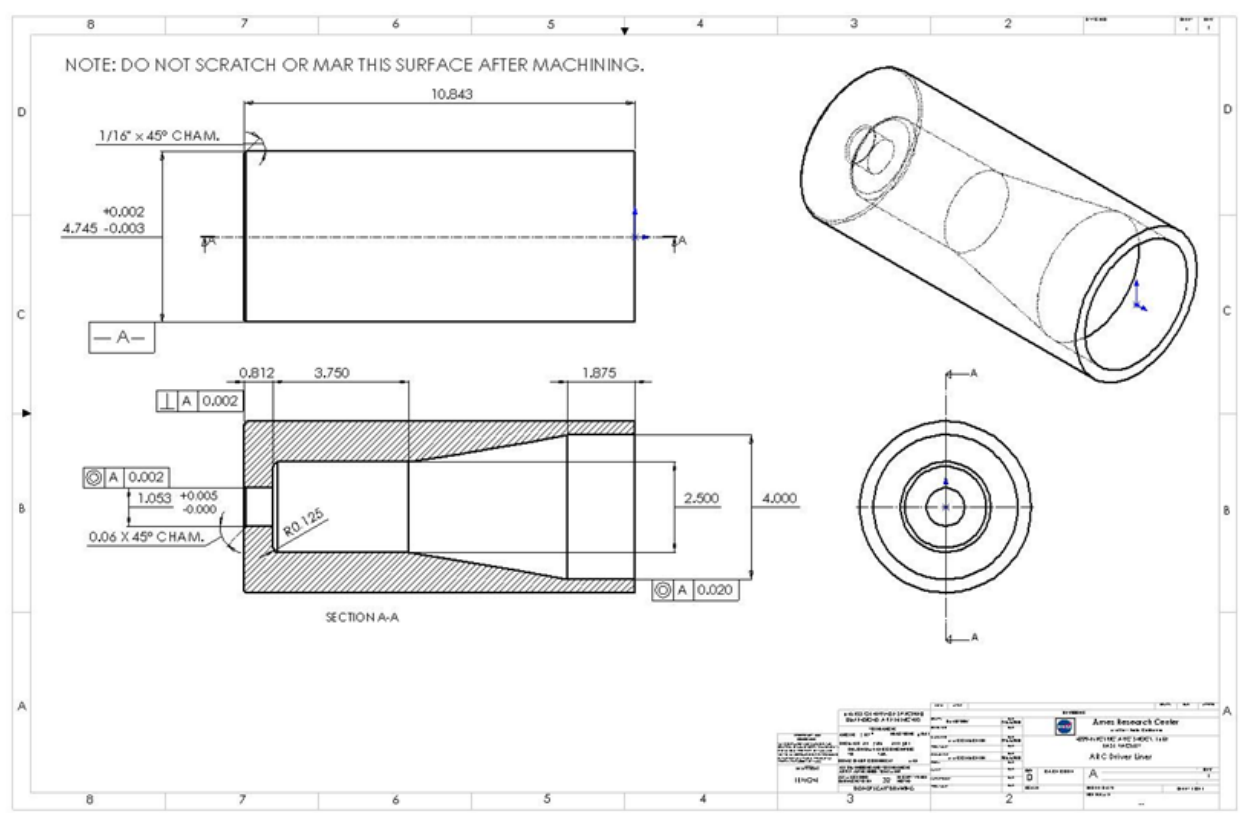

Figure A.1. Fabrication drawing for the Arc Driver Liner. 


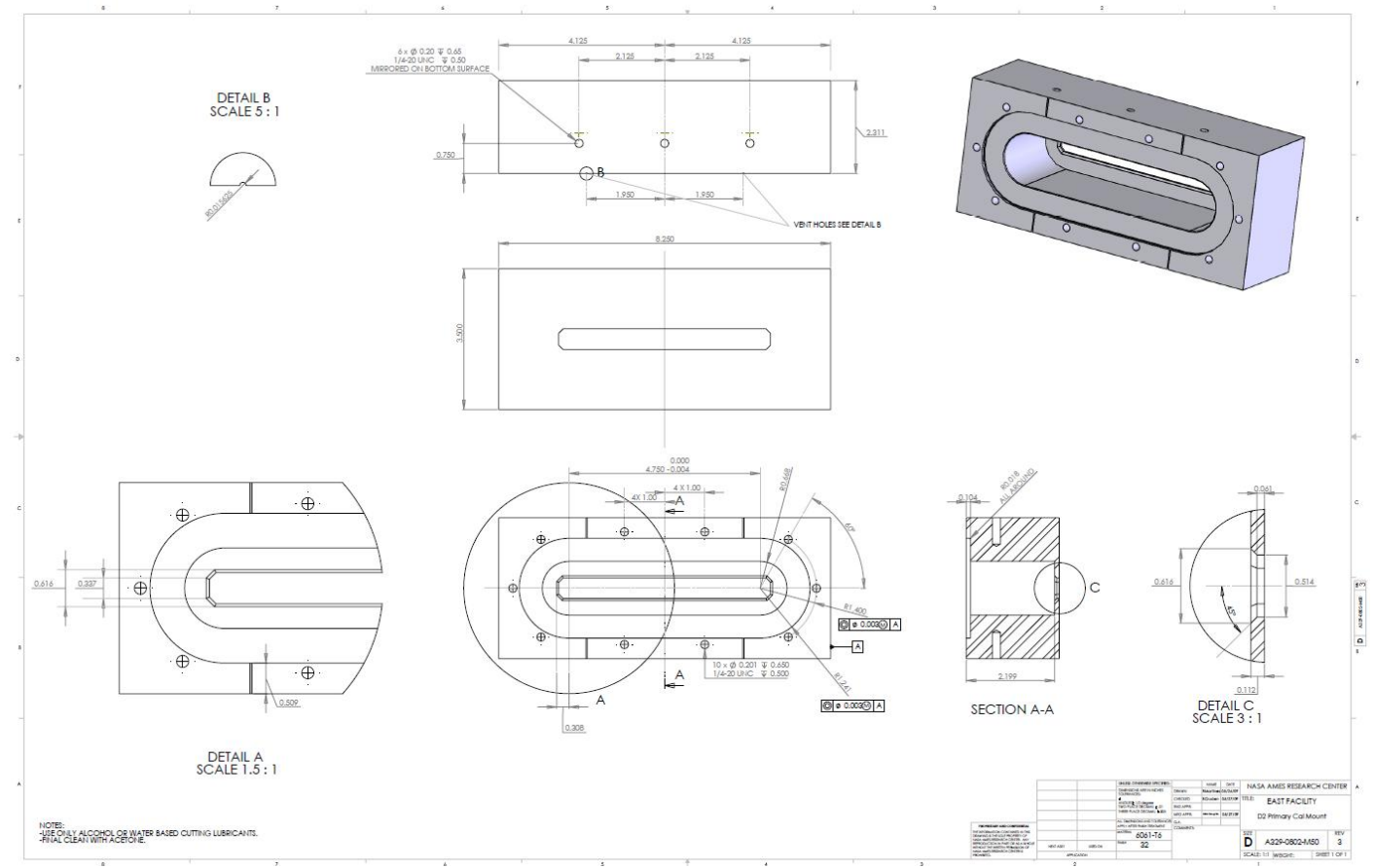

Figure A.2. Fabrication drawing for the $\mathrm{D}_{2}$ Primary Cal Mount.

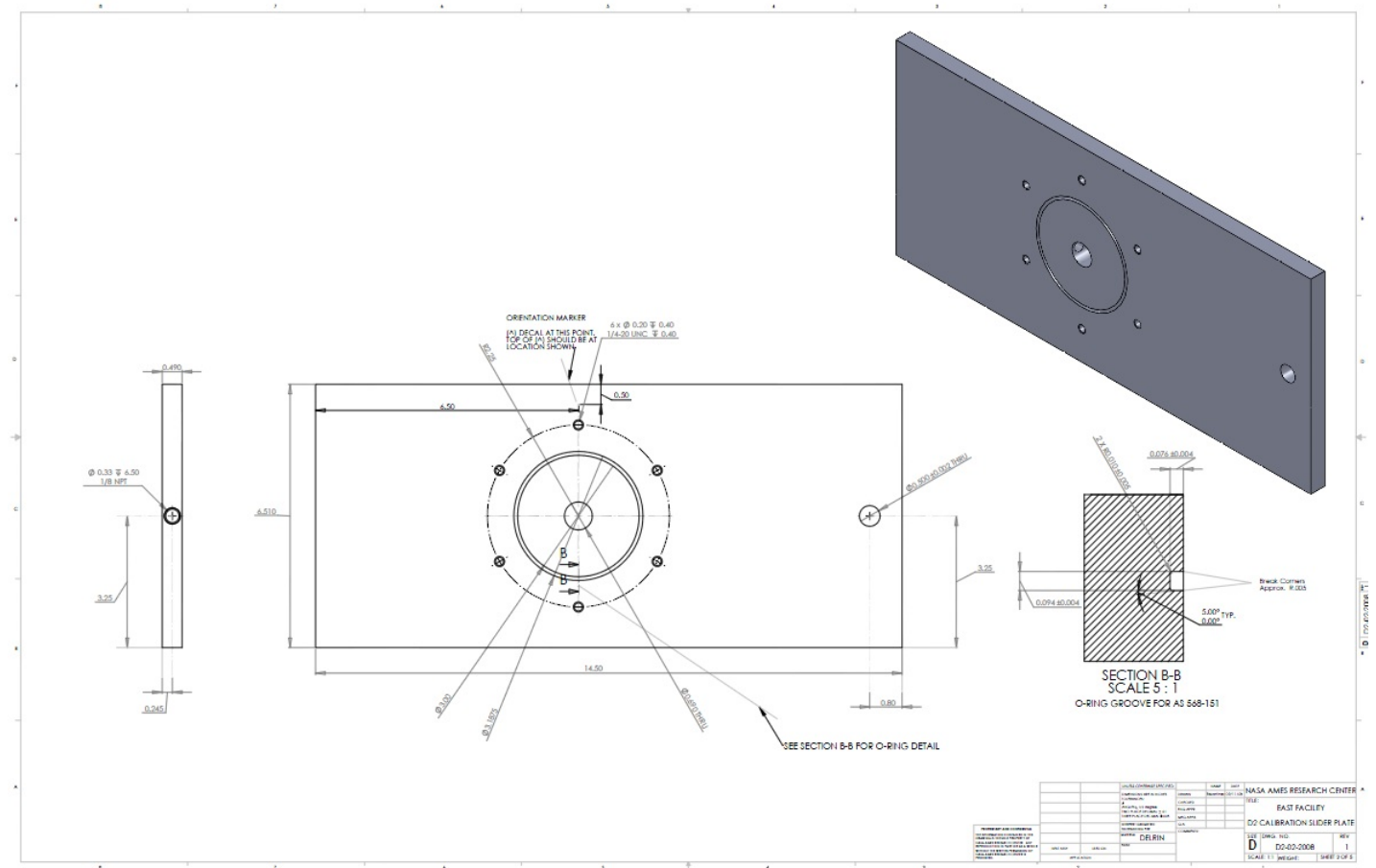

Figure A.3. Fabrication drawing for the $\mathrm{D}_{2}$ Calibration Slider Plate. 


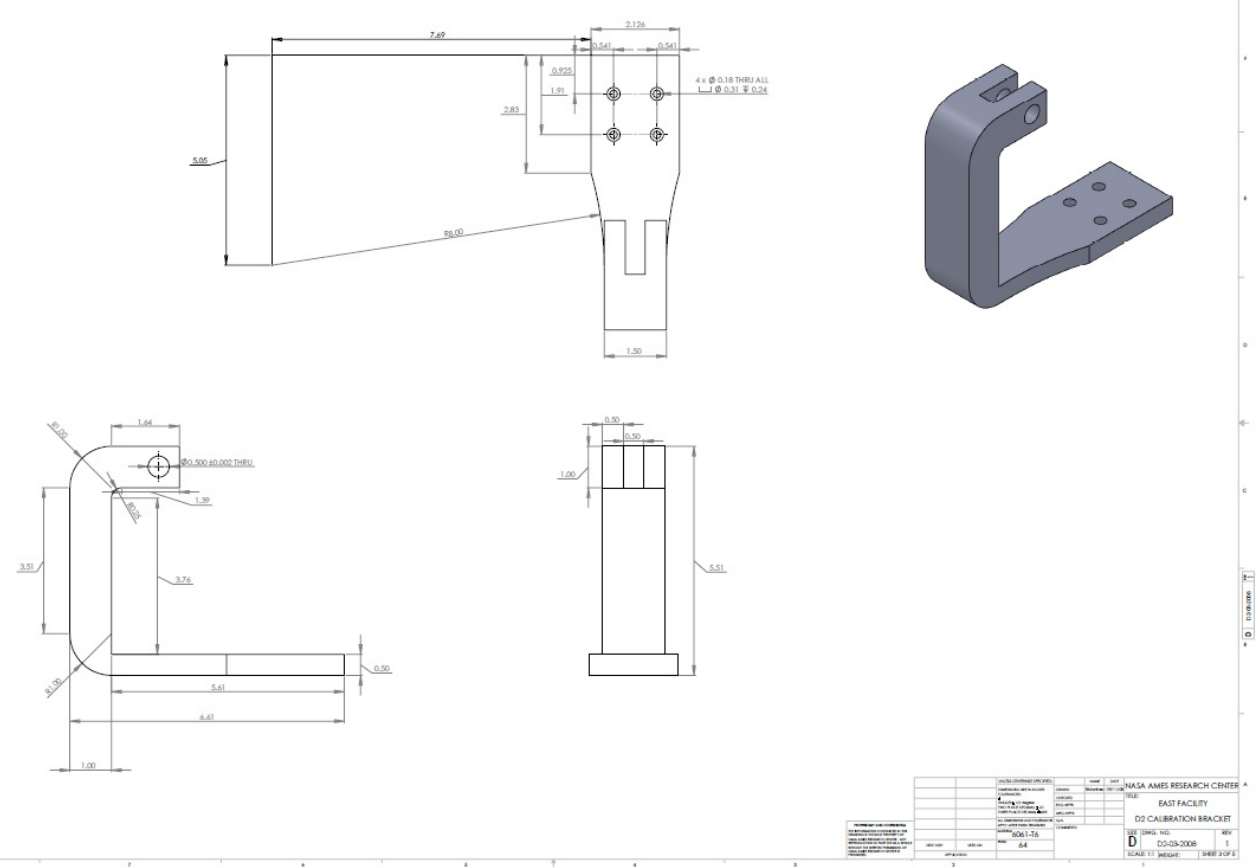

Figure A.4. Fabrication drawing for the $\mathrm{D}_{2}$ Calibration Bracket.

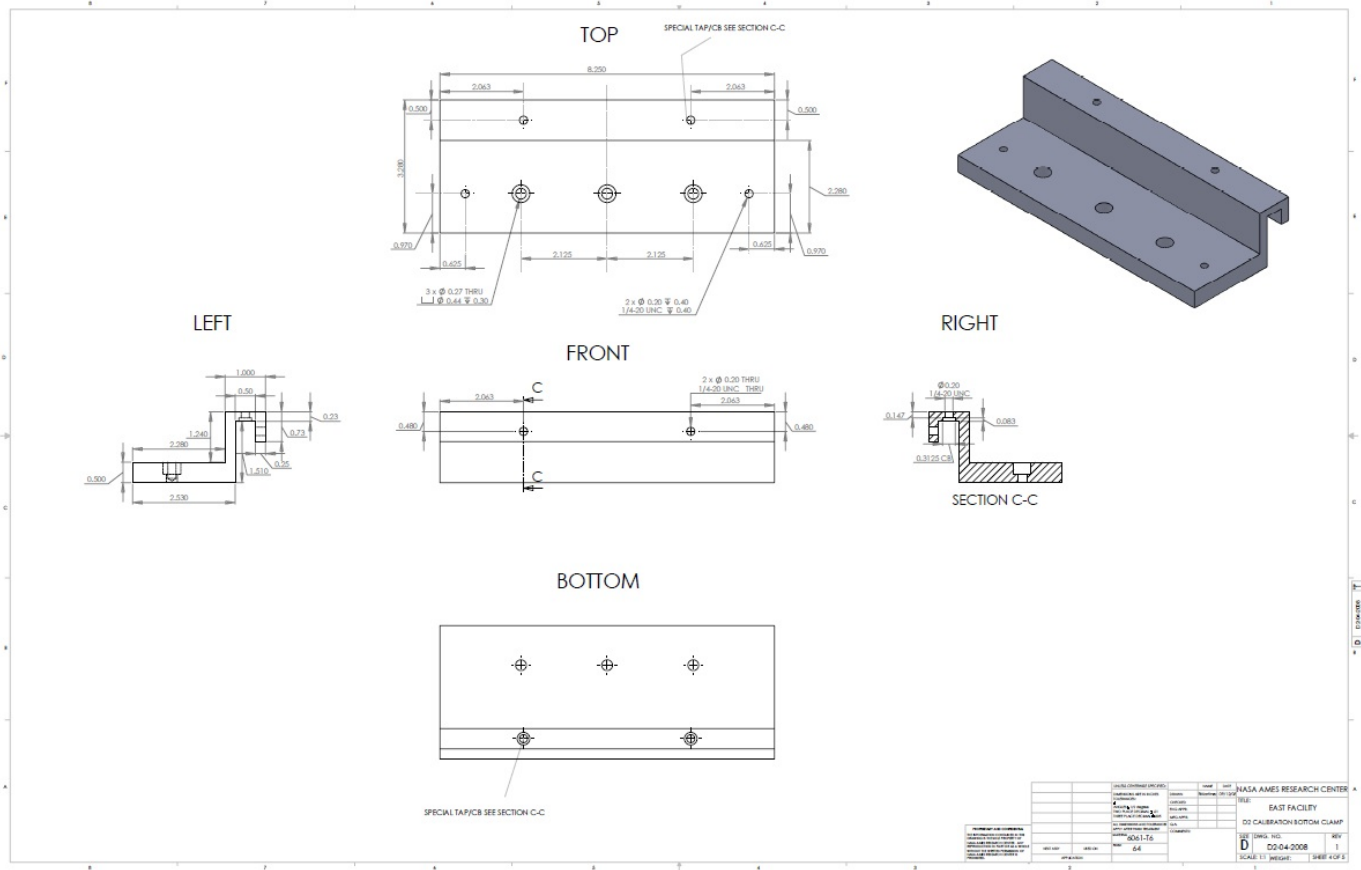

Figure A.5. Fabrication drawing for the $\mathrm{D}_{2}$ Calibration Clamp. 


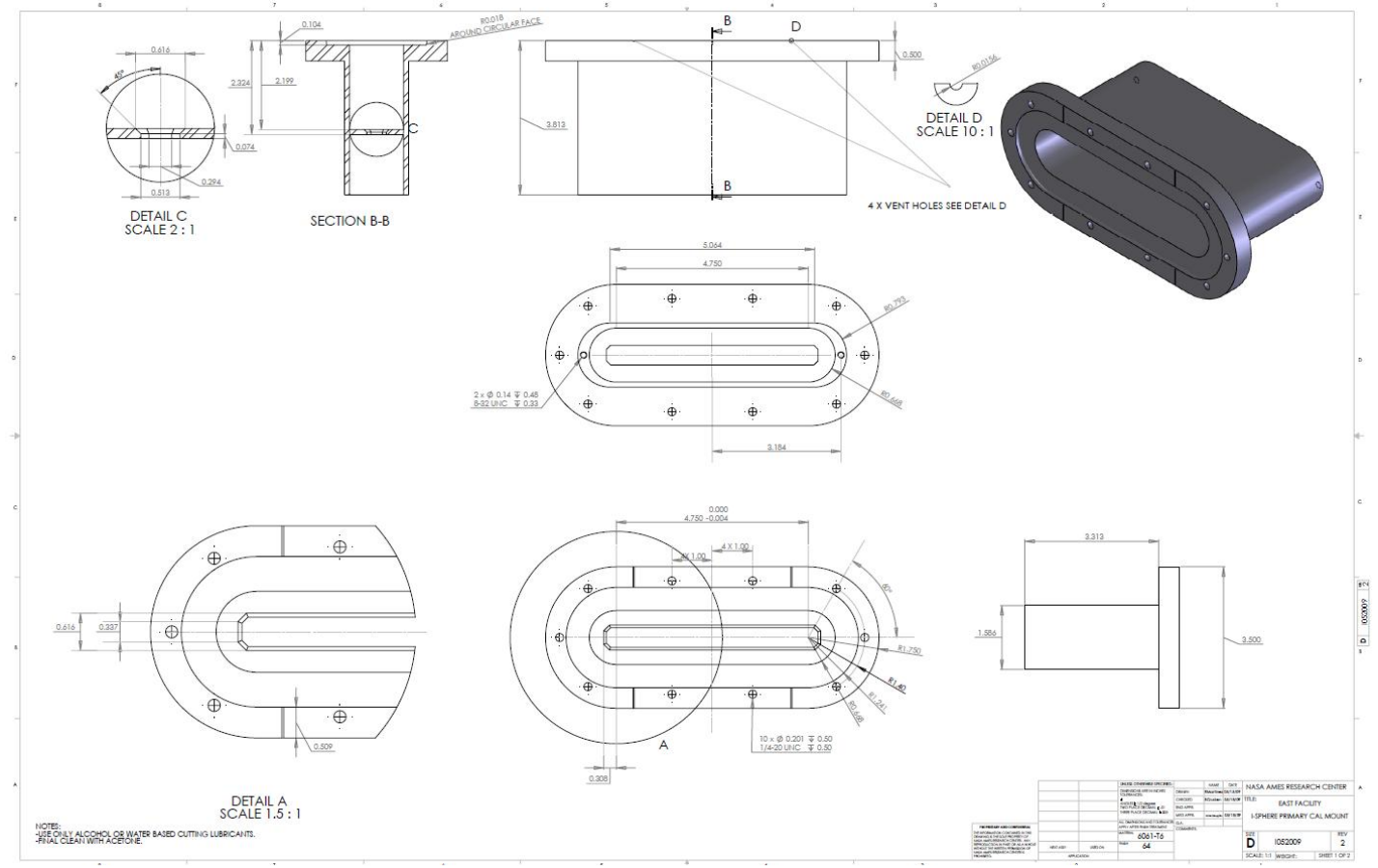

Figure A.6. Fabrication drawing for the I-sphere Primary Cal Mount.

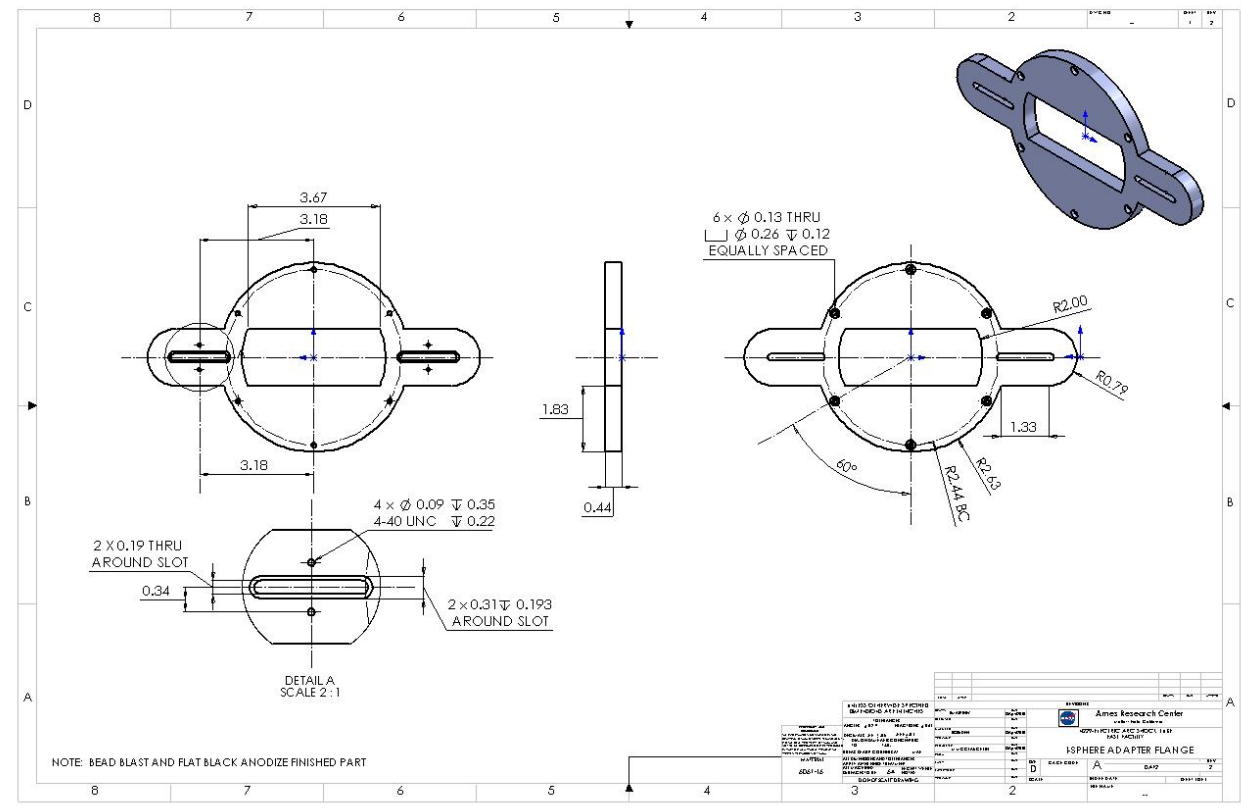

Figure A.7. Fabrication drawing for the I-sphere Adapter Flange. 